DISSERTATIONES LINGUISTICAE UNIVERSITATIS TARTUENSIS

14 

DISSERTATIONES LINGUISTICAE UNIVERSITATIS TARTUENSIS

14

\title{
LIIVI HOLLMAN
}

\author{
Basic color terms \\ in Estonian Sign Language
}

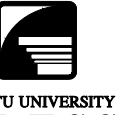

TARTU UNIVRRSTYY 
University of Tartu, Institute of Estonian and General Linguistics; Institute of the Estonian Language, Tallinn; Doctoral Schools "Linguistics and Language Technology" and "Linguistics, Philosophy and Semiotics"

Dissertation accepted for the commencement of the degree of Doctor of Philosophy on March 23rd, 2009 by the Committee of the Institute of Estonian and General Linguistics, Faculty of Philosophy, University of Tartu

Supervisor: Prof. Urmas Sutrop, Doctor of Philosophy, University of Tartu, and the Institute of the Estonian Language, Tallinn

External PhD faculty opponent:

Victoria Nyst, Doctor of Philosophy, Leiden University

Commencement: May 13rd, 2009 at 14.00, room 139 in University main building, Ülikooli 18, Tartu

This study has been supported by the Estonian Science Foundation grant No 6744 "Language family tree and some lexico-semantic fields (colors, the human being)"; the Doctoral Schools "Linguistics and Language Technology" and "Linguistics, Philosophy and Semiotics"; the Institute of the Estonian Language (basic funding from the Estonian Ministry of Education and Research). Printing costs have been covered by the Institute of the Estonian Language.

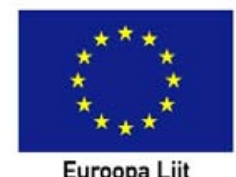

Euroopa Sotsiaalfond

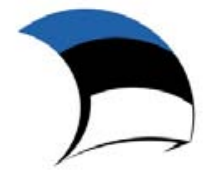

Eesti tuleviku heaks

ISSN 1406-5657

ISBN 978-9949-19-341-7 (trükis)

ISBN 978-9949-19-342-4 (PDF)

Autoriõigus Liivi Hollman 2010

Tartu Ülikooli Kirjastus

www.tyk.ee

Tellimus nr. 167 


\section{ACKNOWLEDGEMENTS}

The research resulted in the present dissertation, started in 2005 at the Institute of the Estonian Language. The study was supported by Estonian Science Foundation grant No 6744: "Language family tree and some lexico-semantic fields (colors, the human being)", the Institute of the Estonian Language and the Doctoral School "Linguistics and Language Technology". The study has been completed thanks to a number of people.

First of all, I would like to express my gratitude to my supervisor, Prof. Urmas Sutrop, for his proficient tutoring, attentive care and encouraging attitude during the last five years. I am deeply grateful to him for being patient with me while I slowly became familiar with the world of linguistics. I would also like to thank my first sign language teacher and colleague, Regina Paabo, who encouraged me to step into this process and who was always there to advise and support me.

My thanks also go to all the deaf people to whom I owe the knowledge of sign language and who generously contributed to the study. I would especially like to thank the cameramen, Aivo Erm, who travelled with me throughout Estonia to record all the interviews, and Kert Kalvik, who recorded and edited the ESL summary of the dissertation; the artists, Jüri Laumets and Ivo Kaunissaare, whose drawings illustrate the study; Triin Jõeveer, who took the photos and Maret Õun, who presented the signs in the photos. I would also like to thank all my colleagues in the local deaf clubs in Tartu, Tallinn, Pärnu and Võru, who contacted deaf people and arranged for me to interview the subjects. And, of course, I am grateful to all the subjects without whose input the present study would not have been possible.

I would like to express my gratitude to my opponent Victoria Nyst for her valuable remarks and my deepest respect to Prof. Ian Davies for his substantial comments and revisions. I am also grateful to Richard Adang for proofreading all my English texts and Annika Kilgi for reading and commenting on the summary in Estonian.

Above all, my special thanks go to my family and friends for their love, support and patience, and my interpreter colleagues who took on all the workload while I was drowning in the study. 



\section{CONTENTS}

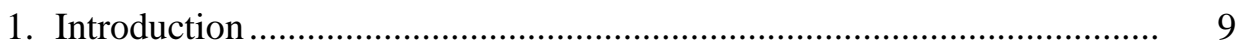

2. Sign languages and sign language communities ....................................... 11

2.1. Sign language communities ............................................................ 11

2.2. Sign languages and other visual communication systems ............... 12

2.3. History of sign languages.................................................................. 13

2.4. Universalities and diversities in sign languages ............................. 16

2.5. Lexical development in sign languages .......................................... 23

3. Estonian Sign Language .......................................................................... 27

3.1. Estonian deaf community …………………….......................... 28

3.2. ESL phonological system ………............................................... 30

3.3. ESL lexicon.............................................................................. 37

4. Basic color terms .................................................................................. 42

4.1. Basic color term theory ................................................................. 42

4.2. Definition of a basic color term ................................................. 49

4.3. Basic color terms in sign languages................................................ 54

5. Basic color terms in Estonian Sign Language.......................................... 56

5.1. Research method............................................................................ 56

5.2. Description of the subjects...................................................... 58

5.3. Results of the list task .............................................................. 60

5.4. Results of the color-naming task.................................................... 75

5.5. Etymology of the ESL color terminology ........................................ 90

5.6. Combined results and discussion .................................................... 100

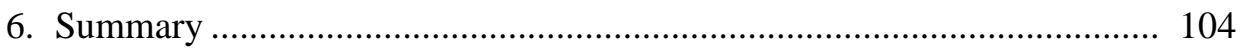

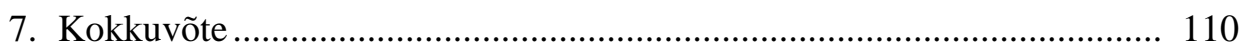

7.1. Viipekeeled ja nende muutumine.................................................... 110

7.2. Põhivärvinimede teooria ............................................................. 112

7.3. Põhivärvinimed viipekeeltes ............................................................. 116

7.4. Põhivärvinimed eesti viipekeeles................................................ 118

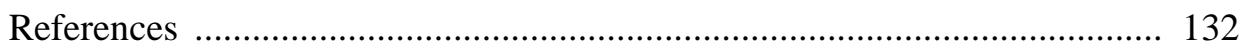

Conventions for sign notation ............................................................ 136

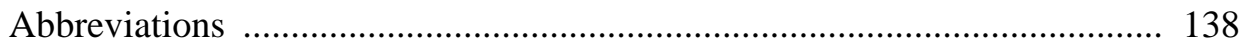

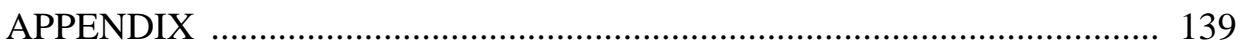

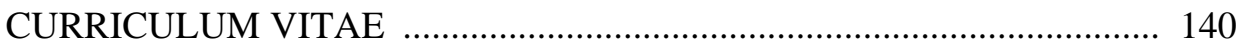

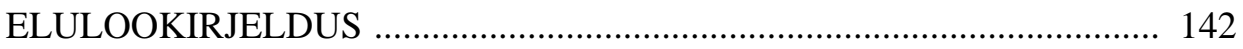


Summary in Estonian Sign Language on DVD

Recorded by Deaf ESL signer Kert Kalvik Presented by Liivi Hollman

Length: 24:55

Format: MPEG Video 


\section{INTRODUCTION}

Since Brent Berlin and Paul Kay formulated the theory of basic color term universals in 1969, basic color terms have been extensively studied in many languages. As opposed to the extreme linguistic relativity doctrine, Berlin and Kay began with the hypothesis that color words translate too easily among various pairs of unrelated languages. Their theory relies on a sample of ninetyeight languages from different language groups and it states that there is a universal inventory of eleven basic color categories from which the basic color terms of any given language are always drawn. The number of basic color terms varies from 2 to 11 and, in a language which has a fully developed color system, there are eleven basic color terms: white, black, red, green, yellow, blue, brown, purple, pink, orange and gray. If a language encodes fewer than eleven basic color categories, there are strict limitations on which categories it may encode (Berlin \& Kay 1969: 1-3). Numerous studies on different languages, following Berlin's and Kay's work, have confirmed and expanded their theory (Kay 1975, Kay \&McDaniel 1978, Kay, Berlin \& Merrifield 1991, Kay \& Maffi 1999, Kay \& Regier 2006, Kay \& Regier 2007, Davies \& Gorbett 1994, Sutrop 2002, Uusküla 2008b etc.).

Basic color terms in sign languages have not been as widely studied. However, the existing studies show that lexicalization of basic color terms in sign languages follows the same pattern found in spoken languages.

The current study is focused on the color terminology in Estonian Sign Language (ESL).

ESL is a small language used by approximately 1,400-1,500 deaf people. ESL research only started about two decades ago and has since then been used as a primary language in deaf education. Although still comparatively understudied, it is now a legally recognized language in Estonia. The redaction of the Language Act from 03.01.2007 states that ESL is an independent language and signed Estonian a form of Estonian (Language Act, §1 (3)). Under the act, the state is obliged to support the usage and development of ESL and signed Estonian (Language Act, §1 (4)).

The aim of the current study is to define the set of salient color terms in ESL and to find out whether the theory formulated by Berlin and Kay applies to ESL.

The current doctoral thesis is divided into five chapters. In the next chapter, an overview is given of sign languages and deaf communities in general, and some misconceptions commonly held regarding sign languages are expanded upon. Sign language lexicons are described in more detail, with the stress on the principles of lexical development in sign languages. The third chapter looks more deeply into ESL, its history, phonology and lexicon. In the fourth chapter, basic color term theory and studies of basic color terms in sign languages are introduced. Some issues concerning the application of the theory by Berlin and Kay to sign languages described by different authors are highlighted and discussed. In the fifth chapter, the study of basic color terms in ESL is described 
and an analysis of the outcome is presented. An inventory of basic color terms in ESL is proposed and some assumptions regarding the etymology of ESL color terminology are presented.

Examples from ESL are given in drawings by the deaf ESL users Jüri Laumets and Ivo Kaunissaare. For the color terms in ESL, there are photos of the signs, signed by Maret Õun and photographed by Triin Jõeveer. The types of arrows used in pictures follow the principles explained in Conventions for sign notation. In some tables, color signs are notated using the ESL transcription system (Paabo, Födisch \& Hollman 2009). 


\section{SIGN LANGUAGES AND SIGN LANGUAGE COMMUNITIES}

Contrary to the popular belief that sign language is universal and international, deaf communities in different countries actually use their own distinctive languages, with their own specific lexicons and grammars, e.g. Estonian Sign Language (ESL), American Sign Language (ASL), British Sign Language (BSL), Russian Sign Language etc. are all different languages evolved naturally and independently in different communities. Similarly to spoken languages, some sign languages share closer historical or genealogical relations or are influenced by each other through language contact, while others are more isolated. However, sign languages often share many common traits irrespective of historical relations, because they are all visual languages.

Sign languages are produced by the hands and body and are perceived visually. Despite their unusual modality, they are manifestations of the same cognitive processes as spoken languages and are therefore comparable to any other human language, both in structure and functions.

The elements of sign languages were described by William C. Stokoe in 1969 (Stokoe 1978). He was the first to point out that signs have an internal structure similar to words. The units forming a sign are hand configuration, location, where a sign is formed, distinctive hand movement, orientation of the palm and fingers while articulating a sign, and facial expression accompanying sign formation. These smallest contrastive units are called parameters or aspects, and they function in the same way as phonemes in a spoken language; a change in one phoneme also changes the meaning of a sign. Thus, in sign languages signs in minimal pairs differ either in their hand form, location of the sign, or movement or orientation of the signing hand. Sign languages follow their own grammatical principles, many of them common to different sign languages; there are many differences from one sign language to another.

Sign languages are used by deaf people, their families, friends and many others connected with deaf people and their communities.

\section{I. Sign language communities}

The current research is focused on sign languages used by deaf people. The communities communicating in sign languages are, however, broader and are therefore referred to as sign language communities.

Sign language communities are linguistically very heterogeneous. The core of these communities is comprised of deaf people born into deaf families and having access to sign language as their first language, as well as the deaf culture and values recognized and respected by the community from birth. According to different data, the proportion of deaf people born into deaf families and having sign language as their native language is relatively small, as most deaf 
people (90-95\%) are born into hearing families (Laiapea 2007: 112; 29; Anderson 2006: 136, 137; Kyle \& Woll 1995: 25). In addition to this, Trevor Johnston and Adam Schembri (2007) draw attention to the fact that even if the parents are deaf, they are not necessarily native signers themselves (Johnston \& Schembri 2007: 30). Therefore, the majority of signing deaf people acquire sign language in kindergarten or school, or even later in their lives, having either peers or teachers and other adults as their language models. Besides deaf people who have had access to sign language at different ages, sign language communities also include hearing people who were born in deaf families and have acquired sign language as their native language or who have learned it later as a second language.

Deaf people are usually minorities in the hearing society and, to communicate with the society, they also need to be familiar with the local majority language. This makes signing communities, in a way, similar to immigrant communities - although there may be a signing environment at home and school, the local written language is still used to communicate with the outside world. When there is no access to sign language in early childhood and the local majority language is instead learned at home or school, sign language is still used as a primary language in communication inside the deaf community. Therefore, in most cases, signers are bilingual: they use sign language to communicate inside the deaf community and the local majority language to communicate with the outside world.

\subsection{Sign languages and other visual communication systems}

In terms of the linguistic heterogeneity of signing communities, there is a great variety of various communication systems used besides sign languages. For teaching and perceiving spoken languages, cued speech or hand-mouth systems using different hand patterns to mark speech sounds which are not identifiable from lip movement are applied. In deaf education, often different manual codes for local spoken language have been invented. "Sign supported" and signed languages such as Sign Supported English, Signed English (Sutton-Spence \& Woll 2003: 13-15) and Signed Estonian (Laiapea, Miljan, Sutrop \& Toom 2003: 29) are all representations of the respective spoken languages, English or Estonian or any other language, in the signing modality. These systems borrow signs from the sign language lexicon to visualize a spoken language. While sign languages use signing modality as a primary representation of a language, signed languages are the secondary representation of a spoken language, as is true of their written forms.

Another form of visualizing a spoken language is finger-spelling, also known as manual alphabet, hand alphabet or finger alphabet. This is a system where different hand configurations correspond to the letters of spoken 
language, making it possible to spell words in the air. Used by deaf people, and in communication with deaf people, it is not a form of phonetic script but relies only on the spelling of the words from spoken languages. Finger-spelling is also used as an element of sign language for spelling proper names.

Manual alphabets usually vary in different sign languages. ESL uses the onehanded finger-spelling alphabet introduced by Olev Saarep at the end of the 1950s (Saarep 1978). Having gone through some minor changes, it is nowadays in use as seen in figure 1.

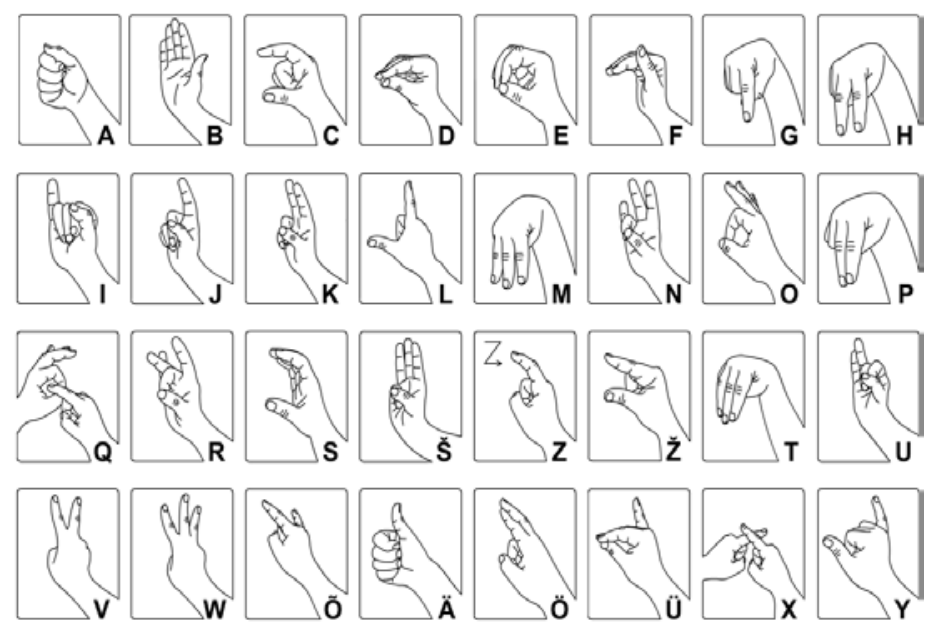

Figure 1. Estonian finger-spelling alphabet, illustrated by Ivo Kaunissaare.

The following introductory chapters concentrate on different aspects of sign languages and ESL in particular.

\subsection{History of sign languages}

The oldest known mention of sign language dates back to Plato and his dialogue Cratylus, where he says, quoting Socrates:

If we had neither voice nor tongue, and yet wished to manifest things to one another, should we not, like those which are at present mute, endeavor to signify our meaning by the hands, head and other parts of the body? ... I think, therefore, that if we wished to signify that which is upwards and light, we should raise our hands towards the heavens, imitating the nature of the thing itself; but that if we wished to indicate things downwards and heavy, we should point with our hands to the earth. And again, if we were desirous of signifying a running horse, or any other animal, you know, that we should fashion the gestures and figures of our bodies, as near as possible, to a similitude of these things. ... In 
this manner then, I think, the manifestations of the body would take place: the body imitating, as it appears, that which it wishes to render apparent (Plato: 1976: 63-64).

Sign languages have also been referred to in the context of deaf education. At the end of the 18th century, many deaf schools were founded all over Europe, starting with the Braidwood Academy, established by Thomas Braidwood in Britain in 1760, a deaf school founded in Paris by Abbé de l’Épée in 1770, and an institute for the deaf in Leipzig founded by Samuel Heinicke in 1778 (Eriksson 1998: 61). In the writings of this era, discussions about sign language as a teaching medium for the deaf may be found. While Heinicke applied a strictly oral approach, allowing only the use of speech and excluding signing, gestures and finger-spelling, and Braidwood used a combined method, the Abbé de l'Épée was the first to make sign language, which he realized to be the first language of the deaf, the teaching medium in deaf education (Kyle \& Woll 1995: 38). He called the language of the deaf the natural language of signs and the system he devised for teaching French grammar, signes méthodiques, or systematized signs. Realizing that deaf students who have been taught only spoken language may recognize the written form of the words as well as pronounce them with fair intelligibility without actually comprehending the concepts behind them (Stokoe 1978: 4-5), he answered the critics of his teaching method by writing to Heinicke:

The hours are devoted solely to speech. There is yet no time for thinking. While the tongue is freed, the mind is held prisoner in darkness (Eriksson 1998: 104).

Characteristic of this era, also called the pre-modern period in regard to linguistic research, was the belief that sign language is a primitive universal gesture language. Although some writers recognized the differences in sign language lexicons, the grammar was considered to be universal by others (Woll 2003:17-19).

In one of his letters to Heinicke, Épée wrote:

You may conclude from this description, learned Sir, that I rightly claim that systematized signs could provide the universal language long sought after by the learned: a system by which people of different nationalities could meet and make themselves understood to one another ... (Eriksson 1998: 112).

The short documented history of different sign languages is often an issue in diachronic sign language research. While mentions of deaf people and sign languages may be found, the descriptions of signs are infrequent. Illustrations of BSL signs, for example, may be found in the publications of John Bulwer, an English physician and anthropologist, and the earliest writer on sign language in Britain, Chirologia or The naturall language of the hand from 1644 and Chironomia and Philocophus or the deafe and dumbe man's friend from 1648. 
Bulwer also expresses the belief that sign language is natural and universal (Kyle \& Woll 1995: 48-49; Woll 2003: 18; Woll 1987: 29-30).

In the written sources related to deafness, however, descriptions of methods used to teach written language and oral speech were focused on and, in the teaching context, also various systems for visualizing spoken language were introduced (Eriksson 1998: 28-59).

The starting point of modern sign language linguistics is marked by Bernhard Tervoort and William C. Stokoe. Tervoort observed the communication system used by a group of five deaf children at the ages of twelve to fourteen in the residential school at St Michielsgestel in The Netherlands, and described it in his dissertation Structurele analyse van visueel taalgebruik binnen een groep dove kinderen (A structural analysis of the visual language of a group of deaf children) in 1953 (Schermer 1987:1; Woll 2003:20; Johnston \& Schembri 2007: 22). He stated that

the esoteric linguistic behaviour these children have developed in mutual communication has never been adequately analyzed, as far as the author is aware, and deeper investigation may reveal that this esoteric language is governed by its own laws different from the laws of ordinary language. ${ }^{1}$

Although it was the first linguistic description of a sign language, written in Dutch, it did not become very influential internationally.

Some years later, in 1960, Stokoe published his Sign Language Structure: an outline of the visual communication systems of the American Deaf, an analysis of ASL, which is considered to be the start of sign language linguistics. Stokoe was the first to suggest that signs have internal structure similar to words in spoken languages. He proposed that signs have three simultaneously combined parameters: (1) the location where the sign is formed, (2) the distinctive hand configuration which articulates the sign, and (3) movement. These aspects of a sign play the same role in language structure as the segmental phonemes of speech, and meaning depends on the unique composition of all three. Orientation of the palm and fingers, considered as independent parameters in later analysis, are looked upon as just more detailed descriptions of what acts (Stokoe 1987: 37, 40; Valli \& Lucas 2000: 243). Stokoe called these three parameters cheremes, from the Greek word cheir for hand. Drawing on this structural analysis, he also introduced the first notation system for transcribing signs. Five years later, The Dictionary of American Sign Language (1965) by W. Stokoe, D. Casterline and C. Croneberg was published (Valli \& Lucas 2000:2628).

In the 1970s, sign language research also started in other countries - Sweden, Denmark, the United Kingdom, Italy etc. In 1972, Stokoe begun publication of Sign Language Studies and, in 1986, the International Sign Linguistics Association was founded (Johnston \& Schembri 2007: 22; Laiapea 2007: 26).

1 http://www.let.ru.nl/sign-lang/tervoort.html, 11.10.2008 
In 1990, the first professorship in sign language was established in Sweden, at the University of Stockholm (Eriksson 1998: 90-91).

Sign language research in Estonia started at the end of the 1980s, with descriptions of the ESL phonology and lexicon. As a result of the research, three small ESL dictionaries were published in 1988 and 1990; since the beginning of the 1990s, ESL has been taught at the University of Tartu as a second language and has been used as a teaching language in deaf schools.

\subsection{Universalities and diversities in sign languages}

There are several myths and misconceptions about sign languages that are very widespread worldwide. One of the most popular beliefs is that sign language is universal. As seen above, this has also been the attitude of people familiar with the field of sign language. Robin Battison and I. King Jordan (1976) drew attention to the definite article in the phrase the sign language in the 19th century titles of books and articles on deaf communication, and the same can also be found in titles from the 20th century: The Sign Language by Long in 1918, and A Handbook of the Sign Language of the Deaf by Michaels in 1923. Both titles seem to refer to the one and only sign language. They also cite Ferdinand Berthier, a deaf educator and writer of the 19th century, and his statement typical of his time:

For centuries scholars from every country have sought after a universal language, and failed. Well, it exists all around; it is sign language (Battison \& Jordan 1976: 1007).

The same attitude is expressed by Abbé de l'Epee, the founder of a Paris school for the deaf, in his L'institution des sourds et muets, par la voie des signes methodiques, published in 1776 (Sallagoity 1975).

Although in early sign language descriptions, sign language was often considered to be universal, comparisons of any documented sign languages from different parts of the world show that sign languages are not identical in their vocabulary or in their grammatical structure. Moreover, variation in vocabulary and grammar can even be observed inside one particular sign language (Johnston \& Schembri 2007: 12). The reasons for variation in linguistic performance inside a sign language may be the age of the signer, educational and linguistic background, or cultural and regional heritage.

As is probably common for many deaf communities, deaf people in Estonia leave for boarding schools and kindergartens at quite an early age, spending most of their time during their years in school not with their family, but with peers, and sharing the same linguistic experience. Therefore, there are several variations found in vocabulary used especially among different generations. Some examples of different signs in ESL are shown in figure 2, although the assumptions regarding the reasons for variation are not based on any research 
but are, instead, observations and subjective interpretations of the signers. In the first case, the sign TEACHER (figure 2a) is considered to be an older ESL sign, while the compound TEACH+PERSON (figure $2 \mathrm{~b}$ ) is also in use, mostly among the younger generation.

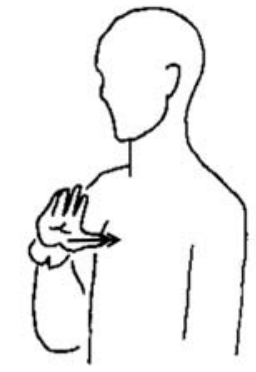

(a) TEACHER 1

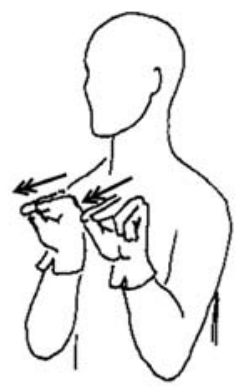

(b) TEACHER 2

Figure 2. Some examples of variation in ESL lexicon: (a) TEACHER 1, (b) TEACHER 2.

In the older sign YESTERDAY (figure 3a), no evident connection to the areas denoting past, present and future may be found, while the new sign YESTERDAY (figure 3b), in contrast, is articulated using the same hand-shape and location as TOMORROW (see figure 8a), only with backward movement, marking past.

The use of signs for woman has also changed over time. While the older sign was articulated on the chest with B hand-shape (figure 4a), the new sign, motivated by the kerchief (figure $4 \mathrm{~b}$ ), is now commonly in use.

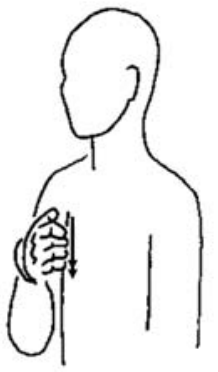

(a) YESTERDAY 1

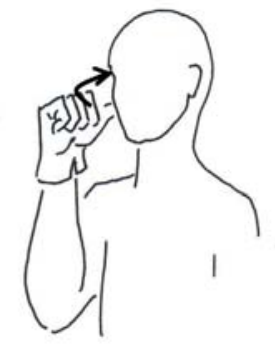

(b) YESTERDAY 2

Figure 3. Some examples of variation in ESL lexicon: (a) YESTERDAY 1, (b) YESTERDAY 2. 


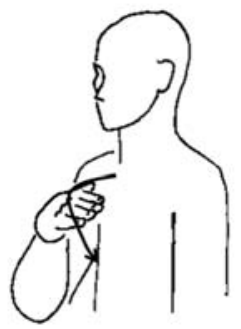

(a) WOMAN 1

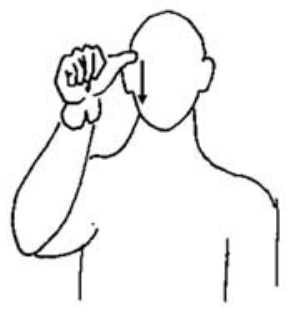

(b) WOMAN 2

Figure 4. Some examples of variation in ESL lexicon: (a) WOMAN 1, (b) WOMAN 2.

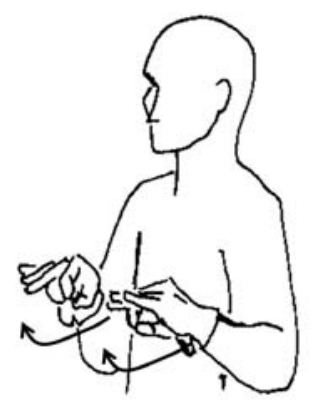

(a) BUS 1

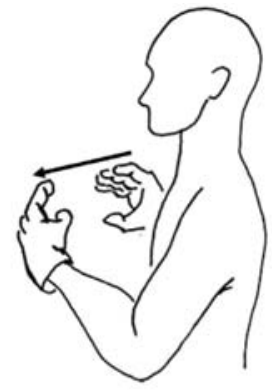

(b) BUS 2

Figure 5. Some examples of variation in ESL lexicon: (a) BUS 1, (b) BUS 2.

Differences may also be found in signs used in different regions. While the sign BUS in the Tartu region is motivated by the wheels of the bus (figure 5a), the sign mainly used in the Tallinn region refers to the shape of the bus (figure 5b).

At the same time, the myth of universality has not emerged without a reason: being all visual languages, sign languages often follow the same patterns, both in their grammatical structure and sign formation. Comparison of a word list in 15 different sign languages by Bencie Woll in 1983 shows that the average percentage of similar signs in two different sign languages is 35-40. The figure is much higher than would be expected for two unrelated spoken languages. Languages with known close historical relationships share an even higher percentage of similar signs: 80\% for BSL and Australian Sign Language (Auslan) and, according to James Woodward's research, 60\% for ASL and French Sign Language (LSF) (Kyle \& Woll 1995: 168-169).

There are also several universal grammatical structures described in different sign languages. A similar aspect marking by movement alteration, has been reported, for example, in a number of sign languages. In Auslan, reduplication of a verb expresses either habitual, durative, iterative or continuative aspect, 
depending on the rate of reduplication and the meaning of the verb, if it is a punctual or durative verb (Johnston \& Schembri 2007: 152). Similar aspectual inflections are also described in ASL, BSL, LSF, Russian SL, Swedish Sign Language and Danish Sign Language (Kyle \& Woll 1995: 170; Sandler \& Lillo-Martin 2006: 47). The inceptive aspect, expressed by beginning a sign and then holding the hand-shape, orientation and location without any further movement, also called initial stop or unrealized inceptive, has been observed in Auslan (Johnston \& Schembri 2007: 153), BSL (Kyle \& Woll 1995: 147), ASL and other sign languages (Sandler \& Lillo-Martin 2006: 48).

The use of negative head-shake or question marking by facial expression are typical examples of sign language universals (Kyle \& Woll 1995: 170). According to Wendy Sandler and Diane Lillo-Martin, all sign languages for which relevant data have been reported employ a negative head-shake to indicate sentential negation (Sandler \& Lillo-Martin 2006: 358-359).

Woll (2003) has presented some reasons explaining why sign languages tend to demonstrate more similarities than spoken languages do. These reasons include

- the relative youth of sign languages (including creolization);

- iconicity;

- a link between sign languages and gesture;

- linear syntax of spoken languages definitely creates greater differences than the spatial syntax characteristic of sign languages. At the same time, Woll also notes that the differences might be there but research studies haven't noticed them (Woll 2003: 25).

Another basis for the myth of universality is the belief that sign language is not a natural language but an artificially created system or a visual representation of a spoken language. Although, as mentioned above, these systems also exist, sign languages are not derived from local spoken languages, but are naturally evolved languages having their own distinctive grammatical structures and lexicons. Therefore, ESL is very different from Estonian; it uses signs corresponding to concepts, not Estonian words, although the mouth patterns accompanying some signs may often be influenced by Estonian. To give an example, Estonian uses the word viskama (to throw) to denote throwing either a ball, javelin or stone, or throwing away garbage. In Estonian it is also possible to throw a glance or even a joke. ESL, in contrast, has different signs depending on what is thrown, where it is thrown and how it is thrown (figure 6). 


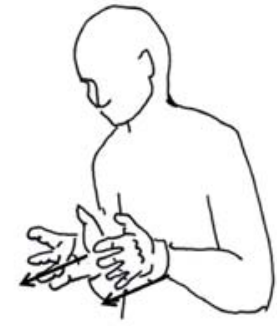

(a) THROW_A_BALL (to a child)

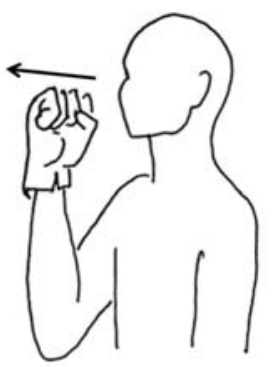

(c) THROW_A_JAVELIN

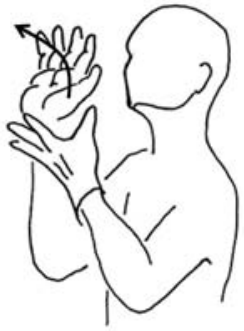

(b) THROW_A_BALL (into the basket)

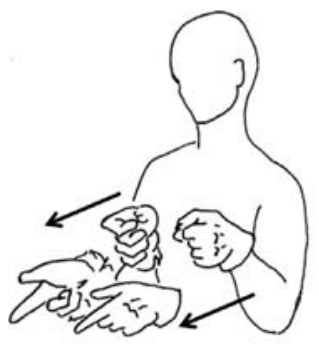

(d) THROW_AWAY_GARBAGE

Figure 6. Examples of ESL signs: (a) THROW_A_BALL (to a child); (b) THROW_A_BALL (into the basket), (c) THROW_A_JAVELIN, (d) THROW_AWAY_GARBAGE.

In the same way, ESL counterparts for the Estonian word sõitma (to drive or to ride) depend on the means of transport - drive a car, bus or motorcycle, ride a bicycle or horse, and go somewhere by train, boat, ship or plane all have different signs in ESL while in Estonian the word sõitma is applicable in all mentioned instances (figure 7).

Although only some of the aspects of ESL grammar have been studied so far, the existing descriptions also show the differences in grammatical structure of these two languages. Comparing adjectival modification in Estonian and ESL, Merilin Miljan (2001) concluded that, while Estonian modifying adjectives usually occur in pre-nominal, or in some cases post-nominal positions, ESL, similarly to other sign languages, allows, besides other options, simultaneous modification, where the modifier is incorporated into the base sign (BASKET_BIG or BASKET_SMALL are both articulated with the same hand shape, location and movement, but different magnitude) (Miljan 2001: 175179). 


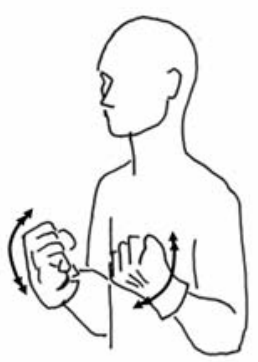

(a) DRIVE_A_CAR

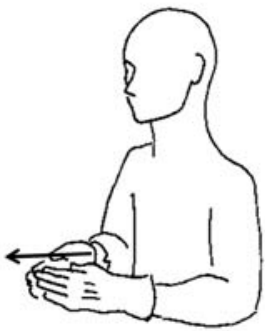

(c) GO_BY_SHIP

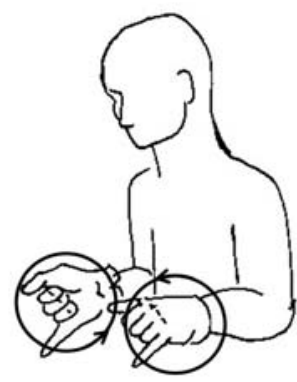

(b) RIDE_A_BISYCLE

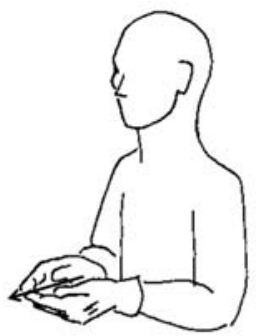

(d) GO_BY_BOAT

Figure 7. Examples of ESL signs: (a) DRIVE_A_CAR; (b) RIDE_A_BISYCLE (c) GO_BY_SHIP, (d) GO_BY_BOAT.

Using space provides sign languages with totally different means for expressing grammatical relations. Monika Trükmann (2006) described how tense can be marked in ESL and concluded that, besides lexical tense markers, five different time lines are used. The imaginary lines in the signing space run (1) perpendicular to the signer's body, on the side of the dominant hand, (2) in front of the signer; (3) from the left side of the signer to the right side, (4) vertically, and (5) a circular motion, imitating the movement of a clock, in front of the signer's body (Trükmann 2006: 55-56). Hand movements along these lines may be the bases of sign formation for signs related to time (e.g. ESL sign TOMORROW, figure 8a, is articulated with frontward arced movement perpendicular to the signer's body, while YESTERDAY 2, as seen in figure 3b, is formed by the same hand-shape in the same location, but with a backward arced movement; the same can be seen in many other ESL signs, such as FUTURE and PAST, BEFORE (figure 8b) and AFTER (figure 8c), EARLY and LATE) but they may also function as grammatical tense markers. 


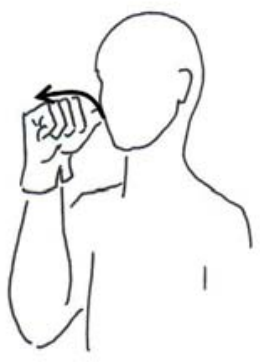

(a) TOMORROW

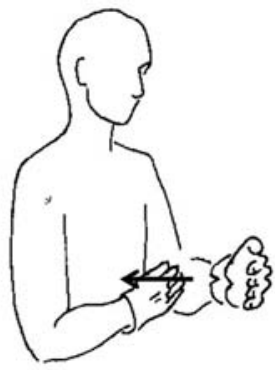

(b) BEFORE

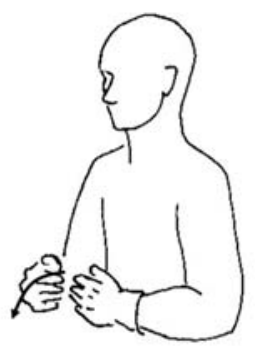

(c) AFTER

Figure 8. Examples of ESL signs: (a) TOMORROW; (b) BEFORE; (c) AFTER.

Signing closer to the body may refer to past tense, while locating signs farther in front of the signer may refer to the future. Thus, as seen in the following example (a), in signing the sign YESTERDAY, the signer's body moves backward to mark past tense, while the sign POSTPONE is accompanied by a forward movement to refer to Friday in the future.

\section{(a) YESTERDAY+c MEETING CANCEL POSTPONE+f FRIDAY The meeting was canceled yesterday and postponed until Friday}

To express successive activities, signed utterance is formed moving from the left side of the signer to the right (see example (b)). Activities happening earlier (eating) are placed to the left side of the signing space, sequentially followed by the signs expressing the next activities (watching TV) moving to the right with each sign.

\section{(b) PRO-1 If EAT READY rt TV WATCH After I have eaten, I'll watch TV}

Use of different time lines has been observed in many sign languages. In BSL, two main locations are used to represent time relations. Similarly to ESL, the first location is used to represent absolute time; the past is viewed as located behind the signer, over the right shoulder, while the cheek represents present and the space in front of the right shoulder denotes future. The second time line in BSL is located in front of the signer's body and it is used to represent succession and duration (Kyle \& Woll 1995: 142-144). The time line perpendicular to the signer's body is also described in ASL (Valli \& Lucas 2000: 116).

The basis of similarities in sign language lexicons and grammar is the visual modality they share, on the one hand, or as Sandler and Lillo-Martin put it, all natural sign languages have an iconic base (Sandler \& Lillo-Martin 2006: 21). On the other hand, sign languages, just like spoken languages, may also be 
historically related or influenced by other sign languages through language contact.

The relationships between different sign languages are mostly described based on historical knowledge, not on genealogical data. The history of sign languages is often linked to the start of deaf education, which in a number of cases was first brought to a country from abroad, together with some influences from the sign language of that other country. Thus, ASL is believed to have arisen from a creolization situation involving LSF and pre-existing local sign varieties (Zeshan 2005: 558-559). Some other groups of related sign languages mentioned by Ulrike Zeshan are:

- BSL - Auslan - New Zealand Sign Language

- LSF - ASL - Russian Sign Language - Northern Dialect of the Dutch Sign Language, Flemish Sign Language, Québec Sign Language - Irish Sign Language and Brazilian Sign Language

- German Sign Language (DGS) - Israeli Sign Language - and perhaps some other sign languages in Europe and the Middle East

- Swedish Sign Language - Finnish Sign Language (Zeshan 2005: 559).

ESL is believed to be related to Russian Sign Language, both because of historical contacts and similarities in the lexicons of these two languages, although the latter is considered to be true mainly based on subjective observations, not on any thorough study.

\subsection{Lexical development in sign languages}

New signs come into sign language in numerous ways, as do words into spoken languages. Timothy G. Reagan (1990) outlines five basic ways in which sign language lexicons expand: through compounding existing signs, borrowing, morphological processes, invention of new signs and semantic expansion (Reagan 1990: 257-258).

There are several examples of ESL signs, such as WEDDING+COUPLE (denoting bride and groom), PHOTOGRAPH+PICTURE (photo), SCREEN+ KEYBOARD (computer), PRINT+EXIT (newspaper) etc., which have obviously come into ESL by compounding already existing signs and not by translating the respective compounds from Estonian. In some sign languages, parts of compounding signs may sometimes be lost in new signs (Reagan 1990: 258; Frishberg 1975: 707). In the same way, ESL's SCREEN+KEYBOARD is losing its movement component characteristic of the sign KEYBOARD.

As in all languages, sign languages also borrow signs from other languages, both signed and spoken. Names of countries and cities are often borrowed from other sign languages. Similarly to ASL, where older name signs for many places have been replaced by the signs used by the local signers (Lucas 2000: 147), ESL uses many borrowed signs, for example FINLAND, SWEDEN, GERMANY, CHINA and JAPAN (EKLVL: 2008). 
For new technical terms, new signs are often invented. In some sign languages, finger-spelled signs are described. These signs, once incorporated into a sign language by finger-spelling a respective word from a spoken language, have undergone certain structural and formational changes and have evolved gradually into standard signs (Reagan 1990: 259). Finger-spelled signs are quite rare in ESL; one of the examples is shown in figure 9. The sign denotes the former Soviet Union and evolved from the Russian abbreviation CCCP (SSSR, i.e. USSR).

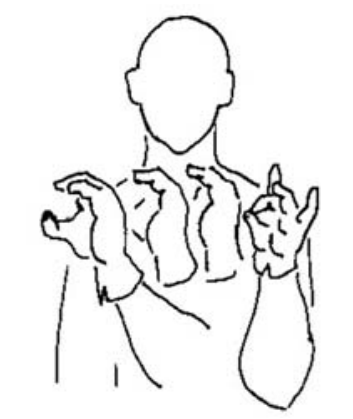

SOVIET UNION / USSR

Figure 9. Example of finger-spelled signs in ESL: Soviet Union.

The documented history of sign languages all over the world is very short, which makes assumptions about the diachronic changes in the sign language lexicon quite arbitrary. As shown above, the very first ESL dictionary was published only in 1988 (Toom 1988) and, therefore, it is very complicated to observe the developmental processes and find the origins of signs in modern ESL. On the bases of sign languages with slightly longer documented history, there are still some patterns drawn which demonstrate the historical change in the sign language lexicon. Nancy Frishberg (1975) compared the descriptions of ASL signs given by French sign scholars of the early and mid-19th century with the descriptions and photographs from a sign language manual published in 1918 by J. Schuyler Long, and with standard usage as reported by Stokoe in 1965. She came to the conclusion that signs move away from their iconic origins to more arbitrary shapes; changes occur within individual parameters to contribute to symmetry, fluidity, locational displacement and assimilation. These changes, analogous to the phonological changes in spoken languages, are motivated by such principles as ease of articulation and ease of perception. Other changes focus the lexical information in the hands (and the movements of the hands) away from more general movements of face or body, along with the hands. And finally, while the direction of change is towards simpler forms, sign morphemes strive to assume and maintain a single constant uniform shape (Frishberg 1975: 700). Frishberg described the following patterns of the changes in signs: 
1. In two-handed signs, where both hands are either active or, in the case of manual location, the hands acquire the same configuration. Signs which previously were one-handed but have become two-handed add the second hand in symmetrical configuration and movement; the hand shape and movement parameters are identical to those in the original one-handed variant. Symmetry obviously facilitates articulation by allowing the signer to program both hands at once. (Frishberg 1975: 700-701) Also, the perception of the sign becomes easier, especially if the two-handed sign is formed in locations that are perceived through peripheral vision (Johnston \& Schembri 2007: 104).

2. Changes in the location of signs:

a. in signs formed in contact with the face, two-handed signs become onehanded; the location on the face changes over time from the center to the perimeter;

b. in signs formed below the neck or, more precisely, signs not in contact with the face, one-handed signs become two-handed; the location becomes more centralized and moves up (Frishberg 1975: 703).

A comparison of location parameters of one-handed and two-handed signs in sign languages other than ASL confirms this principle. In Auslan, of more than 3000 analyzed signs, $78 \%$ of the signs made on or near the head, face and neck are one-handed while, among signs made on the trunk, only 30.5\% of the signs are one-handed (Johnston \& Schembri 2007: 103).

The ASL signs LIKE, FEEL, PLEASE and LOVE, originally formed over the heart, have moved to the center of the chest and, therefore, having previously been iconic representations of the heart, and of the particular culture's attitude that the heart is the seat of emotions, they have moved into a more neutral central position (Frishberg 1975: 704). Following the same principles mentioned above, the ASL sign WRONG, which was made on the mouth in an older form, is now produced on the chin (Valli \& Lucas 2000: 171). Jim G. Kyle and Bencie Woll (1985) described change in location in BSL and added that signs located historically on the lower left arm change location to the left hand, and signs located on the temple or upper face move away from the body (Kyle \& Woll 1985: 121).

Patricia Siple (1978) states that, since sign languages are received and initially processed by the visual system, it is expected that the rules for sign formation would be constrained by the limits of the visual system. The same constraints obviously have an impact on the diachronic change of sign language lexicons. Siple's observations indicate that, while deaf signers are conversing, the receiver tends to focus on the sender's face and not on the hands. Eye movements that do occur tend to be small excursions about the signer's face. Therefore, to become maximally visible, it would be expected that the formational characteristics of the signs depend on their location in the visual field: differences in fine detail are more important in the regions of higher acuity, as small differences in position, motion and hand-shapes can be easily detected, while farther out from the fixation point only gross differences in these aspects 
of a sign may be perceived. Thus, she predicts that signs made on or about the face and upper body will have small motions and signs made off and to the sides of the body will have large motions. Furthermore, these large motions are expected to be made along the vertical and horizontal axes. In areas of lower acuity, a greater amount of internal redundancy within a sign is expected: elements can be added by using two hands instead of one, and information presented to one side of the visual field can be duplicated on the other side (Siple 1978: 1720, 1723-1726).

Therefore signs articulated on the trunk are rather symmetrical doublehanded signs, while signs produced on the face are more detailed and more often one-handed. Signs moving away from the center of the face to the periphery include an opening of the mouth and eyes to convey grammatical and intonational information (Frishberg 1975: 707).

3. In compound signs, hand-shape and/or hand orientation assimilate to smooth the movements and transitions between parts of the compound. Two parts of a compound can be blended into a single integrated motion or one handshape. In some instances, the compound is shortened or, if it is formationally impossible to integrate the two parts of the compound into a single flowing lexical item, either the first or second member of the compound is lost (Frishberg 1975: 708). Kyle and Woll describe here the duality constraint, which states that signs of two of any element are more complex than signs of a single element, and two is the upper limit of complexity. Thus reduction from two hands to one, two location to one, two hand-shapes to one, two movements to one are expected (Kyle \& Woll 1985: 118-119).

4. Articulation of the signs is limited to that which is made with the hands. In ASL, there are many examples of signs which previously required the use of body movement, facial expression or environmental contact in their citation forms, but which today have changed to movements of the hands alone (Frishberg 1975: 711).

As the principles of the described changes are largely based on universal processes aimed to facilitate human motion and vision, it may be assumed that the same principles apply to different sign languages. 


\section{ESTONIAN SIGN LANGUAGE}

Concerning the written sources in Estonian, deaf people and the letters of their finger-language were probably first described in the fourth issue of The World and Something of What It Contains: For the Beneficial and Tutorial Entertainment of the Estonian People, the first Estonian popular science journal, from 1848-1849, by Friedrich Reinhold Kreutzwald. The article Letters of the Finger-Language explains in detail how to use the finger-spelling alphabet and encourages hearing people to learn it to communicate with their deaf friends and relatives (Kreutzwald 1849: 124, reprinted in 2003). In the article, however, there is no mention of sign language. The finger-spelling alphabet referred to is two-handed; almost identical to the one introduced by John Wallis, a professor at Oxford, in 1652 in Great Britain. The latter is, in turn, very similar to the one used in Great Britain today and in Norway until 1970 (Eriksson 1998: 40). Based on the recollections of elderly deaf people, a two-handed alphabet was in use among deaf people in Estonia until the new finger-spelling alphabet, adopted to Estonian, was introduced at the end of the 1950s (Saarep 1978: 4).

The history of sign languages is often related to the establishment of deaf schools. Although Estonian Sign Language had, in all probability, been used in the communication of deaf people in Estonia much earlier, the evolution of ESL may also be very strongly related to the establishment of the first Estonian deaf school in 1866 (Laiapea 2007: 29; Laiapea, Miljan, Sutrop \& Toom 2003: 12). The school was established in Vändra by a German Lutheran pastor, Ernst Sokolovski (Kotsar 1997: 9). The first teacher, Johannes Eglon, emphasized the importance of verbal language in deaf education, and the development of vocal skills in students, and he used the oral teaching method. At the same time, he supported the use of sign language for student communication (Toom 2002: 26). In 1924, the school moved to Porkuni. The tradition of the oral teaching method continued, but despite this the school remained an important center of the deaf, where over time deaf people from different families and from different parts of Estonia came together to form a signing environment and spent a considerable amount of time in this environment.

At the beginning of the 1980s, ESL research was initiated and, since the early 1990s, ESL has been used as the teaching language in the educational system for deaf children. In Tallinn's Helen School, which was established in 1994 (the Tallinn Deaf School at that time), the main teaching method is the bilingual method, and both deaf and hearing teachers either use ESL or sign language interpreters are provided by the school.

ESL is a developing language which is taught in universities and other schools as a second language, and interpreting services from and into ESL are provided for its users. During the last two decades, three small ESL dictionaries have been published (Toom 1988, 1990; Kivisild \& Toom 1990); they contain approximately 700 signs that form the basic vocabulary of ESL. Some general overviews of sign languages and ESL have been published (Laiapea 1992, 2001, 2007). More specific descriptions have focused on noun phrases (Miljan 
2000), adjectives (Miljan 2001), category of number (Miljan 2003) and expressing time relations in ESL (Trükmann 2006), as well as the classification and etymology of personal names and place names (Paales 2002). In 2007, ESL was enacted by the Language Law, which defines ESL as an independent language and signed Estonian as a form of Estonian. The law also stipulates that the state encourages the use and development of ESL and signed Estonian. For deaf people, the right to use ESL or signed Estonian in communication is guaranteed by provision of sign language interpreting services.

Considering historical relationships, it may be assumed that ESL has probably been influenced by German and Russian traditions in deaf education and by Russian SL, which, in turn, on the basis of historical knowledge, is believed to be connected to French Sign Language (SLF) and ASL (Zeshan 2005: 559). A comparison of the ESL lexicon with the Russian SL lexicon, according to Swadesh's 200 -word list, shows that $61 \%$ of the signs are identical in these two languages (123 identical signs, including 83 iconic and 40 arbitrary signs) (Taniroo 2007: 23), confirming the assumption that these languages are related somehow or there is some influence from Russian SL on ESL through language contact.

\section{I. Estonian deaf community}

According to different studies, there are between 1,400 and 2,000 deaf ESL users (Laiapea, Miljan, Sutrop \& Toom 2003: 27, 51; Toom, Trükmann \& Hollman 2006: 285). Considering the average percentage of deaf people worldwide ( $0.1 \%$ of the population), it may be assumed that, despite the lack of a conclusive estimate, the number of deaf people living in Estonia is approximately $1,400-1,500$. ESL is described in the Ethnologue, under the Ethnologue Language Code eso (see also Sutrop 2000a).

The fact that most signers do not learn their primary language from their parents, but from teachers and peers, is characteristic of any sign language community, as approximately 90-95\% of deaf people are born into hearing families (Laiapea 2007: 97; Anderson 2006: 137; Toom 2003: 185; Kyle \& Woll 1995: 25). The core of the signing deaf community is, therefore, quite small, including only deaf people who have acquired sign language in their families. Bearing all this in mind, it may be concluded that ESL, although currently the primary language for approximately 1,500 people, is actually not the first language for the whole community.

The Estonian Association of the Deaf, the main organization uniting and representing deaf people in Estonia since 1922, currently has eight local member organizations in different parts of Estonia. Although its membership does not include all the deaf people living in Estonia, it may be assumed that the membership of the local organizations also reflects the percentage of deaf people actually living in these areas. As seen in figure 10, almost $40 \%$ of EAD membership is congregated in Tallinn and approximately 25\% in Tartu. The 
third biggest center of deaf people in Estonia is Pärnu, with almost $20 \%$ of the membership. Tallinn and Tartu are also educational centers for deaf people. Tallinn's Helen School is a bilingual school, while Tartu's Hiie School uses the oral teaching method.

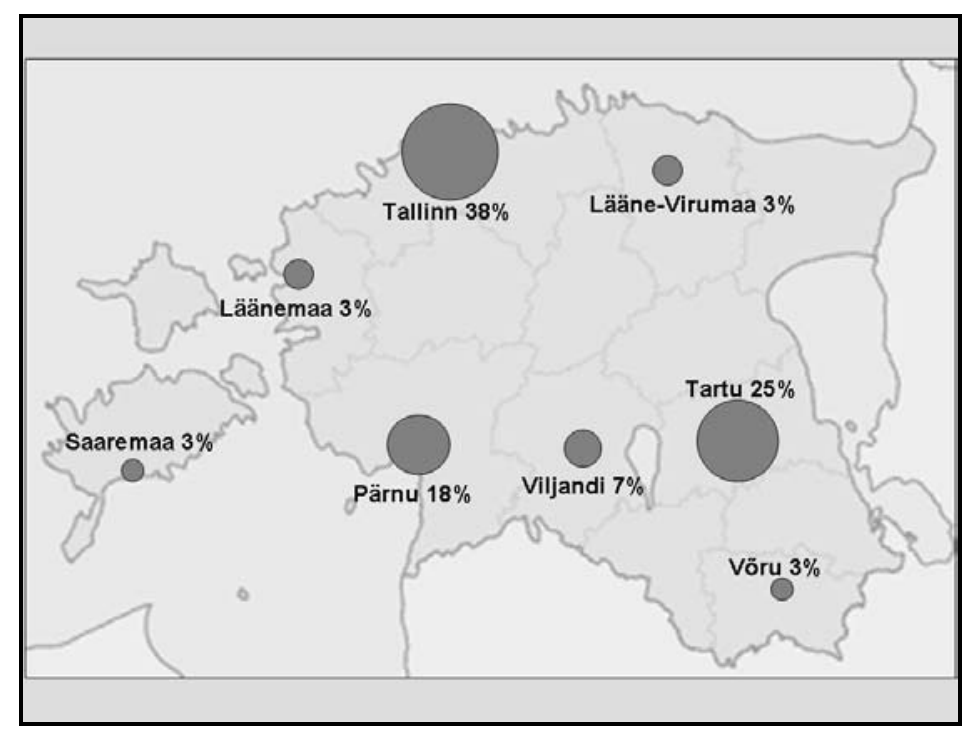

Figure 10. Membership of Estonian Association of the Deaf in 2008.

The official language spoken in Estonia is Estonian, a Finno-Ugric language closely related to Finnish. Russian is the second most common language in Estonia, used by approximately one quarter of the population. Due to the fact that the oral teaching method prevailed in Estonia until the 1990s, signed Estonian is also used in the Estonian deaf community, especially among the older generation, and the influence from spoken Estonian may be observed both in ESL vocabulary and grammar. Being a quite small but active group, the Estonian deaf community nowadays actively communicates internationally through deaf organisations, international events and sports, tourism and family relations. Marriages between Estonian deaf people and those from Scandinavian and Baltic countries, as well as from other European countries, are quite common. Due to active communication with the outside world, the younger generation is also familiar with International Sign. Language contacts with Russian SL continue, as there is still a Russian SL minority group of approximately 300400 people inside the deaf community in Estonia, who use Russian SL or both Russian SL and ESL. 


\subsection{ESL phonological system}

The first efforts to describe ESL signs and their components were made at the beginning of the 1990s, when two research groups, the Sign Language Center directed by Vahur Laiapea in the Porkuni School for the Deaf (1991-1992) and the sign language research group directed by Regina Paabo (Toom) at the University of Tartu (1989-1990), described hand forms used in ESL and introduced systems for noting them down. The research group of the University of Tartu described 36 ESL hand forms (figure 11), 23 locations and 29 movement phonemes. In sign analyses, the orientations of the palm and fingers were also taken into consideration, as well as the relationship of both signing hands.

The Sign Language Center of the Porkuni School for the Deaf introduced 38 ESL hand forms (figure 12).

Comparison of the figures shows that these two systems differ not only in the number of hand forms. There were 29 hand-shapes common to both, the research group in the University of Tartu had 7 additional hand forms in their descriptions (figure 11, hand forms 4, 7, 10, 13, 26, 31 and 33) and the Sign Language Centre in Porkuni described 9 additional hand-shapes (figure 12, hand forms 2, 13, 14, 16, 20, 23, 28, 30 and 33).

The symbols used by the Sign Language Centre are the iconic representations of the fist or palm, the fingers are numbered and, if needed, numbers are used to show which fingers are bent or straightened. The arc above the symbol represents curved fingers and the dash a bend of straight fingers.

Most of the hand forms described by only one of the research groups can be considered to be varieties of the main hand forms, not having a distinctive function in ESL itself (figure 13).

The use of a hand form or its variants is dependent on the co-articulation possibilities of the respective phoneme with other parameters of the sign. Therefore, while the sign SATURDAY (figure 14c) is formed by the A hand form (figure 14a) to smooth the movement along the body, the sign SEPTEMBER (figure 14d), in contrast, is articulated with the Aa (figure 14b) variant to ease the contact between two hands articulating the sign. Similarly, while TALLINN (figure 14h) may be articulated with the B hand-shape, formation of the sign MORNING (figure 14i) by movement along the cheek requires the $\mathrm{Bb}$ (figure 14f) hand-shape. The sign MOTHER (figure 14j) may be articulated either by the B or B. (figure 14g) hand form, without any change in its meaning. 
1

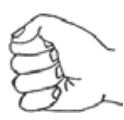

A

7

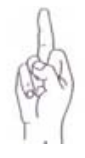

$\lambda$

13

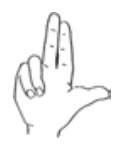

K

19

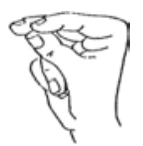

$\hat{3}$

25

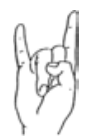

Џ

31

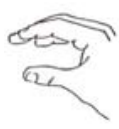

S
2

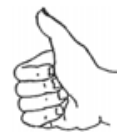

A

8
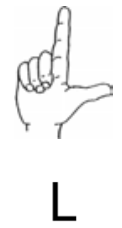

14
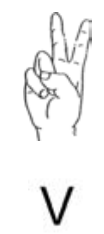

20

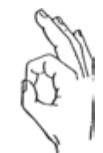

$\mathrm{O}$

26

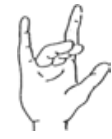

32
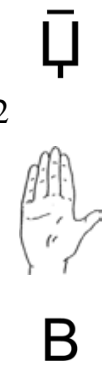

3

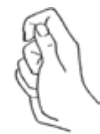

$\hat{A}$

9

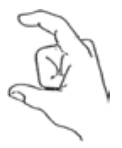

$\dddot{L}$

15
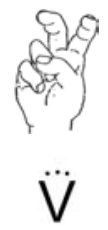

21

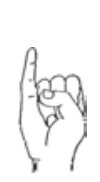

27

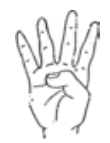

4

33

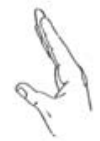

B
4

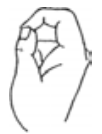

Å

10

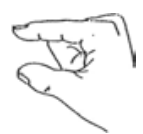

L

16
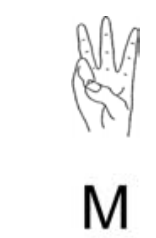

22

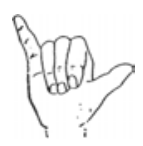

23

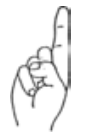

6

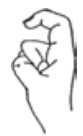

j

11

12
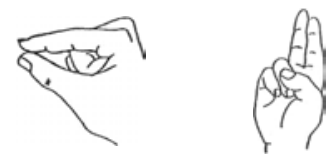

$\hat{L}$

17

18
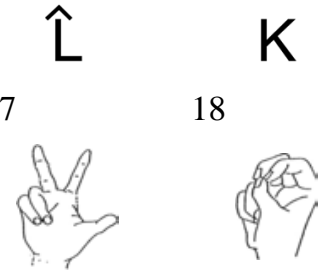
3

24
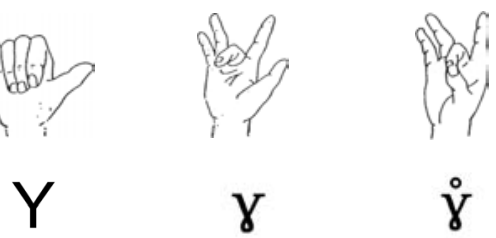

28

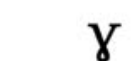

ช 30
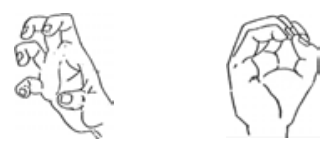

5

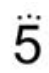

5

$34 \quad 35$

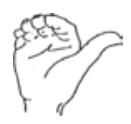

36
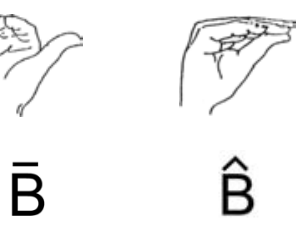

Figure 11. ESL hand forms presented by the sign language research group at the University of Tartu, 1989-1990. 
1

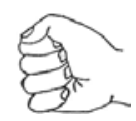

o

7

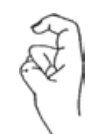

13

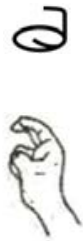

ब

19
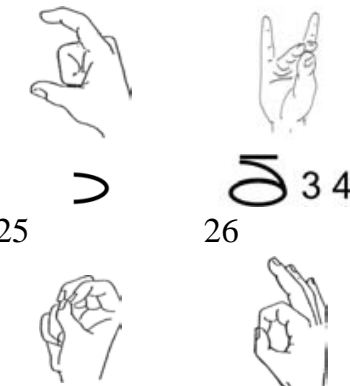

31
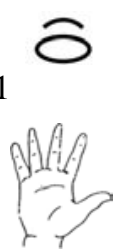

ய

37

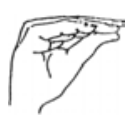

$\bar{\sigma}$
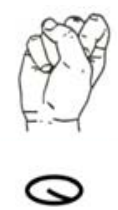

8
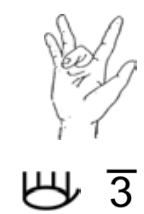

14
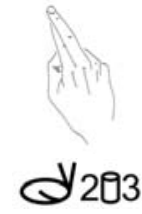

20

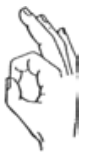

32

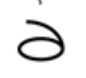

3

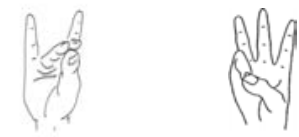

9
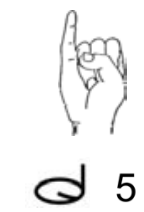

15

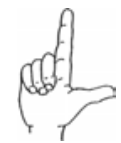

16
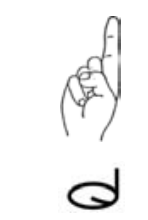

10
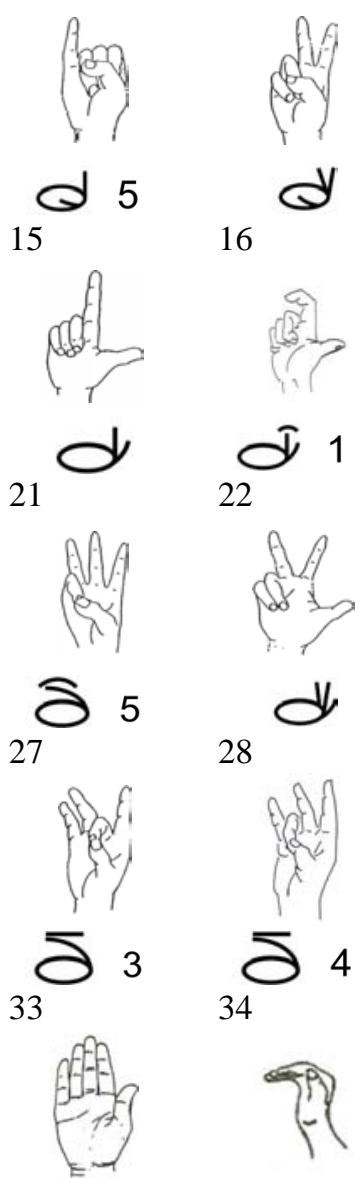

口
5

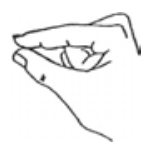

6

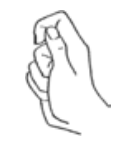

11

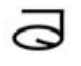

12
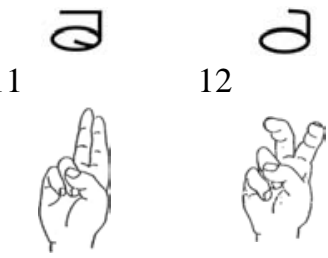

17

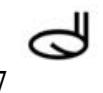

18
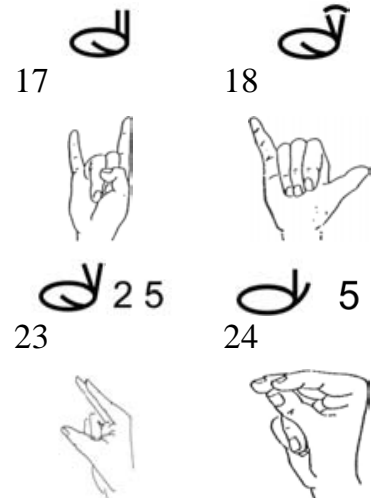

29
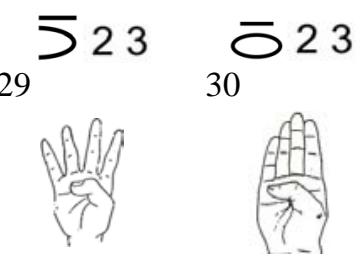

35

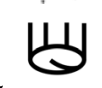

36
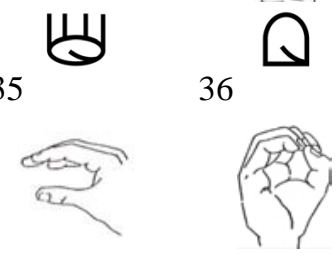

9

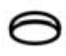

Figure 12. ESL hand forms presented by the Sign Language Center of the Porkuni Deaf School, 1991-1992. 


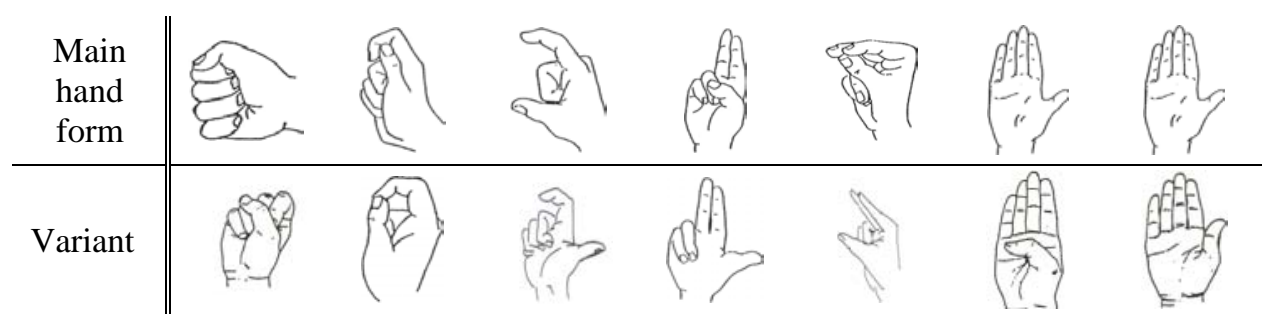

Figure 13. Some varieties of the main hand forms described by different research groups.

The other examples of the differences in the above-described systems include both productive ESL hand-shapes such as $\mathrm{N}$ (figure 12, hand form 28, figure $15 a)$ or $L_{-}$hand forms (figure 11, hand form 10, figure 15b) and hand-shapes disappearing from ESL (figure 11, hand form 7) or used only in the ESL fingerspelling alphabet (figure 12, hand form 14, figure 14c).

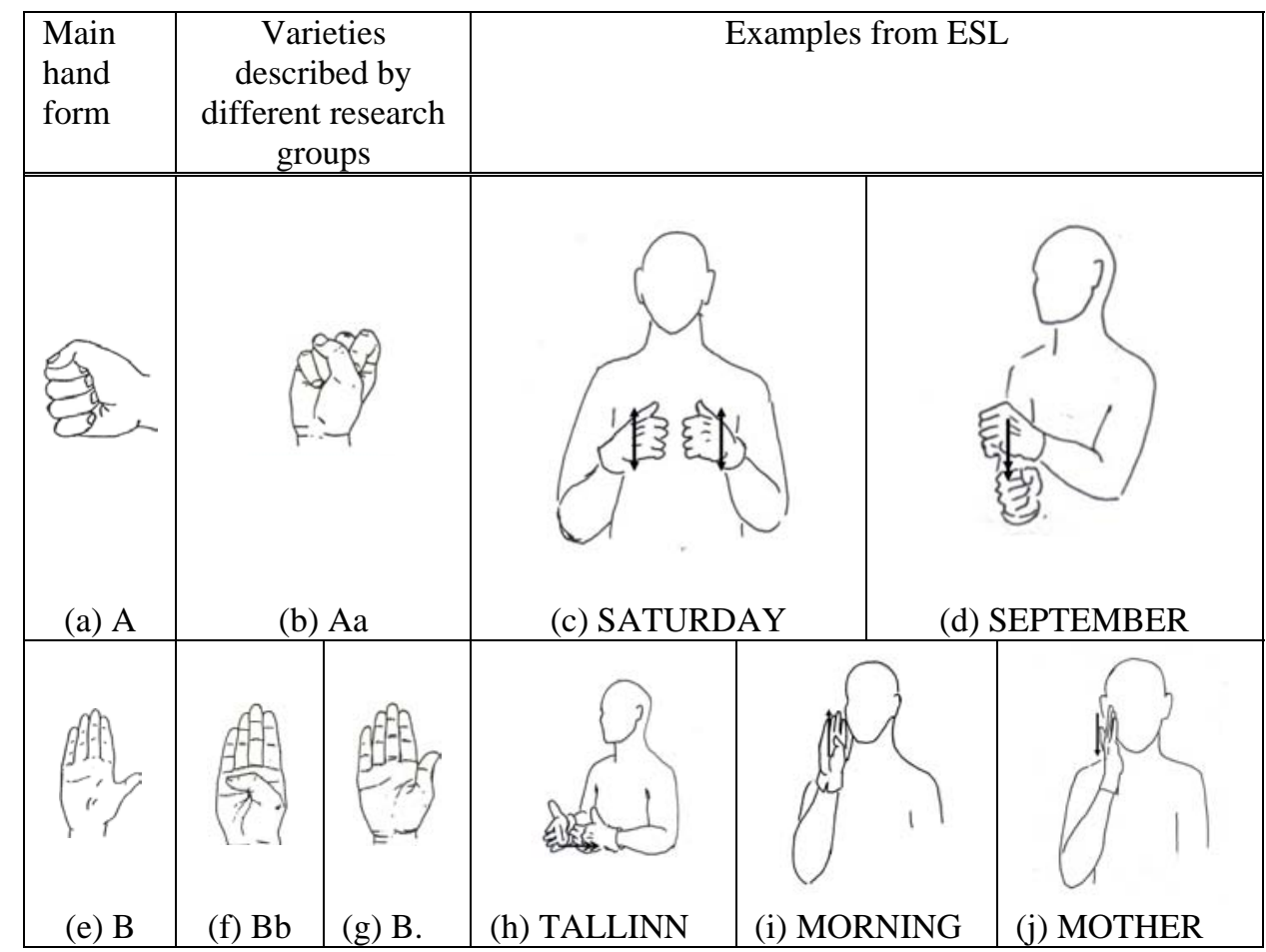

Figure 14. Some varieties of the main hand forms described by different research groups and the examples of their use. 
Further research on ESL phonology has revealed more changes in the abovementioned systems. Analyses of 383 signs from an ESL dictionary (Toom 1988) showed that these signs contain a total of 80 phonemes: 34 different hand forms, 19 locations and 27 movements (Püvi 2006: 31). Although the number of signs in this study is too small to make any definitive conclusions, it is interesting to make some observations. Out of 34 hand forms, 33 were also described earlier by the research group of the University of Tartu and, in addition, two hand-shapes were observed. One of them was also described by the Sign Language Center and mentioned above in figure 14a; the other one is not listed in either of the described systems but is obviously used only in one of the foreign loan signs (figure 16).

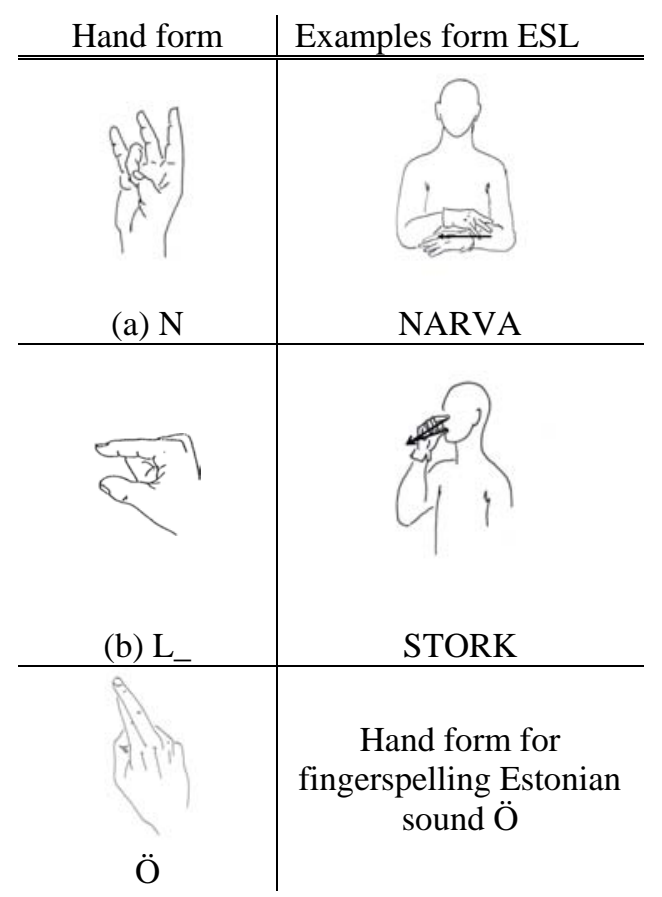

Figure 15. Some ESL hand forms described by different research groups and examples of their use.

Three hand forms from the first mentioned table (figure 11, hand forms 7, 10 and 13) and seven from the second (figure 12, hand forms 2, 13, 14, 16, 23, 30 and 33) were missing in Püvi's analyses. Hand-shape 31 from figure 11 is considered to be a variation of shape 34 and hand-shape 2 from figure 11 a variation of shape 1, according to Püvi. Hand-shapes 30 and 33 (B ja Bb) are variations of hand-shape 33 (Püvi 2006: 31).

Hand form 20 has a slightly different form in Püvi's description: in the former it is described with closed thumb and middle fingers, but in the latter 
with open fingers. In consequence, adding to the above-mentioned systems one hand form (figure 16), Püvi excludes the hand-shapes disappearing from ESL or used only in the ESL finger-spelling alphabet, and the varieties shown in figure 13. Some of the varieties are observed but defined as variants of the main form.

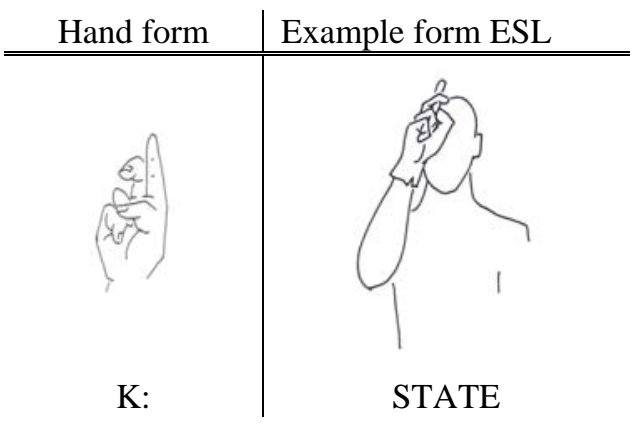

Figure 16. ESL hand form K: and the sign STATE where it is used.

According to Püvi (Püvi 2006: 26, 28), the most productive location in ESL sign formation is the neutral space, defined as a space in front of the signer's body, below the face and above the waist, where $47 \%$ of all the studied signs were articulated. The non-dominant hand (26\% of studied signs) - upper arm, forearm, elbow, palm and back of the arm and different parts of the head (18\% of studied signs) - face, forehead, temple, eyes, nose, cheek, ear, lips, chin and neck - and body ( $9 \%$ of studied signs) - chest, waistline and thigh - follow. There are 27 different movements observed, the most common of them being vertical linear movements.

Drawing on earlier research, Toom, Trükmann and Hollman (2006) presented a hypothetical set of 36 ESL hand forms, with the aim of introducing a transcription system for ESL. In 2009, the system was revised (Paabo, Födisch \& Hollman 2009). In addition to the main hand forms (figure 17), nine variations of the main forms are given (Paabo, Födisch \& Hollman 2009: 409411). All the symbols of the hand forms originated from the Estonian fingerspelling alphabet and number system.

The symbols of the hand forms again originated from the Estonian fingerspelling alphabet and number system. A dot (.) after the symbols represents the thumb moved away from the hand, a dot (.) before the symbols represents the thumb moved close to the hand, a colon (:) represents curved fingers, lowercase $o$ (o) shows contact between curved thumb and fingers, circumflex $(\wedge)$ contact between straight thumb and fingers and a dash $\left(\_\right)$a rectangular bend of fingers without contact with the thumb. 


\begin{tabular}{|c|c|c|c|c|c|c|c|c|}
\hline No & $\begin{array}{l}\text { Hand } \\
\text { form }\end{array}$ & Symbol & No & $\begin{array}{l}\text { Hand } \\
\text { form }\end{array}$ & Symbol & No & $\begin{array}{l}\text { Hand } \\
\text { form }\end{array}$ & Symbol \\
\hline 1. & & A & 2. & & A. & 3. & & $A^{\wedge}$ \\
\hline 4. & & $\mathbf{J}$ & 5. & & J: & 6. & & $\mathbf{L}$ \\
\hline 7. & & L: & 8. & & $\mathbf{L}_{-}$ & 9. & & $\mathbf{L}^{\wedge}$ \\
\hline 10. & & $\mathrm{~K}$ & 11. & & V & 12. & & V: \\
\hline 13. & & $\mathbf{M}$ & 14. & & 8 & 15. & & 80 \\
\hline 16. & & $8^{n}$ & 17. & & 0 & 18. & & I \\
\hline 19. & & $\mathbf{Y}$ & 20. & & $\mathbf{Q}$ & 21. & & $\mathbf{R}$ \\
\hline 22. & & $\mathbf{N}$ & 23. & & Õ & 24. & & $\tilde{\text { Õ }}$ \\
\hline 25. & & 4 & 26. & & 5 & 27. & & 5: \\
\hline 28. & & $E$ & 29. & & B & 30. & & B_ \\
\hline 31. & & $\mathrm{~s}$ & 32. & & $F$ & 33. & & D \\
\hline 34. & & K: & 35. & & Ö & 36. & $\neq 19$ & $\tilde{0}^{\wedge}$ \\
\hline
\end{tabular}

Figure 17. ESL hand forms presented by Paabo, Födisch and Hollman. 
For the detailed notation of the signs and internal movements of the hand during sign formation, as well as palm and finger orientation, the relationship of the two signing hands are described. The notation system allows for the noting of 27 locations and 20 different movements (Paabo, Födisch \& Hollman 2009: 414-418). However, the presented set of phonemes is not based on analyses of the productivity of ESL phonemes and, therefore, definitely does not describe ESL phonological structure in full.

\subsection{ESL lexicon}

All sign languages use visually motivated signs, where similarity between the form of a sign and the referent is obvious and, therefore, in terms of the sign language lexicon, iconicity and arbitrariness have often been focus on. At the same time, there are also many signs where visual motivation was once very common but the form of the sign has changed and the original motivation is, without diachronic examination, no longer evident.

Frishberg (1975) came to the conclusion that ASL signs, changing from their pantomimic origins to forms which are easier to articulate as well as perceive, have become less transparent, pantomimic and iconic, and more arbitrary, conventionalized and symbolic. At the same time, new signs coming into the language follow the constraints outlined for modern signs, reducing the transparent iconicity in the language (Frishberg 1975: 718). Kyle and Woll (1985) pointed out that signers often attribute visual symbolism to a sign without considering its historical change. These supposed motivations, which are not actually there, can in turn lead to a change of sign form (Kyle \& Woll 1985: 123).

Brita Bergman (1978) divides the signs in Swedish Sign Language on the bases of their motivation as:

(a) arbitrary signs

(b) motivated signs

(c) indirectly motivated signs (Laiapea 2007: 46-47).

According to her definitions, arbitrary signs lack any similarity or other kind of motivation between the form of a sign and the referent (e.g. ESL GIRL, figure 18a), while in motivated signs this similarity can be found. Directly motivated signs may follow either the form of the referent, motion or relationship (beside, on or under). Following the form of the referent, signs make a picture of the referent, either by drawing it or making the shape of it with the hands, using different hand-shapes (e.g. ESL HOUSE, figure 18b) or the hand-shape becomes a referent (e.g. ESL PHONE, figure 18c). In the case of presentable actions, an action or motion is performed (e.g. a motion imitating eating in the ESL sign EAT, figure 18d; in the sign RAISE_HAND, the hand is raised, and in the sign SCRATCH_ONE'S_HEAD, the movement of the scratching hand is imitated etc.), or the action shows how the object is held (e.g. BSL FISHING, 
ELECTRIC-PLUG, CAR, DRIVE and INJECTION) (Sutton-Spence \& Woll 1998: 174-176; Kyle \&Woll 1985: 114).

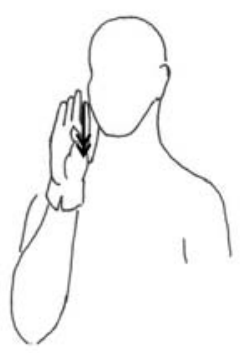

(a) GIRL

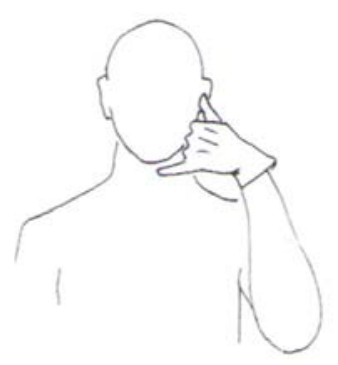

(c) PHONE

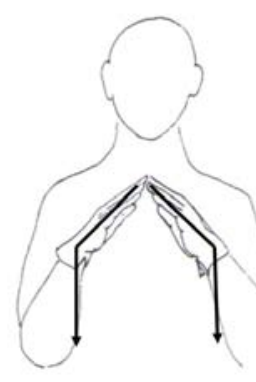

(b) HOUSE

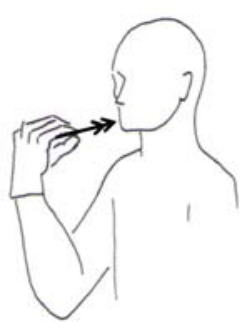

(d) EAT

Figure 18. Examples of arbitrary signs in ESL: GIRL; and motivated signs: HOUSE, PHONE and EAT.

Another form of direct motivation is pointing (e.g. the ESL signs for the body parts EYE, EAR and NOSE, formed by indexing to the respective part of the body, figure 19a; or indexing to people in the signing space, in the case of the personal pronouns YOU, ME, WE and THEY), grasping the referent (e.g. the BSL signs NOSE and HAIR, and the ESL sign HAIR) or indicating the area of the referent (e.g. the BSL and ESL signs CLOTHES). In the case of more abstract ideas (TIME and MIND), the area which represents the concept by the association may be pointed to (e.g. ESL THOUGHT/IDEA and THINK figure 19b) (Sutton-Spence \& Woll 1998: 175; Kyle \& Woll 1985: 114).

In the case of indirect motivation, there is a certain base element characteristic of the referent, from which the sign is motivated. The sign in this case is iconic in relation to the base element, not the referent (Laiapea 2007: 68). The base element can be part of the referent as a whole (e.g. ESL RABBIT, motivated by the ears of the rabbit, figure 19c) or a quality of a referent (e.g. ESL DIRECTOR, motivated by the bunch of keys characteristic of a director, figure 19d). 


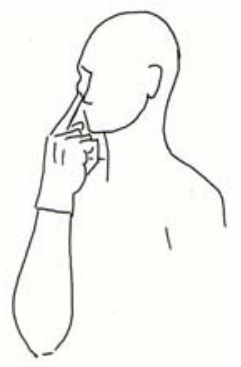

(a) NOSE

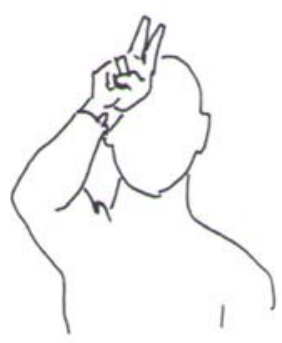

(c) RABBIT

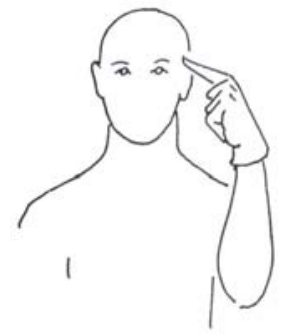

(b) THOUGHT/THINK

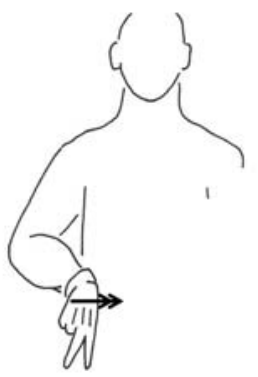

(d) DIRECTOR

Figure 19. Examples of motivated signs in ESL: NOSE, THOUGHT/THINK, RABBIT and DIRECTOR.

Elements of a spoken language can also become a motivation base for new signs. According to Vahur Laiapea (2007), there are three types of indirectly motivated signs, whose motivation base lies in spoken Estonian.

(a) The signs are motivated by the methods used in teaching deaf students to articulate certain Estonian sounds. In this way, the palm, used to control the air flow while articulating the sound $h$, pronounced characteristically with the open mouth, has become a base for the ESL sign JUICE ( $\mathrm{mahl}$ in Estonian), and the name signs HAAPSALU (figure 20a), and HIIUMAA (a compound HAAPSALU+ISLAND); the index finger, used to feel the nasal vibration while articulating $n$, has become a base for distinguishing the signs JUNE (index finger pointing at nose, figure 20b) and JULY (index finger pointing at cheek), as well as forming the sign NÕMME (figure 20b) (Laiapea 2007: 71, Paales 2002: 159).

(b) Motivation is based on the initial letter of the respective word from the Estonian language, and the sign is formed by the hand-shape of the letter (Laiapea 2007: 71). The initialized signs are also widespread in other sign languages (the ASL signs BLUE, GREEN and YELLOW are formed with the initial letters of the respective English words). In ESL there are examples of initialized signs among name signs (NARVA, figure 15a), 
names of the weekdays (TUESDAY, WEDNESDAY and THURSDAY) and some color terms (PURPLE and ORANGE).

(c) Motivation is based on the homonym of the respective word from the Estonian language (vocational school - INVITE+SCHOOL, from the Estonian word kutse, meaning both invitation and vocation) (Laiapea 2007: 72), and city hall - CITY+GRAY, from the Estonian word hall, meaning both gray and hall).

Laiapea (2007) uses two distinctive terms, iconicity and motivation, to differentiate between direct similarity and indirect motivation. While the first term is used to stress the direct similarity of the sign form and the referent, the second term refers to indirect relation (Laiapea 2007: 66).

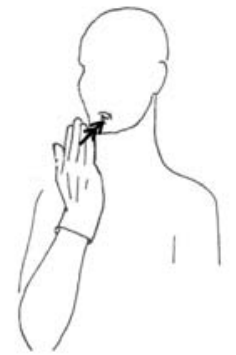

(a) JUICE / HAAPSALU

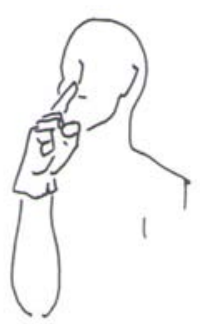

(b) JUNE / NÕMME

Figure 20. Examples of ESL signs motivated from Estonian: JUICE/HAAPSALU.

In some sign languages, there are elements in hand-shapes and locations which may convey certain meanings. In BSL, many signs which label emotional processes are located on the trunk (FEEL, ANGRY and INTEREST), while signs relating to cognitive processes are located on the temple (THINK, KNOW and UNDERSTAND) (Kyle \& Woll 1985: 114). The same tendency is clearly seen in ESL: LOVE (figure 21a) ANGRY, SAD, JOY and other signs are articulated on the chest, while THINK (figure 21b), KNOW, UNDERSTAND, PLAN and DREAM are all formed on the temple.

Drawing the line between word classes characteristic of many spoken languages is quite problematic in sign languages. Categorization is often based on the meaning (if it denotes an object, activity, process or quality) rather than on the form of the sign (Laiapea 2007: 48). The data from Miljan (2001) suggest, for example, that the class of adjectives in ESL can only be established on semantic grounds, as there are no morphological or syntactic criteria for distinguishing signs that function as adjectives from signs functioning as nouns. At the same time, there is a set of ESL adjectival signs that may undergo aspectual modulation and display, therefore, orientation towards verbs (Miljan 2001: 174). In some sign languages, however, nouns and verbs which share the same hand-shapes and locations differ in the movement component. In these 
related forms in BSL the form of the noun is characterized by ending with a hold, while the verb ends with a change (Sutton-Spence \& Woll 1998: 109). In ASL, nouns can be derived from verbs by reduplication of the basic structure of the verb (Valli \& Lucas 2000: 55) and, therefore, it is also possible to categorize signs in formal bases.

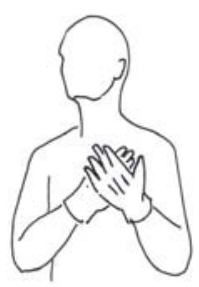

(a) LOVE

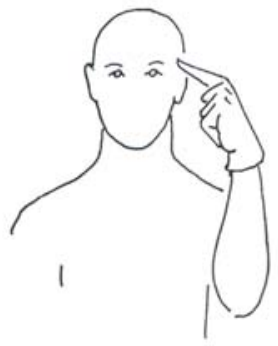

(b) THINK

Figure 21. Examples of locations conveying certain meanings in ESL: LOVE and THINK.

The ESL color lexicon has not been studied before, but some of the color signs may be found in the first ESL dictionary (Toom 1988), which includes seven color terms - the signs for white, black, red, green, yellow, blue and brown, in that order. A total of 381 signs have been organized under different topics, including the subdivision of Colors and Clothes. The presentation of the signs in the dictionary is topical, following neither the alphabetical order of Estonian words nor the grouping of ESL phonemes. Therefore, it is interesting to note that the presentation of the color signs precisely follows the ordering of basic color terms according to Berlin and Kay.

The color signs presented in the dictionary are henceforth referred to as WHITE 2, also carrying the meaning of CLEAN, WHITE 1, BLACK, RED 2, GREEN a, YELLOW, BLUE and BROWN (Toom 1988). Their salience in ESL, according to the present study, is analyzed in the following chapters. 


\section{BASIC COLOR TERMS}

\section{I. Basic color term theory}

Basic color terms have been extensively studied since Brent Berlin and Paul Kay published their Basic Color Terms in 1969. In their theory, Berlin and Kay point out that the basic color terms of any language are drawn from a set of eleven universal color categories, and these universal categories become encoded in a certain order. The eleven basic color categories are: white, black, red, green, yellow, blue, brown, purple, pink, orange and gray. If a language encodes fewer than eleven basic color categories, there are strict limitations on which categories it may encode (Berlin \& Kay 1969: 2). This universal distributional pattern was formulated by the following propositions:

1. All languages contain terms for white and black.

2. If a language contains three terms, then it contains a term for red.

3. If a language contains four terms, then it contains a term for either green or yellow (but not both).

4. If a language contains five terms, then it contains terms for both green and yellow.

5. If a language contains six terms, then it contains a term for blue.

6. If a language contains seven terms, then it contains a term for brown.

7. If a language contains eight or more terms, then it contains a term for purple, pink, orange, gray, or some combination of these (Berlin \& Kay 1969: 2-3).

Berlin's and Kay's study included 98 languages. Considering the eleven basic color categories and the possibility that a language may encode from two to eleven of them, there would be 2,048 $\left(2^{11}\right)$ logically possible combinations of different categories. However, only 22 different combinations (table 1) actually occurred in the basic color lexicons of the examined languages.

These 22 types were summarized by a simple rule (figure 22), where $a<b$ shows that if $\mathrm{b}$ is present in a language, $a$ also exists in the particular language (Berlin \& Kay 1969: 4).

The described six equivalence classes correspond to seven temporal-evolutionary stages, illustrated by the following schema (figure 23). The emergence of green and yellow each signals a separate stage of development, that is, in stage III either green or yellow may appear, leaving the other one to stage IV (Berlin \& Kay 1969: 15).

Synchronically, the hierarchy described by Berlin and Kay states that if a language has a term for a certain color it also possesses the terms preceding it in the hierarchy. Diachronically, a language currently in a certain stage must have passed through all prior stages in the order described in the hierarchy (Berlin \& Kay 1969: 15). 
Table 1. The twenty-two actually occurring types of basic color lexicon by Berlin and Kay (1969:3)

\begin{tabular}{|c|c|c|c|c|c|c|c|c|c|c|c|c|}
\hline \multirow[b]{2}{*}{ Type } & \multirow[b]{2}{*}{$\begin{array}{l}\text { No of } \\
\text { basic } \\
\text { color } \\
\text { terms }\end{array}$} & \multicolumn{11}{|c|}{ Perceptual categories encoded in the basic color terms } \\
\hline & & $\stackrel{\frac{9}{7}}{\frac{7}{3}}$ & $\begin{array}{l}\frac{\pi}{0} \\
\frac{\pi}{3}\end{array}$ & 胥 & $\begin{array}{l}\text { षี } \\
\text { 매 }\end{array}$ & $\frac{3}{0}$ & $\stackrel{\mathscr{Z}}{0}$ & 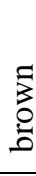 & 节 & 尝 & 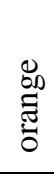 & 死 \\
\hline 1 & 2 & + & + & - & - & - & - & - & - & - & - & - \\
\hline 2 & 3 & + & + & + & - & - & - & - & - & - & - & - \\
\hline 3 & 4 & + & + & + & + & - & - & - & - & - & - & - \\
\hline 4 & 4 & + & + & + & - & + & - & - & - & - & - & - \\
\hline 5 & 5 & + & + & + & + & + & - & - & - & - & - & - \\
\hline 6 & 6 & + & + & + & + & + & + & - & - & - & - & - \\
\hline 7 & 7 & + & + & + & + & + & + & + & - & - & - & - \\
\hline 8 & 8 & + & + & + & + & + & + & + & + & - & - & - \\
\hline 9 & 8 & + & + & + & + & + & + & + & - & + & - & - \\
\hline 10 & 8 & + & + & + & + & + & + & + & - & - & + & - \\
\hline 11 & 8 & + & + & + & + & + & + & + & - & - & - & + \\
\hline 12 & 9 & + & + & + & + & + & + & + & + & + & - & - \\
\hline 13 & 9 & + & + & + & + & + & + & + & + & - & + & - \\
\hline 14 & 9 & + & + & + & + & + & + & + & + & - & - & + \\
\hline 15 & 9 & + & + & + & + & + & + & + & - & + & + & - \\
\hline 16 & 9 & + & + & + & + & + & + & + & - & + & - & + \\
\hline 17 & 9 & + & + & + & + & + & + & + & - & - & + & + \\
\hline 18 & 10 & + & + & + & + & + & + & + & + & + & + & - \\
\hline 19 & 10 & + & + & + & + & + & + & + & + & + & - & + \\
\hline 20 & 10 & + & + & + & + & + & + & + & + & - & + & + \\
\hline 21 & 10 & + & + & + & + & + & + & + & - & + & + & + \\
\hline 22 & 11 & + & + & + & + & + & + & + & + & + & + & + \\
\hline
\end{tabular}

Therefore, at stage I in the evolution of lexical color categories, two terms, the term for black and all dark hues and the term for white and all light hues, appear. At stage II, the third category emerges, which includes all reds, oranges, yellows, browns, pinks and purples. At stage III, the range of white and black reduces again and the category of green or yellow appears (Berlin \& Kay 1969: 17). 


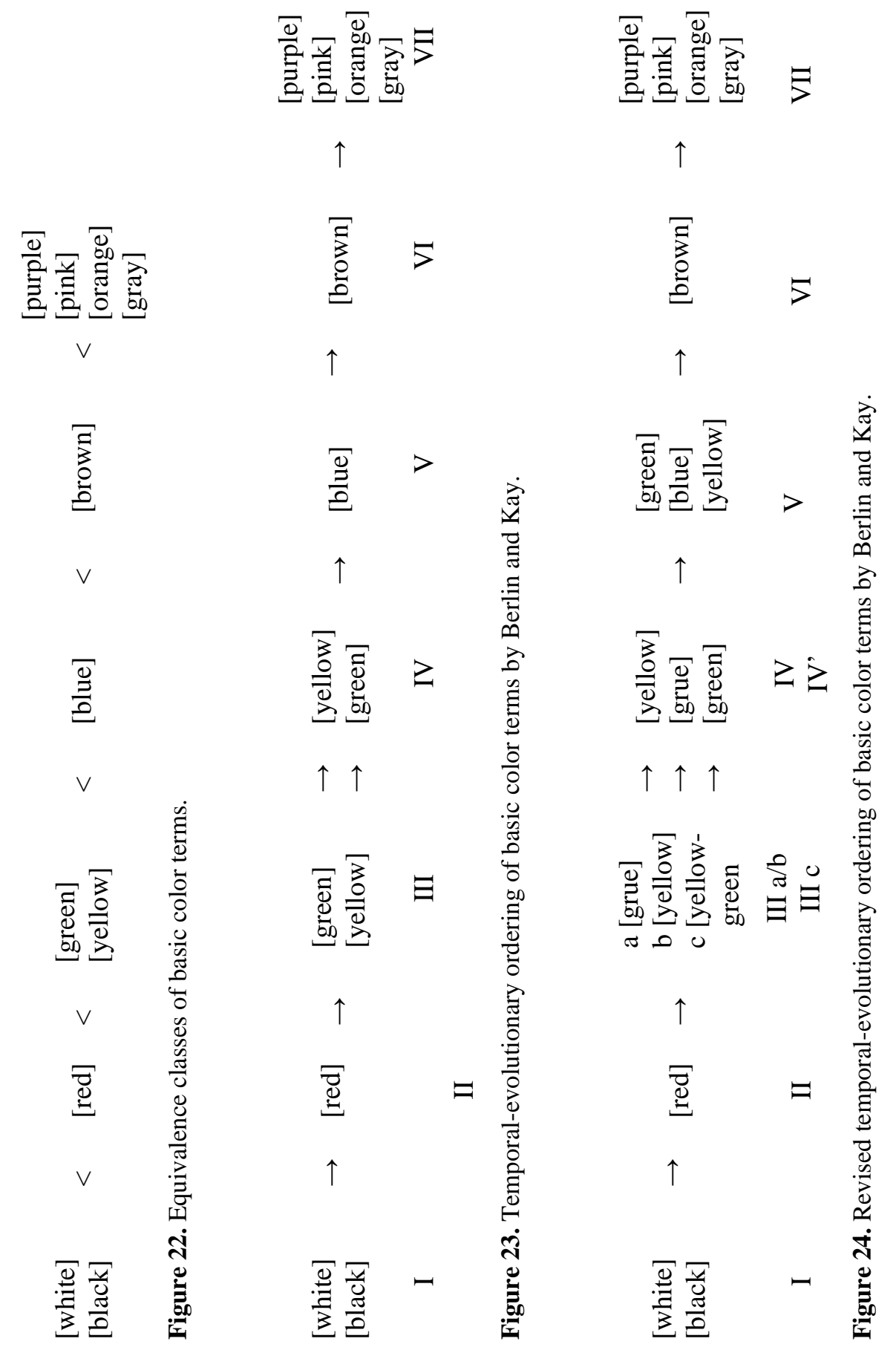


Six years later, Kay introduced some revisions of the basic color terms theory. First, the simple brightness contrast stated to be the basis for the color lexicon in two-term systems was found to be inaccurate, considering examples from languages having two color terms. These systems contrast dark and cool hues against light and warm hues, rather than only dark and light hues as stated before (Kay 1975: 258). Secondly, the new data showed that the blue focus may be encoded before or simultaneously with the green focus, not only after the green focus is encoded, as shown in the original ordering scheme. This may be realized through the category of grue, which emerges either before or after the yellow focus is encoded; however, it is never split into two basic terms until after the yellow focus is also named at the basic level. The new statements led to the modifications of the original temporal-evolutionary ordering of basic color terms, as shown in figure 24 (Kay: 1975: 260-261).

The revised scheme is interpreted by Kay as follows:

Stage I consists of two basic categories: WHITE, which includes white, very light shades of all colors, all warm colors, and may have its focus in either white, red or pink, and BLACK, which includes black, some very dark browns and purples, all but the lightest blues and greens, and which probably has variable focus in black and in dark greens and blues. At stage II, RED is marked by a basic color term and includes all warm colors with the focus in English focal red; this stage represents no departure from stage II as described in Berlin \& Kay (1969), except that RED can be considered to have come out of WHITE rather than to have emerged in part from WHITE and in part from BLACK. At stage III, either the yellow focus is accorded a basic color term (IIIb) or the category GRUE is accorded a basic term (IIIa). In the latter case, the focus may be either on blue or on green or perhaps on both, but there is no evidence that in any language the focus of GRUE is on what we would call 'blue-green'. At stage IV, stage IIIa systems add yellow and stage IIIb systems add GRUE, so that all stage IV systems contain terms for WHITE, BLACK, RED, GRUE and yellow, with foci as described for stage III. Then, at stage V, GRUE is split into green and blue. Stages VI and VII remain unchanged (Kay 1975: 260-261).

The possible appearance of gray before stage VII, highlighted already by Berlin and Kay (1969: 45), is also supported by the data provided by Kay (1975: 261).

Stating that in languages undergoing change in the color system interspeaker variation in color terminology is greater than in others, Kay also formulates some predictions about languages in which the color term system is undergoing change:

(a) the most salient secondary terms will be those that become basic at the next stage;

(b) the relative degrees of salience follow the ordering of the predicted evolutionary sequence;

(c) not all speakers are at the same stage with respect to color lexicon;

(d) the totality of stages represented is contiguous in the sequence; 
(e) difficulties in classifying speakers as to stages involves only stages adjacent in the sequence;

(f) the basic color terms added at later stages are present as secondary terms for speakers at earlier stages; and

(g) stage of speaker correlates with various social factors, depending on the local social situation, but there should be a pervasive correlation with age (Kay: 1975: 263-264).

In 1978, Kay and McDaniel explained that the constraints on the possible basic color lexicons arise from the structure and function of human visual perception. They introduce four fundamental chromatic color categories and two additional achromatic brightness categories, based on the opponent process model of the neural mechanisms that underlie human vision. These categories corresponding to semantic color categories are red, yellow, green and blue, as well as black and white as achromatic categories. Applying the fuzzy set theory to these fundamental color categories, Kay and McDaniel conclude that all basic color categories are formed from the human visual system's six fundamental response categories by one of three fuzzy-logical operations: identity, fuzzy union or fuzzy intersection. They refer to six semantic color categories based on identity, with the fundamental response categories as primary basic color categories (black, white, red, yellow, green and blue), color categories based on fuzzy union as composite basic color categories (light-warm, dark-cool, warm and cool (grue)) and categories based on fuzzy intersection as derived basic color categories (brown, pink, purple, orange and gray). Thus, Stage I systems are entirely made up of composite categories of light-warm and dark-cool. Systems at stages II, III and IV contain both primary and composite categories. The transition between these stages takes place through partial or total decomposition of composite categories, with the separate encoding of the primary categories of which they are composed. Beyond stage V, the basic color term lexicon no longer develops through the addition of primary categories and the loss of composites, but through the addition of terms referring to the regions of color space where the fundamental color categories overlap (Kay \&McDaniel 1978: 610-637).

Kay and McDaniel admit that of all the possible unions of the six fundamental color categories only four have actually been observed (Kay \& McDaniel 1978: 630); however, they do not attempt to examine the theoretical reasons.

Relying on the new data from World Color Survey, which includes 111 languages, Kay, Berlin and Merrifield (1991) give an explanation for this phenomenon with the illustration shown in figure 25, where the six nodes represent the six fundamental color categories, with the horizontal and vertical lines representing adjacency in perceptual color space, the horizontal dimension of the diagram representing the sequential adjacencies of hue, and the vertical dimension representing the dimension of lightness. The diagonal dotted line through yellow indicates that, at the semantic level, while yellow may be associated in a composite category with either red or white or both, and, on the 
other hand with green and through green to colors extending to the right in the diagram, no composite category has been found that crosses the dotted line (Kay, Berlin \& Merrifield 1991: 15).

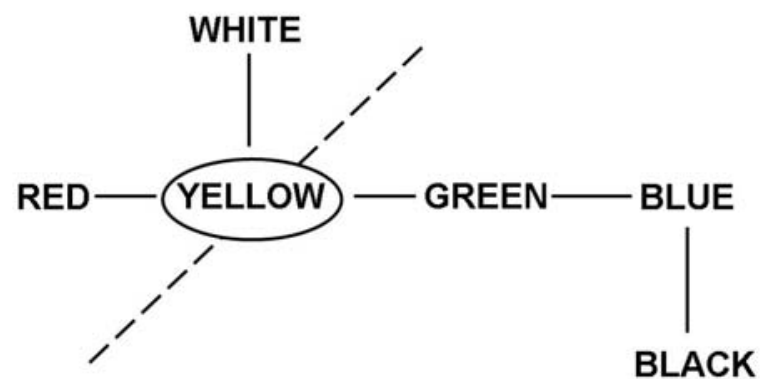

Figure 25. Visual and linguistic relations among fundamental color categories.

According to this finding, they formulated the Composite Category Rule:

A possible composite category is any fuzzy union of a subset of fundamental neural response categories which, in Figure 2 [here figure 25], forms an unbroken association chain not crossing the diagonal line (Kay, Berlin \& Merrifield 1991: 16).

The rule sets an empirical limit of nine on the 63 logically possible composite categories which might be formed from all possible subsets of the six fundamental color categories, one of the possible nine categories not attested by the data (Kay, Berlin \& Merrifield 1991: 16-17). Thus, in Stage I to Stage V languages, separate basic color terms designate the color categories listed in table 2 (Sutrop 2002: 52).

Following the partition principle, Kay and Maffi (1999) observe the evolutionary trajectories the languages pass through, developing from Stage I to Stage V. They describe five possible paths ending in Stage V, and show that 83\% of the 110 World Color Survey languages follow the trajectory called the main line in their color term evolution (figure 26, Kay \& Maffi 1999: 749). 
Table 2. All possible color categories in the Stage I - Stage V languages (Sutrop 2002: 52)

\begin{tabular}{ll}
\hline white & simple \\
white/yellow & composite \\
white/yellow/red & composite \\
red & simple \\
red/yellow & composite \\
yellow & simple \\
yellow/green & composite \\
yellow/green/blue & composite \\
yellow/green/blue/black & composite, not attested \\
green & simple \\
green/blue & composite = grue \\
green/blue/black & composite \\
blue & simple \\
blue/black & composite \\
black & simple \\
\hline
\end{tabular}

\begin{tabular}{|c|c|c|c|c|c|c|c|c|}
\hline $\begin{array}{l}\text { white/red/ } \\
\text { yellow }\end{array}$ & & $\begin{array}{l}\text { white } \\
\text { red/yellow }\end{array}$ & & $\begin{array}{l}\text { white } \\
\text { red/yellow }\end{array}$ & & $\begin{array}{l}\text { white } \\
\text { red } \\
\text { yellow }\end{array}$ & & $\begin{array}{l}\text { white } \\
\text { red } \\
\text { yellow }\end{array}$ \\
\hline $\begin{array}{l}\text { black/ } \\
\text { green/blue }\end{array}$ & $\rightarrow$ & $\begin{array}{l}\text { black/ } \\
\text { green/blue }\end{array}$ & $\rightarrow$ & $\begin{array}{l}\text { green/blue } \\
\text { black }\end{array}$ & & $\begin{array}{l}\text { green/blue } \\
\text { black }\end{array}$ & $\rightarrow$ & $\begin{array}{l}\text { green } \\
\text { blue } \\
\text { black }\end{array}$ \\
\hline & & 6 & 3 & 3 & 4 & 41 & 11 & 23 \\
\hline I & & II & & III & & IV & & V \\
\hline
\end{tabular}

Figure 26. The main line of evolutionary development of basic color lexicons, together with the number of the total of 91 languages following the trajectory in the World Color Survey shown in the second row (Kay \& Maffi 1999: 750).

In 2006, Kay and Regier reviewed the developments of the color-naming research and distinguished between two main opposite views in color-naming theory. On the one hand, from the universalist point of view, the variation in color naming across the languages is constrained. On the other hand, from the relativist point of view, due to the variation in the color term boundaries across languages, speakers of different languages also apprehend color differently. The linguistic differences seem to not only correlate with cognitive differences but also to cause them (Kay \& Regier 2006: 52). Looking closer into the color terminology of Berinmo in 2007, they show that contradistinction of these two views actually impedes understanding of cross language color naming and color cognition, as their data supported both the existence of universal constraints on color naming and the influence of cross language differences on color memory and discrimination (Kay \& Regier 2007: 289, 297). 
In their original study of 1969, Berlin and Kay mention Russian and Hungarian as unique because the former appears to have two basic terms for blue, different in terms of relative brightness, and the latter has two basic terms for red. With the existing data stated to be inconclusive, they suggest that goluboi must be considered a secondary term in Russian and admit that, if the situation were verified by further research, an additional stage might be postulated (Berlin \& Kay 1969: 36, 99). Kay and McDaniel (1978) also mention the possible exception of Russian. However, they consider it an accident rather than a theoretical inevitability. They admit that the Russian goulboy, light blue (white+blue), is a potential instance of a twelfth basic color term, but state that it is currently a basic term for some Russian speakers though probably not for all (Kay \& McDaniel 1978: 640). According to the field study by Ian Davies and Greville Gorbett (1994), to clarify the status of the two terms for blue the basic color term inventories can be extended beyond the upper limit of 11 , as the two terms for blue - goluboi and sinii, light blue and dark blue are found to be among the highest scoring terms on every measure denoting non-overlapping regions of color space. According to Davies and Gorbett, both terms fully meet the requirements of basicness defined by Berlin and Kay, confirming that Russian indeed possesses 12 basic color terms (Davies \& Corbett 1994: 87).

The similar tendency of unusually high position of two terms for blue, blau cel (sky blue) and blau marí (navy blue) is also observed in Catalan, however, despite the high frequency the terms fail to meet the criterion of basicness because they are not monolexemic and their signification is included in the term blau (blue) (Davies, Corbett \& Margalef 1995: 41).

Besides the Hungarian terms for red, it has also been suggested that Czech may possess two basic terms for red. With her research based on fieldwork in Hungarian and Czech, Mari Uusküla (2008), however, shows that both Hungarian and Czech possess exactly 11 basic color terms, which they encode in the universal way (Uusküla 2008a: 25). She states that the second term for red, vörös, is not basic in Hungarian, as its naming frequency was very low and there was no consensus among the subjects as to which color it actually refers to (Uusküla \& Sutrop 2007: 121; Uusküla 2008b: 34).

\subsection{Definition of a basic color term}

A basic color term is defined by Berlin and Kay as

(1) a mono-lexemic term whose meaning is not predictable from the meaning of its parts; (2) a term whose signification is not included in that of any other color term; (3) a term whose application is not restricted to a narrow class of objects and (4) a term which is psychologically salient for subjects (having a tendency to occur at the beginning of elicited lists of color terms, and stability of references across subjects and across occasions of use and occurrence in the idiolects of all subjects). 
For the handling of doubtful cases that may arise, Berlin and Kay provide the following subsidiary criteria:

(5) the doubtful form should have the same distributional potential as the previously established basic terms;

(6) color terms that are also the names of objects characteristically having that color are suspect and would be excluded if they were doubtful cases on the basis of the first four criteria;

(7) recent foreign loan words may be suspect;

(8) and in cases where lexemic status is difficult to assess, morphological complexity is also given some weight as a secondary criterion (Berlin \& Kay 1969: 6-7).

The definition of a basic term has been amended by several authors since Berlin and Kay. T. D. Crawford (1982) challenges the definition of a basic color term, referring mainly to the contradiction of a semantic entity being defined by formal characteristics and historical factors. Leaving out the linguistic criteria provided by Berlin and Kay, he formulates the definition as follows:

A basic color term occurs in the idiolects of all informants. It has stability of reference across informants and across occasions of use. Its signification is not included in that of any other color term. Its application is not restricted to a narrow class of objects (Crawford 1982: 324).

Urmas Sutrop (2002) summarizes the discussion of linguistic and psychological basicness, stating that

on purely linguistic grounds one can distinguish between basic and non-basic terms but one is not able to decide whether there is an internal hierarchy in the basic term groups or not (Sutrop 2002: 38).

He provides a definition of a basic color term, considering both psychological salience and formal aspects of the term:

A basic color term is a psychologically salient, in most cases morphologically simple and native word, which belongs to the same word class and has the same grammatical potential as the prototypical color terms(s). That term denotes a quality of color at the basic level, and is applicable in all relevant domains (Sutrop 2002: 40).

Davies, Corbett and Margalef (1995) stress that

a crucial property of a basic color term is that there should be good agreement across speakers on the best instances of what a term denotes - its focus in other words; there will be less agreement among speakers in the boundary areas (Davies, Corbett \& Margalef 1005: 20). 
Uusküla (2008) adds that the first criterion given by Berlin and Kay could be misunderstood because of the word monolexemic, as it usually rules out morphologically complex words which consist of two parts but are semantically simple (the Finnish vaaleanpunainen for pink, consisting of two parts, light/ white and red, with the established meaning of pink) (Uusküla 2007: 390; Uusküla 2008b: 27). She formulates a reformed basic color term definition as follows:

A basic color term is a semantically consistent and psychologically salient term which appears in the idiolects of all language speakers. It has a tendency to occur at the beginning of the elicited color term lists. In reference to a certain color, native speakers use the term consistently. Its meaning is not included in the meaning of other basic color terms. In some exceptional cases, the term may be restricted to a narrow class of objects, but is granted the basic status if it meets the criteria of psychological salience in the language/culture under consideration (Uusküla 2008b: 29).

The emphasis in the latter definitions is on semantic and psychological basicness, rather than on formal simplicity and a lack of markedness only.

The question of how to define a basic term has also been the main issue in the studies of color terms in sign languages. The main signs in dispute are color signs motivated by indexing to body parts, typically having the respective color and initialized signs. Initialized signs are formed by the finger-spelling handshape of the first letter from the respective color word in the local spoken language (the ASL sign BLUE formed by the B hand-shape, YELLOW by the $Y$ hand-shape and GREEN by the $G$ hand-shape; ESL ORANGE (oranž) formed by the $\mathrm{O}$ hand-shape, PURPLE (lilla) by the L hand-shape etc.) and are therefore considered loans from spoken language.

The methodological problem in defining a basic color term in sign languages is mentioned by several authors. Victoria Nyst (2007) gives five different ways in which color terms are formed in sign languages:

1. derivation: the meaning of the sign for an entity with a typical color is extended to include reference to the typical color;

2. pointing: an object directly available in the environment is pointed at. In several sign languages, pointing color signs point at the body part typically bearing the specific color (eyebrows, teeth and lips);

3. mouthing: mouth movements based on spoken language color words combined with a generic manual sign;

4. initialization: signs incorporating a finger-spelling hand-shape representing the initial letter(s) of the color terms used in spoken language;

5. arbitrary color signs: signs with none of the above-mentioned motivations.

She states that only the arbitrary color signs should be considered basic terms, all other types being either derived or non-native. The examples from different sign languages where the first three colors in the color hierarchy are expressed by pointing to body parts (eyebrows, teeth, lips and white skin), indicating the 
color typically associated with the body part, show that these color signs are derived and thus, strictly speaking, are not basic terms (Nyst 2007: 92).

On the other hand, the list above includes the typical means sign languages use to expand their lexicons. Berlin and Kay refer to derivation in their secondary criteria, and this would exclude a term from basic terms only if the first four criteria are not met. Therefore, a derived color sign, being psychologically salient and semantically and morphologically simple, applicable to all domains, may be a basic color term. Occasional pointing to an object is obviously not a basic term, while signs once originated from pointing and now lexicalized in a language can certainly be considered basic. The same applies to initialized signs, as new loans are again, according to Berlin and Kay, only excluded by additional criteria, i.e. only if any doubt about their basicness arises on the basis of the primary criteria. On the other hand, although arbitrary signs are most likely also basic terms, arbitrariness alone is not a criteria of basicness.

In his Sign Language Structure, Stokoe analyzes ASL color signs, showing that color signs for red, white and black are genuine signs that use arbitrary hand-shape, movement and location (Stokoe 1978: 65-66). The signs BLACK (made on the brow), WHITE (made on the chest) and RED (made on the lips) have no alphabetical association. Their hand-shapes, the pinching hand (thumb and forefinger or middle finger) and the index hand, are two of the least marked of all sign hand-shapes; that is, they are most typical in the sense that they occur in all sign languages, are used for more signs than are other hand-shapes in these languages, and are among the first to appear in the signing of infants growing up in deaf signing homes (Stokoe 1987: 10-11). At the same time, he also points out that it might be the case that the three stage I-II color terms in French and American signing are not basic in the strictest sense. As indexes in semiotic terms, they represent directly by pointing or proximity: the brow for black or dark, the lips for red, and the collar or neck linen for white (Stokoe 1987: 11). However, in mentioning this, he contrasts these signs as arbitrary signs with signs which have been derived by directly borrowing the color word from a spoken language (Stokoe 2005: 163), as mentioned above.

The research on the Ban Khor Sign Language also challenges the notion of the basic term in sign languages, as all three basic color terms are signed by pointing to objects representing these colors - hair for black, teeth for white, and lips for red. At the same time, the author admits that all three of these terms are fully lexicalized in the Ban Khor Sign Language, and thus the pointing involved in these signs differs from the pointing associated with expression of other colors. Thus, although the historical origin of these terms may have been iconic representation, this is no longer the case (Nonaka 2004: 751). The same has been stated about basic color terms in ASL, where signs for black and red, which originated from pointing, are now fully lexicalized and formally distinct from referential pointing (Nyst 2007: 92).

As seen in the examples above, these color signs originated from pointing are lexicalized, psychologically salient simple native terms corresponding to the definition of a basic term in every aspect. The signs for respective body parts 
(BROW, LIPS, NECK etc.), although derived from indexing as well, differ from the color signs. Therefore, as indexing is the unique means characteristic of sign languages, something oral languages just cannot apply because of the different modality, it shouldn't be a sufficient reason for excluding a sign from basic terms.

Following Berlin's and Kay's definition of a basic color term, James Woodward $(1978,1989)$ concluded that the ASL signs BLUE, YELLOW and GREEN cannot be considered to be basic terms, because they are formed by the hand-shape representing the first letter of the respective color term in English. As initialization is influenced by finger-spelling, and therefore shows evidence of borrowing from spoken languages, he considers ASL to be a language of three color terms, having native signs for black, white and red (Woodward 1978: 687; Woodward 1989: 146, 150).

Initialization in ASL, and in the sign languages influenced by French and American sign languages, is explained by the signes méthodiques used by Abbe de l'Epeé. Stokoe described three strategies used to create new signs by Abbe de l'Epeé: (1) derivation from French, by making a distinctive movement with a hand-shape representing the initial letter of the French word, (2) combining two or more simple signs of the native sign language and (3) combining simple signs with those formed with alphabetic hand-shapes. As a result, the sign languages in France and in America by the middle of the 19th century included signs for green, yellow, blue, brown, pink, orange and purple, belonging culturally with all the spoken languages of Berlin and Kay's stage VII. The American signs for yellow, green, blue and purple are recognizable at once as alphabetical hand-shapes (respectively Y, G, B and P), displayed shoulder high, a little distance from the signer's face. French signers named these same colors with the displayed letters of the French words: J (jaune), V (vert), B (bleu) and P (pourpre). Thus, the color signs found in stages III, IV, V, VI and VII reveal that contact with French culture accounts for their presence (Stokoe 1987: 9-10; Stokoe 1978: 65).

According to Berlin and Kay, only if any doubt arises on the basis of the first four criteria might recent foreign loans become suspects. Therefore, either interpreting initialization as borrowing or just having a motivation base from a spoken language, it can still meet all the requirements of a basic term.

Although all the studies of basic color terms in sign languages mentioned here admit the problem in handling the definition of a basic term if a language in focus is a sign language, the examples above show that these discussions mainly include the secondary criteria of a basic term. The way a certain sign evolved into a language is not a sufficient reason for excluding it from basic terms if it meets the preliminary requirements of basicness. In most cases described above, signs motivated from either pointing or spoken language color words are now lexicalized salient terms clearly differentiated from occasional pointing, signs for body parts or spoken language color words. 


\subsection{Basic color terms in sign languages}

The study by Berlin and Kay did not include any data from sign languages. While basic color terms in spoken languages have been extensively studied, this has not been the case with sign languages. Woodward (1989) examined lexicalization of basic color terms in ten sign languages from seven different sign language groups and came to the conclusion that lexicalization of basic color terms follows the same pattern found in spoken languages. His research included ASL, LSF, Auslan, Japanese SL, Taiwanese SL, Chinese SL, Hong Kong SL, Providence Island SL, Indian (New Delhi) SL and Arabian SL, and the data showed that those languages that have only two basic color terms (e.g. Providence Island SL) corresponding to the I evolutionary stage of lexical color categories, have terms for black and white, while in sign languages with three basic color terms (e.g. ASL), the term for red also exists. Four-term systems also include yellow (Mainland Chinese SL) or grue (SLF), and six-term systems (Hong Kong SL) have terms for black, white, red, yellow, green and blue. Seven-term systems, such as Indian SL and Saudi Arabian SL, also contain signs for brown, and eight-term systems, such as Japanese SL and Taiwanese $\mathrm{SL}$, include a term for purple. Auslan is considered to have a nine-term color system, which also includes a sign for pink (Woodward 1989: 150).

The indigenous sign language of Ban $\mathrm{Khor}^{2}$ has, according to the preliminary research of Angela M. Nonaka (2004), three basic color terms and, consistent with Berlin's and Kay's theory, these terms are BLACK, WHITE and RED (Nonaka 2004: 749-750). The description of the Adamorobe Sign Language (AdaSL) ${ }^{3}$ by Victoria Nyst (2007) also confirms Berlin's and Kay's theory. She concluded that, according to the strict criteria of a basic color term by Berlin and Kay, AdaSL has no basic color terms. Yet, the grouping of color signs based on their motivation is in line with the implicational hierarchy described by Berlin and Kay. AdaSL uses signs for white, red and black, which all are formed by the same manual sign and are distinguished by mouthing. The signs can be modified for intensification by re-duplication. The signs for yellow and green are signs based on the entity bearing the respective color (FAT CHICKEN or BANANA SOFT for yellow and LEAVES or BANANA HARD for green). According to Nyst's survey, there were no separate signs found for blue, purple, gray or brown (Nyst 2007: 95-96). Similarly to AdaSL, where color signs can be modified for intensification, Woodward also mentions that in some sign languages color signs undergo modulation (either variation in the

\footnotetext{
2 A small village community in north-eastern Thailand with a total population of 2741 people, among them 16 deaf individuals. Both hearing and deaf people in Ban Khor sign (Nonaka 2009: 213-214)

3 The sign language used in the village of Adamorobe in the Eastern Region of Ghana, unrelated to any other sign language. The total population of the village in 2001 was 1356, and the incidence of deafness 2\%. (Nyst 2007: 17, 24-25)
} 
movement or addition of facial expression or activity) to indicate additional color features, such as brightness (Woodward 1989: 151).

Margalit Fox (2007), a journalist, describes a sign language in a remote village $^{4}$ in Israel with an unusually high rate of deafness, in her monograph Talking Hands, and reports that Al-Sayyid Bedouin Sign Language is a stage I language having two basic color terms, signs for black and white. Other colors are expressed by pointing to an object or piece of fabric of the appropriate hue. The pure black-and-whiteness of that language is in contrast with the major spoken languages of that region, Hebrew and Arabic, and Israeli Sign Language, which are Stage VII languages. Fox concludes that such a situation provides extra evidence that Al-Sayyid Bedouin SL emerged outside the region (2007: 77).

Quite a few of the studies of the basic color terms in sign languages referred to here actually highlight the method used for data collection. Nyst's survey of AdaSL also includes many other aspects, such as phonology, kinship terms, counting and monetary terms, time terms, names, expression of size and shape and expression of motion, in addition to basic color terms. She collected three types of data: spontaneous texts, cartoon retellings, and single signs in AdaSL. The single signs, in citation form, were collected from six signers, using different methods. First, signers were presented a Ghanaian SL form, which they were asked to give an AdaSL equivalent for. Next, signers were encouraged to think of lexical items in a given semantic field presented by the researcher, such as food, colors and animals. Finally, signs were cut out of a running text on a video and presented to deaf signers to repeat in isolation (Nyst 2007: 40-41).

Sign languages with a small number of basic color terms still have a wide range of possibilities in describing colors, using compounding, borrowing, derivation and other strategies. According to Woodward, signers on Providence Island index color by pointing to or naming objects with well known colors, e.g. pointing to a red object or using the sign BLOOD for red etc. (Woodward 1989, 150-151). The latter may also be the third basic term in Providence Island SL if the primary criteria of basicness are met. Unfortunately, the study does not reflect the salience of the color terms. In the Ban Khor SL, two strategies are also used to express other colors: if an object of the respective color can be found in the immediate physical environment, the object is pointed at; if the color in question cannot be located in the immediate environment, non-basic color terms are expressed using one of the three basic terms (Nonaka 2004: 750). Signers of a number of sign languages may also finger-spell various colors, using the terms of the spoken language of the majority (Woodward 1989: 151).

4 An isolated traditional community; nearly 150 of the 3,500 residents are deaf (Fox: 2007: 7) 


\section{BASIC COLOR TERMS IN ESTONIAN SIGN LANGUAGE}

\section{I. Research method}

A survey of color terms in Estonian Sign Language was carried out during the summer of 2005 among 50 Estonian deaf signers. The research consisted of three tasks, following Davies and Corbett's field method (Davies \& Corbett 1994: 69-72; 1995: 25-27; Davies, Corbett \& Margalef 1995: 22-26), which has also been used for a basic color terms survey in Estonian (Sutrop 2000b, 147-148; 2002, 58), Hungarian, Finnish and Czech (Uusküla \& Sutrop 2007: 105; Uusküla 2007: 372; Uusküla 2008a: 8-9; Uusküla 2008b: 30-33).

In the list task, the subjects were asked to name as many colors as they could. The respondents had not previously been informed of the topic of the experiment. There was no time limit set for the subjects; however, the longest lists were completed within two minutes and ten seconds. The first long break in listing the colors was noted down by the interviewer. All the responses were video-recorded.

After the list task, the subjects' ability to see color was assessed using The City University Color Vision Test. The test consisted of ten black plates, each carrying a color dot surrounded by four dots of different colors. The subjects were asked to identify the one surrounding dot most similar to the central one: above, below, right or left (Fletcher 1998). If the respondents failed the color vision test, they also completed the next task, but their answers were not included in the data analysis.

The third task was the color-naming task, which involved showing the subjects 65 different color squares, one square at a time, in random sequence. The plates were presented on a neutral gray cloth. The subjects were asked to name the colors of the tiles. All the squares were $5 \times 5 \times 0.4 \mathrm{~cm}$ wooden plates covered with colored paper from the Color-Aid Corporation range of colors. The systematic selection of 65 stimuli had been presented by Davies et al (1992). A total of 219 colors in the Color-Aid Corporation set were arranged in 24 color tones or hues (six basic colors: Y - yellow, O - orange, R - red, V violet, B - blue and G - green, eighteen intermediate colors, e.g. YO - yelloworange and YOY - yellow-orange-yellow), and seven variants of each hue: four tints $\left(T_{1}\right.$ to $\left.T_{4}\right)$ and three shades $\left(S_{1}\right.$ to $\left.S_{3}\right)$. The tints and shades maintained the same hue but varied from their parent hue in the content of white and content of black respectively. There was also a separate gray scale for seven achromatic colors, ranging from white through gray to black, and some extra-system colors of particular significance to artists, such as Sienna Brown and Rose Red (Davies et al 1992: 1097).

After the three tasks were completed, a questionnaire was filled out. The questionnaire covered the following background information about the subjects: age, sex, place of residence and place of origin, time of moving away from the 
place of origin, education, schools attended, occupation, degree of deafness, hearing status of parents and siblings, access to sign language, and time when ESL was learned (see also appendix 1).

All the tasks were carried out indoors and in natural daylight, avoiding both direct sunlight and dark shades. Instructions and questions, including the questionnaire on the background information, were given in ESL by Liivi Hollman, the author of the current study, a hearing fluent signer. Both the list task and the color-naming task were video-recorded by a deaf cameraman to encourage direct signing contact with the subject. Answers to the questionnaire were given in ESL and written down by the interviewer. The interviews were conducted in rooms of local deaf clubs in Pärnu, Tartu, Tallinn and Võru, and in a deaf church in Tallinn.

The recorded data was reviewed and all the color signs used by the subjects, both in the list task and the color-naming task, were transcribed for further analyses. The collected data was notated using the Estonian Sign Language transcription system (Paabo, Födisch \& Hollman 2009) and analyzed using the methodology of Davies and Corbett (1994) and Sutrop (2001, 2002). The form of notated signs may be seen in Table 3 in the following analyses. In addition to the traditional analyses, the data collected was analyzed both in terms of vocabulary and concept to detect possible ambiguity in the signs.

Variations in the articulation of the signs, as well as sign order in compounds, were registered while transcribing the research data, but were not considered in the analyses as different signs, e.g. compounds such as BLUE LIGHT, LIGHT BLUE and LIGHT BLUE LIGHT were analyzed as the same signs (having the meaning of light blue) if the signs LIGHT and BLUE were the same. In the same way, simple signs which were articulated with only one different phoneme (a difference in hand form, location, movement, or orientation of the palm or fingers) were regarded as variants of the main sign, e.g. the sign GREEN for green was considered as a main sign articulated in the neutral signing space with a downward movement. The sign had two different variants: one articulated with the same movement but having a different location, the face, and the second articulated in the same location, but with an upward movement. Both of them were considered to be variations of the same sign. In the same way, the sign BLUE had different variants, which were articulated either on the nose or in the neutral signing space; in the analyses, these were also regarded as variations of the main sign.

Different signs denoting the same color were numbered, starting with the most salient color name. The sign marked in the data analyses as RED 1 was articulated with the ESL A, F or S hand-shape on the cheek, while RED 2 was considered to be a different sign, differing from the first in practically all its parameters and having a totally different etymology. The sign WHITE 2 for white also couldn't be regarded as a variety of WHITE 1, because both the orientation of the palm and the movement were different. Therefore, these signs were referred to as WHITE 1 and WHITE 2 in the analyses. 
The first parameter used in the data analyses was term frequency $(F)$, i.e. the number of the lists where the term is listed. Considering the number of respondents, terms mentioned only by three or fewer subjects were excluded from the analyses. In the list task, mean position $(\mathrm{mP})$ of a term in the lists containing the given term was also calculated according to the following formula:

$$
m P=\left(\sum R_{j}\right) / F,
$$

where $F$ is the frequency of the term, and $R_{j}$ is the rank of a term in an individual list (Sutrop 2001: 273). The main parameter in the analyses of the list task data was the cognitive salience index designed by Sutrop (2001: 270, 273):

$$
S=F /(N m P),
$$

where $N$ is the total number of lists. The index combines two indicators of the psychological salience of a basic term by Berlin and Kay - the tendency to occur at the beginning of the lists and the occurrence in the idiolects of all subjects (Berlin \& Kay 1969: 6). (Berlin \& Kay 1969: 6; Davies, I., Davies C. \& Corbett 1994: 38). If a term appears in all the lists $(\mathrm{F}=\mathrm{N})$ in the first position $(\mathrm{mP}=1)$, the quotient $\mathrm{S}$ equals $1(\mathrm{~S}=\mathrm{F} / \mathrm{F} 1)$ and if a term does not appear in any of the lists $(\mathrm{F}=0)$, the quotient $\mathrm{S}$ equals 0 . Therefore, an ideal psychologically most salient term has a designation of 1 and a term that does not appear in the list task has a designation of 0 (Sutrop 2001: 271).

\subsection{Description of the subjects}

The subjects participating in the survey were selected from four different regions: Tallinn and Tartu, as the biggest centers of the deaf in Estonia, with deaf schools and deaf clubs and all the opportunities for social interaction between deaf people, Pärnu, as an active center of the deaf, believed to be the area of the oldest extant ESL, and Võru, as a small center with quite a few deaf people and with ESL therefore probably more influenced by Estonian. The proportion of the subjects from all four regions followed the overall proportions of the actual number of deaf people living in these areas. A total of 50 subjects were interviewed, 20 of them from Tallinn, 13 from Pärnu, 11 from Tartu, five from Võru and one from Rakvere.

The subjects were contacted through local deaf clubs. All the volunteers were informed that they would participate in an ESL study, without any prior reference to color terms, and were assigned certain times for interviews. The only criteria set for the subjects were fluency in ESL and hearing impairment. Hearing ESL signers were not included in the study. However, the selection of deaf and hearing-impaired subjects was absolutely random and their fluency in ESL was not tested. Therefore, there were subjects having ESL as their first language, as well as subjects who had been raised and taught in an environment 
where Estonian was the main language and ESL was acquired later. Information about access to ESL was elicited in the questionnaire and the data is also differentiated according to access in the following analyses.

Among the subjects, there were 24 men and 26 women, between the ages of 15 and 74, with an average age of 43 years. Respondents from Pärnu had the highest average age (57 years), while the subjects from Võru were only 20 to 30 years of age. As seen in figure 27, the age of subjects from Tallinn was quite evenly distributed from 15 years to 61 years, but the respondents from Tartu and Pärnu were mostly older than the average age of the subjects.

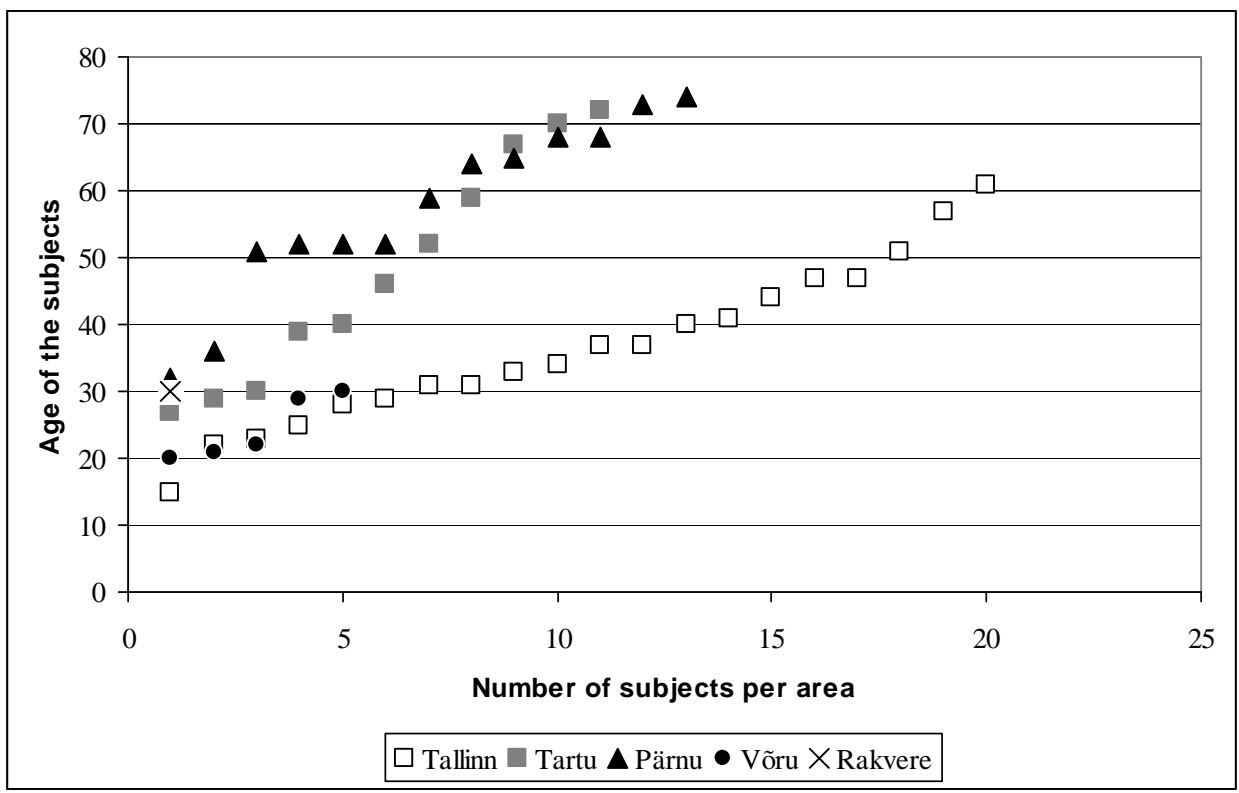

Figure 27. Age-class distribution of the subjects from different regions.

Although half of the subjects (25 subjects) had lived in the same city throughout their lives, only two of them had actually studied in the local deaf school. The others, even if they were living in their place of their origin, had either been in a Tartu school for hearing-impaired students or in the Porkuni Deaf School for many years. Thirty-six subjects had studied in the Porkuni Deaf School, some younger subjects had started their education in the Porkuni Deaf School and then continued their education in the Tallinn Deaf School, 12 subjects had studied in the Tartu Hiie School and the youngest subject was still a student of the Tallinn Deaf School. Only one of the subjects had attended the local mainstream school. Most of the subjects had basic (22 subjects, 44\%) or uppersecondary education (15 subjects, $30 \%)$, nine (18\%) had a primary education and only four (8\%) had graduated from universities. Half of the female respondents (13 people, $26 \%$ of all subjects) worked as seamstresses, and the 
most common occupation among male subjects was carpentry (5 people, 10\% of all subjects). Twelve percent of the subjects worked as teachers and $8 \%$ of all respondents were students. Among the subjects, there were also builders, pastors, shoemakers, janitors, tailors, an artist, a cameraman, a baker, a librarian, a housewife and representatives of other professions.

Thirty-eight subjects (76\%) were profoundly deaf, and 12 (24\%) had some residual hearing, or identified themselves as hearing-impaired rather than deaf. All of the subjects communicated in ESL, but only eight (16\%) were from deaf families, and 7 (14\%) people from hearing families stated that they had access to ESL in their families before they entered a school or kindergarten for the deaf, mainly because of deaf siblings. Thirty-five subjects (70\%) were from totally hearing families, and had started to learn ESL at the age of two to fourteen. Eighteen subjects had access to ESL when they went to kindergarten at the age of two to five, thirteen found themselves in a signing environment only when they went to school at the age of six to nine, and three started to learn ESL at the age of 12 to 14. One of the subjects did not know at what age he had started to learn ESL.

As mentioned above, generally about $90 \%$ of deaf children are born into hearing families and therefore it might be concluded that although most of the subjects in the study did not come from the core of the deaf community, they still represented a typical selection of deaf sign language users.

\subsection{Results of the list task}

In the list task, the 50 subjects named a total of 681 color terms. One of the subjects only listed four terms, and two of the subjects named 25 different color terms. The average number of terms given by a subject was 13.62, of which 11.38 terms were named prior to the first longer pause for thinking. Subjects from deaf families having access to ESL from birth and subjects from hearing families with early access to ESL at home listed more color signs than the average number of color terms by a subject. The average number of terms listed by the subjects from deaf families was 15.63 and by the subjects from hearing signing families 14.57, while the subjects from hearing families listed 12.97 terms. The variation was the highest in the group of subjects from signing hearing families (standard deviation $\sigma=5.01$ ) and the smallest in the group of subjects from hearing non-signing families $(\sigma=4.05)$. 


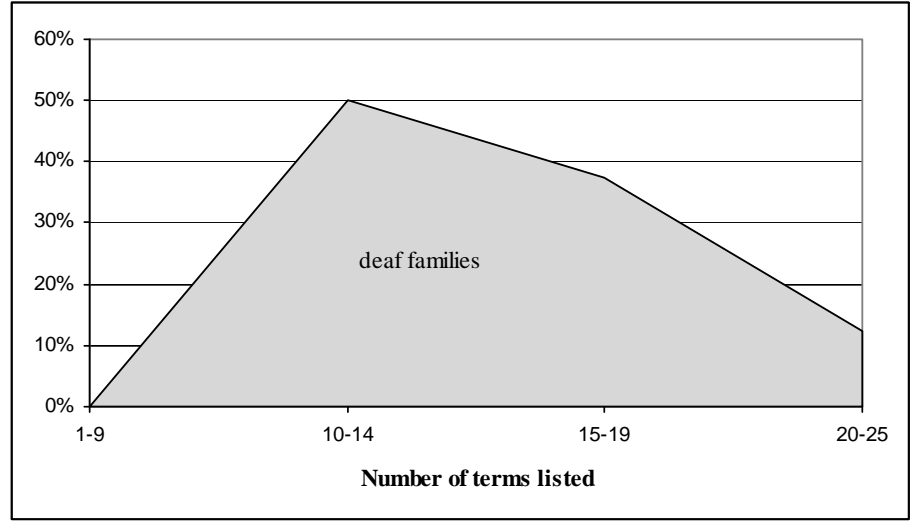

(a)

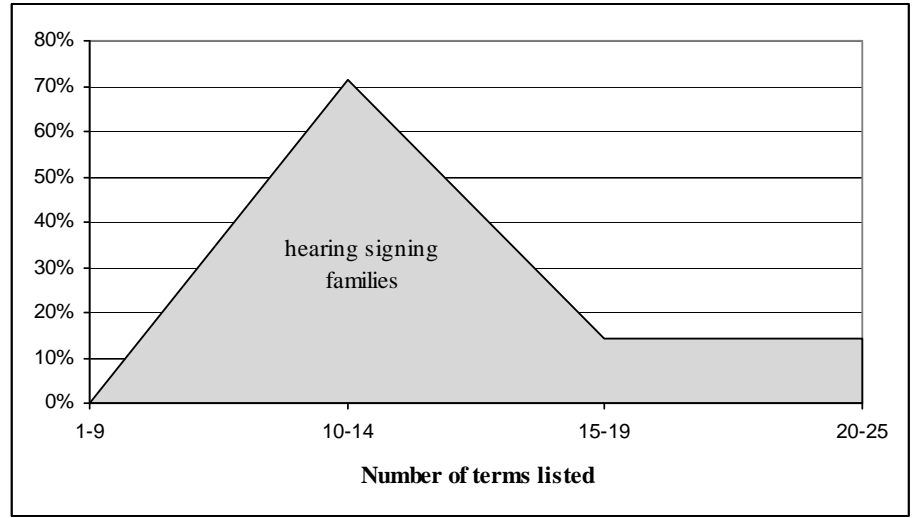

(b)

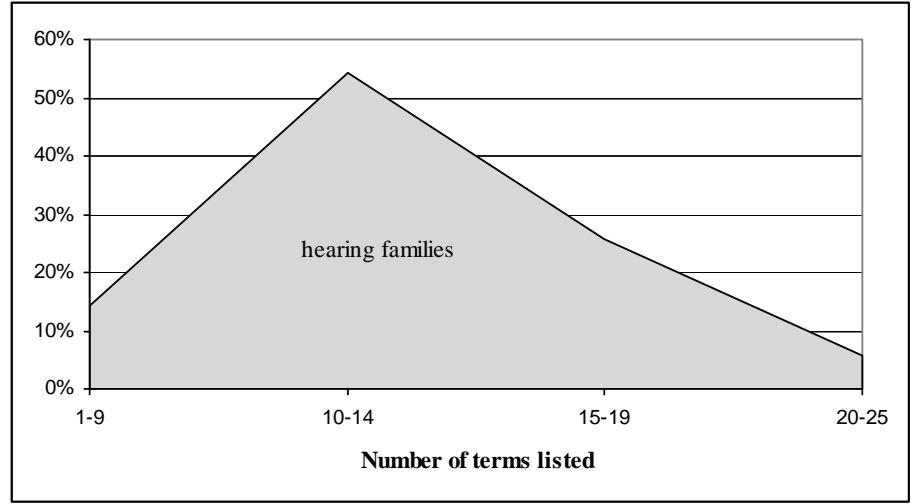

(c)

Figure 28. The lengths of lists given by subjects from (a) deaf families, (b) hearing signing families, and (c) hearing non-signing families on the list task.

Although the mentioned sub-groups are obviously too small to draw any conclusions, it may be seen that the proportion of longer lists is higher among 
the subjects from deaf families than the lists from other groups. By the subjects from either signing deaf or signing hearing families no lists shorter than 10 terms were given, while $14.3 \%$ (5 subjects) from non-signing hearing families listed fewer than 10 terms (figure 28).

The subject who couldn't recall more than four color terms was a 73-yearold man from Pärnu; deaf himself, he had come from a hearing family and did not know the approximate time when he started to learn sign language. He studied at a school for hearing-impaired students, which leads to the assumption that he did not learn sign language before going to school. He had no trouble naming the colors in the next task, but the fact that he mostly used Estonian words instead of ESL signs confirmed the assumption that Estonian had probably remained his first language, even after learning to communicate in ESL.

The subjects listing 25 different terms were a 68-year-old female tailor from Pärnu, who was also from a hearing family but had a deaf brother to sign with early in her childhood, and a 37-year-old painter, graduated from the Estonian Art Academy, also from a hearing family. The total of 681 color terms was comprised of 109 different signs (table 3), including compounds, denoting 70 different shades of colors.

The bilingualism of deaf communities has been outlined above. As seen above, $70 \%$ of the subjects in the study came from hearing families with no other deaf signing family members. Considering the average age of the respondents and the fact that ESL has been used in deaf education as a teaching language only since 1994, it might also be concluded that ESL was not the main language for most of the subjects in school either. Therefore, according to expectations, parallel to ESL signs, Estonian color terms were also used by the subjects. Considering this, both ESL signs as well as their translations into Estonian were transcribed for the data analyses. If no mouth pattern accompanied the sign formation, the translation into ESL was given by the interviewer according to the usual meaning of the sign. When the Estonian word articulated parallel to the ESL sign differed from the usual denotation of the sign, the Estonian word used by the subject was written down as a translation of the sign.

Out of 70 different colors, 35 were named only once and therefore were excluded from further analyses. The most frequent color referred to (see also table 4) was black ( $\mathrm{F}=49)$, followed by white and blue (both $\mathrm{F}=48)$, red $(\mathrm{F}=47)$, yellow $(\mathrm{F}=46)$, green and brown (both $\mathrm{F}=45)$, orange $(\mathrm{F}=40)$, gray $(\mathrm{F}=39)$, purple $(\mathrm{F}=37)$ and pink $(\mathrm{F}=33)$. The next most frequent concept was mentioned only by 22 subjects and was a compound (light blue); the mono-lexemic terms beige and purple were mentioned only 18 and three times, respectively. 
Table 3. All ESL signs named in the list task, transcribed using the transcription system by Paabo, Födisch \&Hollman (2009)

\begin{tabular}{|c|c|c|c|c|c|}
\hline No & Sign transcription & Gloss in English & $\mathbf{F}$ & $\mathbf{m P}$ & SI \\
\hline 1 & $A \mid " 1) C$ & red & 43 & 2.33 & 0.370 \\
\hline 2 & L:OZ+ & blue & 48 & 3.48 & 0.276 \\
\hline 3 & $5^{\star}|| 5^{\star} / \mathrm{O} / \mathrm{V} \%$ & green & 42 & 4.43 & 0.190 \\
\hline 4 & ||$+\mid \sim-><-$ & yellow & 47 & 5.34 & 0.176 \\
\hline 5 & $\mathrm{~J}^{\wedge} \wedge$ & black & 49 & 5.78 & 0.170 \\
\hline 6 & Fv1"|2=Bv1)2<- & white & 34 & 5.50 & 0.124 \\
\hline 7 & $B * \mid " 1) \wedge$ & pink, purple & 42 & 8.14 & 0.103 \\
\hline 8 & 5:)X & gray & 42 & 9.24 & 0.091 \\
\hline 9 & $A=A C$ & brown & 34 & 8.09 & 0.084 \\
\hline 10 & Bv1"|2=B/1)2> & white & 12 & 4.25 & 0.056 \\
\hline 11 & L) $1 / O / Z+$ & purple & 16 & 6.06 & 0.053 \\
\hline 12 & O) $1 / 0 / Z+$ & orange & 17 & 9.12 & 0.037 \\
\hline 13 & F.v1"|2=Bv1)2Z+ & brown, beige & 14 & 8.07 & 0.035 \\
\hline 14 & $\mathrm{~L}: \mathrm{OZ}+5 \| 5 / \mathrm{O} / \mathrm{V}[\mathrm{A} \| \mathrm{A}]$ & dark blue & 16 & 10.75 & 0.030 \\
\hline 15 & L:OZ+ 5||5"|1Z+ & light blue & 13 & 11.31 & 0.023 \\
\hline 16 & B"|1//2/O/Z+ & beige & 11 & 11.18 & 0.020 \\
\hline 17 & L:)1/O/VZ+ & orange & 5 & 5.60 & 0.018 \\
\hline 18 & Juv+ & red & 4 & 4.50 & 0.018 \\
\hline 19 & $5 *|| 5^{\star} / \mathrm{O} / \mathrm{5} / \mid 5 / \mathrm{O} / \mathrm{V}[\mathrm{A} \| \mathrm{A}]$ & dark green & 10 & 11.60 & 0.017 \\
\hline 20 & $A \mid " 1) C 5|| 5 / O / V[A \| A]$ & dark red & 8 & 10.13 & 0.016 \\
\hline 21 & $\mathrm{~L}: \mathrm{OZ}+\mathrm{E} \| \mathrm{E} / \mathrm{O} / \mathrm{N}[5|| 5]$ & light blue & 9 & 11.78 & 0.015 \\
\hline 22 & $5 \star|| 5 * / O / \vee \% 5|| 5 " \mid 1 Z+$ & light green & 6 & 11.00 & 0.011 \\
\hline 23 & AoU"|1U[L] & golden & 6 & 11.67 & 0.010 \\
\hline 24 & $\mathrm{D} / \mathrm{1}(2=\mathrm{B} / 1) 2 \mathrm{X}+$ & silvery & 6 & 12.83 & 0.009 \\
\hline 25 & ||$+\mid \sim-><-E \| E / O / /[5|| 5]$ & light yellow & 5 & 11.00 & 0.009 \\
\hline 26 & $\mathrm{R} / \mathrm{O} / \mathrm{Z}+$ & orange & 4 & 10.00 & 0.008 \\
\hline 27 & $5^{\star}|| 5^{\star} / \mathrm{O} / \mathrm{O} \% \mathrm{E}|| \mathrm{E} / \mathrm{O} / /[5|| 5]$ & light green & 4 & 10.50 & 0.008 \\
\hline 28 & $A=A C E \| E / O / /[5|| 5]$ & light brown & 5 & 13.20 & 0.008 \\
\hline 29 & ||$+|\sim-><-5||5 "| 1 Z+$ & light yellow & 4 & 11.50 & 0.007 \\
\hline 30 & $5:) \times 5 \| 5 / O / V[A \| A]$ & dark gray & 4 & 11.50 & 0.007 \\
\hline 31 & 5:)X E\|||E/O//[5||5] & light gray & 4 & 15.25 & 0.005 \\
\hline 32 & $\left.B^{*} \mid " 1\right) \wedge 5|| 5 " \mid 1 Z+$ & light pink & 3 & 7.00 & 0.009 \\
\hline 33 & I-i-I-I-a & purple & 3 & 7.33 & 0.008 \\
\hline 34 & r-o-o-s-a & pink & 3 & 9.00 & 0.007 \\
\hline 35 & Al"1)C 5||5"|1Z+ & light red & 3 & 9.00 & 0.007 \\
\hline 36 & B*|"1U & orange & 3 & 10.00 & 0.006 \\
\hline 37 & $5 / \mid 5 / \mathrm{O} / \mathrm{N}+$ & purple & 3 & 10.00 & 0.006 \\
\hline 38 & $\mathrm{~L}: \mathrm{OZ}+5^{\star} \mathrm{v} 1 / \mathrm{O} / \mathrm{D}>$ & azure & 3 & 10.33 & 0.006 \\
\hline
\end{tabular}


Table 3. continued

\begin{tabular}{|c|c|c|c|c|c|}
\hline No & Sign transcription & Gloss in English & $\mathbf{F}$ & $\mathbf{m P}$ & SI \\
\hline 39 & |5||5"|1/O/Z+ & green, beige, orange & 3 & 11.33 & 0.005 \\
\hline 40 & $\begin{array}{l}\text { F.v1"|2=Bv1)2Z+ } \\
\text { El|E/O//N51|5] }\end{array}$ & light brown & 3 & 12.33 & 0.005 \\
\hline 41 & $\mathrm{D} / 1 \mid \mathrm{X}+$ & bronze & 3 & 14.00 & 0.004 \\
\hline 42 & B"|1//2/O/Z+ E||E/O//[5||5] & light beige & 3 & 14.67 & 0.004 \\
\hline 43 & $A=A C 5 \| 5 / O / V[A \| A]$ & dark brown & 3 & 16.67 & 0.004 \\
\hline 44 & $L: \sim " \mid 1)<-$ & orange & 2 & 5.00 & 0.008 \\
\hline 45 & $\left.5^{\star "} \mid 1\right) /<-$ & orange & 2 & 6.00 & 0.007 \\
\hline 46 & $\mathrm{~J}^{\wedge} \wedge$ 5||5/O/V[A || $\left.\mathrm{A}\right]$ & dark black & 2 & 7.50 & 0.005 \\
\hline 47 & $\mathrm{I}(1 " \mathrm{2}=\mathrm{B} / \mathrm{Z}+$ & yellow & 2 & 7.50 & 0.005 \\
\hline 48 & E) $/ N[5]$ & pink & 2 & 7.50 & 0.005 \\
\hline 49 & $\left.\mathrm{~B}^{*} \mid " 1\right) / 5|| 5 / \mathrm{O} / \mathrm{V}[\mathrm{A} \| \mathrm{A}]$ & dark purple & 2 & 9.00 & 0.004 \\
\hline 50 & $L: " \mid 1) C<-$ & orange & 2 & 9.50 & 0.004 \\
\hline 51 & A|"1)C El|E/O//N5||5] & light red & 2 & 10.00 & 0.004 \\
\hline 52 & V"|1/O/> & violet & 2 & 11.00 & 0.004 \\
\hline 53 & $5^{\star}|| 5^{\star} / O / V \%$ n-e-o-o-n & neon green & 2 & 11.00 & 0.004 \\
\hline 54 & $J^{\wedge} \wedge$ E ||E/O// [5||5] & light black & 2 & 12.00 & 0.003 \\
\hline 55 & $\begin{array}{l}\text { F.v1"|2=Bv1)2Z+ } \\
5|| 5 / O / V[A \| A]\end{array}$ & dark brown & 2 & 12.00 & 0.003 \\
\hline 56 & $\left.B^{*} \mid " 1\right) / \mathrm{E} \| \mathrm{E} / \mathrm{O} / /[5|| 5]$ & light purple, liaht pink & 2 & 12.00 & 0.003 \\
\hline 57 & $E \| E / O / / \Lambda[5|| 5]$ & white & 2 & 16.50 & 0.002 \\
\hline 58 & $\mathrm{~B}(1 / 12 / \mathrm{O} / \mathrm{W}$ & silvery & 2 & 18.00 & 0.002 \\
\hline 59 & $\mathrm{~K}:\left(1^{\wedge} \mathrm{V}+\right.$ & orange & 1 & 3.00 & 0.007 \\
\hline 60 & $\mathrm{~L}: \mathrm{OZ}+\mathrm{B}(1$ “"|2|IB/A1X+ & middle blue & 1 & 6.00 & 0.003 \\
\hline 61 & $\mathrm{~L}:)(\mathrm{oD} / \mathrm{A}+$ & green & 1 & 6.00 & 0.003 \\
\hline 62 & $F^{*} \mathrm{~V} 1(2 \mathrm{U}<-$ & light brown & 1 & 6.00 & 0.003 \\
\hline 63 & $\mathrm{~K} \mid " 1(0) \mathrm{D}>$ & purple & 1 & 7.00 & 0.003 \\
\hline 64 & $5 *|| 5 * / O / V \% R||>$ & electric green & 1 & 7.00 & 0.003 \\
\hline 65 & V“|1v2/O/Z+ 5||5/O/V[A & dark cherry & 1 & 8.00 & 0.003 \\
\hline 66 & Juv+ 5\|5/O/V[A\|A] & dark red & 1 & 9.00 & 0.002 \\
\hline 67 & $5^{\star}|| 5^{\star} / \mathrm{O} / \mathrm{J} \% \mathrm{~J} \sim \| \mathrm{J} \sim \wedge 1 \mid$ |"2Y<- & poison-green & 1 & 9.00 & 0.002 \\
\hline 68 & $\mathrm{~L}:)(\mathrm{oD} / \mathrm{A}+5 \| 5 / \mathrm{O} / \mathrm{V}[\mathrm{A} \| \mathrm{A}]$ & dark green & 1 & 10.00 & 0.002 \\
\hline 69 & ||$+|\sim-><-A| " 1) C$ & yellowy-red & 1 & 10.00 & 0.002 \\
\hline 70 & Fv1" $\mid 2=B \vee 1) 2<-||+\mid \sim-><-$ & whitish-yellow & 1 & 10.00 & 0.002 \\
\hline 71 & b-e-e-ž & beige & 1 & 10.00 & 0.002 \\
\hline 72 & $A \mid " 1) C$ n-e-o-o-n & neon red & 1 & 10.00 & 0.002 \\
\hline 73 & $\begin{array}{l}5\|5 / O / N+5\| 5 / O / V[A \| A] \\
\text { V“|1v2/O/Z+ }\end{array}$ & dark purple cherry & 1 & 10.00 & 0.002 \\
\hline 74 & $\mathrm{~L}: \mathrm{OZ}+5^{\star}|| 5^{\star} / \mathrm{O} / \mathrm{V} \%$ & blueish green & 1 & 12.00 & 0.002 \\
\hline
\end{tabular}


Table 3. continued

\begin{tabular}{|c|c|c|c|c|c|}
\hline No & Sign transcription & Gloss in English & $\mathbf{F}$ & $\mathbf{m P}$ & SI \\
\hline 75 & F.v1"|2=Bv1)2Z+ 5||5"|1Z+ & light brown & 1 & 12.00 & 0.002 \\
\hline 76 & $\mathrm{~A} / \mathrm{O} /[\mathrm{L}]$ & color of aluminum & 1 & 12.00 & 0.002 \\
\hline 77 & $\mathrm{I}(1 "|2=\mathrm{B} / \mathrm{Z}+5| \mid 5 / \mathrm{O} / \mathrm{V}[\mathrm{A} \| \mathrm{A}]$ & dark yellow & 1 & 13.00 & 0.002 \\
\hline 78 & $\mathrm{E} / \mathrm{O} / \mathrm{C}$ & orange & 1 & 13.00 & 0.002 \\
\hline 79 & V"|1/O/> 5||5"|1Z+ & light violet & 1 & 14.00 & 0.001 \\
\hline 80 & Juv+ 5||5"|1Z+ & light red & 1 & 14.00 & 0.001 \\
\hline 81 & $\left.\left.B^{\star} \mid " 1\right) \wedge A \mid " 1\right) \vee$ & faded pink & 1 & 14.00 & 0.001 \\
\hline 82 & $5:) \times 5|| 5 " \mid 1 Z+$ & light gray & 1 & 14.00 & 0.001 \\
\hline 83 & V"|1/O/> 5||5/O/V[A ||$A]$ & dark violet & 1 & 15.00 & 0.001 \\
\hline 84 & ||$+\mid \sim-><-$ AoU"|1U[L] & golden yellow & 1 & 15.00 & 0.001 \\
\hline 85 & AoU"|1U[L] B|IZ+ & golden & 1 & 15.00 & 0.001 \\
\hline 86 & B"|1//2/O/Z+k-a-k-a-o & cocoa brown & 1 & 15.00 & 0.001 \\
\hline 87 & $A=A C 5 \| 5^{\prime \prime} \mid 1 Z+$ & light brown & 1 & 15.00 & 0.001 \\
\hline 88 & JUX & violet & 1 & 17.00 & 0.001 \\
\hline 89 & S|“1oDv B|IZ+ & ivory & 1 & 17.00 & 0.001 \\
\hline 90 & $\mathrm{D} / 1|| \mathrm{X}+\mathrm{B} \mid \mathrm{Z}+$ & bronze & 1 & 17.00 & 0.001 \\
\hline 91 & $5\|5 / O / N+E\| E / O / /[5 \| 5]$ & light purple & 1 & 17.00 & 0.001 \\
\hline 92 & $\begin{array}{l}\mathrm{L}: \mathrm{OZ}+\mathrm{E} \| \mathrm{E} / \mathrm{O} / /[5|| 5] \\
\mathrm{Bv1}|2 / \mathrm{O} / \mathrm{D}>+\mathrm{B}| \mathrm{IZ+}\end{array}$ & light blue color of sea & 1 & 18.00 & 0.001 \\
\hline 93 & $\mathrm{~A} \mid " 1) \mathrm{C}$ B||B“|2/O/Dv & beet-red & 1 & 18.00 & 0.001 \\
\hline 94 & $5\|5 / O / N+5\| 5 / O / V[A \| A]$ & dark purple & 1 & 18.00 & 0.001 \\
\hline 95 & I-a-i-m B|IZ+ & color of lime & 1 & 19.00 & 0.001 \\
\hline 96 & $\mathrm{~L}:)(\mathrm{OD} / \mathrm{A}+\mathrm{E} \| \mathrm{E} / \mathrm{O} / /[5|| 5]$ & light green & 1 & 19.00 & 0.001 \\
\hline 97 & $A=A C$ L.:||L.:" $\mid 2 / O / \%$ & chocolate brown & 1 & 19.00 & 0.001 \\
\hline 98 & O) $1 / \mathrm{O} / \mathrm{Z}+5 \| 5 / \mathrm{O} / \mathrm{V}[\mathrm{A} \| \mathrm{A}]$ & dark orange & 1 & 20.00 & 0.001 \\
\hline 99 & $\mathrm{~L}:)\left(\mathrm{OD} / \wedge+++\mathrm{B} \_\| \mathrm{B} \_\# / \mathrm{O} /[\mathrm{D} \| \mathrm{D}]\right.$ & green like moss & 1 & 20.00 & 0.001 \\
\hline 100 & $\mathrm{~J}^{\wedge} \wedge 5|| 5^{\prime \prime} \mid 1 Z+$ & light black & 1 & 20.00 & 0.001 \\
\hline 101 & JUX 5||5"|1/O/Z+ & turquoise & 1 & 21.00 & 0.001 \\
\hline 102 & $5 *|| 5^{\star} / \mathrm{O} / \mathrm{V} \% \mathrm{~J}(0)<-[5 \| 5]$ & bright green & 1 & 21.00 & 0.001 \\
\hline 103 & $\|+\mid \sim-><-J(0)<-[5|| 5]$ & bright yellow & 1 & 22.00 & 0.001 \\
\hline 104 & $\mathrm{R}|\mathrm{I}>\mathrm{B}| \mathrm{IZ+}$ & electric color & 1 & 22.00 & 0.001 \\
\hline 105 & $0) 1 / O / Z+J(0)<-[5|| 5]$ & bright orange & 1 & 23.00 & 0.001 \\
\hline 106 & L:OZ+ CORNFLOWER & blue like cornflower & 1 & 23.00 & 0.001 \\
\hline 107 & $\left.B^{*} \mid " 1\right) \wedge J(0)<-[5|| 5]$ & bright pink & 1 & 24.00 & 0.001 \\
\hline 108 & $A \mid " 1) C B^{*} \mid " 1 U$ & carmine red & 1 & 24.00 & 0.001 \\
\hline \multirow[t]{2}{*}{109} & (bordoopunane) & Bordeaux red & 1 & 25.00 & 0.001 \\
\hline & Total & & 681 & & \\
\hline
\end{tabular}


Table 4. List task, most frequent concepts named: frequencies (F), mean positions $(\mathrm{mP})$, salience indexes (SI) and their respective rank orders $(\mathrm{R})$

\begin{tabular}{|c|c|c|c|c|c|c|c|}
\hline & $\begin{array}{l}\text { Concept gloss in } \\
\text { English }\end{array}$ & $\mathbf{F}$ & $\mathbf{R}$ & $\mathbf{m P}$ & $\mathbf{R}$ & SI & $\mathbf{R}$ \\
\hline 1 & red & 47 & 4.0 & 2.51 & 1.0 & 0.374 & 1.0 \\
\hline 2 & blue & 48 & 2.5 & 3.41 & 2.0 & 0.281 & 2.0 \\
\hline 3 & green & 45 & 6.5 & 4.60 & 3.0 & 0.196 & 3.0 \\
\hline 4 & yellow & 46 & 5.0 & 4.93 & 4.0 & 0.186 & 4.0 \\
\hline 5 & black & 49 & 1.0 & 5.77 & 6.0 & 0.170 & 5.5 \\
\hline 6 & white & 48 & 2.5 & 5.64 & 5.0 & 0.170 & 5.5 \\
\hline 7 & brown & 45 & 6.5 & 7.84 & 9.0 & 0.115 & 7.0 \\
\hline 8 & purple & 37 & 10.0 & 7.08 & 7.0 & 0.105 & 8.0 \\
\hline 9 & orange & 40 & 8.0 & 8.65 & 10.0 & 0.092 & 9.0 \\
\hline 10 & gray & 39 & 9.0 & 9.10 & 12.0 & 0.086 & 10.0 \\
\hline 11 & pink & 33 & 11.0 & 9.00 & 11.0 & 0.073 & 11.0 \\
\hline 12 & light blue & 22 & 12.0 & 11.50 & 22.5 & 0.038 & 12.0 \\
\hline 13 & beige & 18 & 13.0 & 10.89 & 18.0 & 0.033 & 13.0 \\
\hline 14 & dark blue & 16 & 14.0 & 10.75 & 17.0 & 0.030 & 14.0 \\
\hline 15 & dark green & 12 & 15.0 & 11.25 & 21.0 & 0.021 & 15.0 \\
\hline 16 & light green & 11 & 16.0 & 11.55 & 24.0 & 0.019 & 16.0 \\
\hline 17 & dark red & 9 & 18.5 & 10.00 & 14.0 & 0.018 & 17.0 \\
\hline 18 & light yellow & 9 & 18.5 & 11.22 & 20.0 & 0.016 & 18.0 \\
\hline 19 & light brown & 10 & 17.0 & 13.00 & 28.0 & 0.015 & 19.0 \\
\hline 20 & light red & 6 & 22.0 & 10.17 & 15.0 & 0.012 & 20.0 \\
\hline 21 & golden & 7 & 21.0 & 12.14 & 25.0 & 0.012 & 21.0 \\
\hline 22 & silvery & 8 & 20.0 & 14.13 & 31.0 & 0.011 & 22.0 \\
\hline 23 & light pink & 4 & 25.5 & 9.25 & 13.0 & 0.009 & 23.0 \\
\hline 24 & dark gray & 4 & 25.5 & 11.50 & 22.5 & 0.007 & 24.5 \\
\hline 25 & dark brown & 5 & 23.0 & 14.80 & 35.0 & 0.007 & 24.5 \\
\hline 26 & light gray & 4 & 25.5 & 13.00 & 28.0 & 0.006 & 26.5 \\
\hline 27 & azure & 3 & 29.5 & 10.33 & 16.0 & 0.006 & 26.5 \\
\hline 28 & bronze & 4 & 25.5 & 14.75 & 34.0 & 0.005 & 29.0 \\
\hline 29 & dark black & 2 & 33.5 & 7.50 & 8.0 & 0.005 & 29.0 \\
\hline 30 & violet & 3 & 29.5 & 13.00 & 28.0 & 0.005 & 29.0 \\
\hline 31 & light black & 3 & 29.5 & 14.67 & 32.5 & 0.004 & 32.0 \\
\hline 32 & light beige & 3 & 29.5 & 14.67 & 32.5 & 0.004 & 32.0 \\
\hline 33 & neon green & 2 & 33.5 & 11.00 & 19.0 & 0.004 & 32.0 \\
\hline 34 & light purple & 2 & 33.5 & 12.50 & 26.0 & 0.003 & 34.5 \\
\hline 35 & dark purple & 2 & 33.5 & 13.50 & 30.0 & 0.003 & 34.5 \\
\hline
\end{tabular}

Although black was the most frequent color referred to, the most salient concept was red (table 4, SI=0.374), as it was generally named at the beginning of the lists $(\mathrm{mP}=2.5)$. Eleven color concepts were mentioned by at least half of the 
subjects: according to the salience index, blue ( $\mathrm{SI}=0.281)$, green ( $\mathrm{SI}=0.196)$, yellow ( $\mathrm{SI}=0.186)$, black and white $(\mathrm{SI}=0.170)$, brown $(\mathrm{SI}=0.115)$, purple $(\mathrm{SI}=$ $0.105)$, orange $(\mathrm{SI}=0.092)$, gray $(\mathrm{SI}=0.086)$ and pink $(\mathrm{SI}=0.073)$ followed red.

Comparing these concepts with the color names listed by the subjects of the color terms survey of Estonian by Sutrop (2002: 74), it may be seen that the list of color concepts named by ESL users almost exactly corresponds to the most frequent color names listed by Estonian subjects, with some minor differences in their rank order (table 5).

Table 5. List task, color concepts listed by ESL users compared to Estonian color terms by Sutrop and their respective rank order according to the salience indexes

\begin{tabular}{|l|r|l|r|}
\hline \multicolumn{2}{|c|}{ List task, ESL } & \multicolumn{2}{c|}{ List task, Estonian } \\
\hline Concept gloss in English & R & Term gloss in English & R \\
\hline \hline red & 1.0 & blue & 1 \\
blue & 2.0 & red & 2 \\
green & 3.0 & green & 3 \\
yellow & 4.0 & yellow & 4 \\
black & 5.5 & black & 5 \\
white & 5.5 & white & 6 \\
brown & 7.0 & purple & 7 \\
purple & 8.0 & orange & 8 \\
orange & 9.0 & brown & 9 \\
gray & 10.0 & gray & 12 \\
pink & 11.0 & & \\
\hline
\end{tabular}

According to the color terms survey by Sutrop, at least half of the subjects named 10 color terms. Light-blue $(\mathrm{R}=10)$ and pink $(\mathrm{R}=11)$ were also salient, but were listed by fewer than half of the subjects.

While the concepts mentioned by ESL users are comparable to the color terms in Estonian, considerable differences may be observed when looking at the signs named in the list task. In the following table (table 6), ESL signs used in the list task are shown together with the various meanings attached to the signs. In many cases, the subjects listing the signs also articulated their Estonian translations. Mostly the Estonian equivalent given by the subjects coincided with its usual denotation, but in some cases the mouth pattern accompanying the sign was different. On this point it is not clear if the subjects used the sign to denote a different color or they picked the wrong Estonian word to translate the listed sign. When there were two or more different Estonian equivalents articulated by the subjects together with the sign, all the mentioned glosses are shown for the sign, together with their frequencies in brackets. When no mouth pattern was used by the subjects, the English gloss shown in the table is the usual translation of the sign. Thus, it may be seen from the data presented in 
table 6 that the ESL sign YELLOW was signed together with the Estonian word oranž for orange by three subjects and the sign further notated as PINK/PURPLE was accompanied by both the Estonian words for pink and purple. BROWN/BEIGE was also used to refer to both brown and beige, and in some cases the same sign was used both for gray and purple.

The most frequent ESL sign of the 109 different signs named in the list task was BLACK ( $\mathrm{F}=49)$, followed by BLUE $(\mathrm{F}=48)$, YELLOW $(\mathrm{F}=47,44$ times used to refer to yellow, three times used to refer to orange, as explained above, further in the analyses noted as YELLOW), RED $1(\mathrm{~F}=43)$, GREEN $(\mathrm{F}=42)$ and GRAY ( $F=42$; the sign was used 39 times to refer to gray and three times to denote purple). The sign for pink $(\mathrm{F}=42$, further referred to as PINK/PURPLE) was used with the same frequency, but its meaning did not seem to be as clearly defined, as it referred to pink for 27 subjects, to purple for 11 subjects and to orange for three subjects. One subject even used the same sign for green. The signs for white ( $\mathrm{F}=34$, further referred to as WHITE 1) and brown ( $\mathrm{F}=34)$ followed. Fifty-one signs were named only once during the list task. The first long step in the decrease in frequencies was between the eight-ninth (BROWN, WHITE 1, F=34) and the tenth term (ORANGE 1, F=17).

The most salient sign named in the list task was RED 1 (table $6, \mathrm{mP}=2.3$, $\mathrm{SI}=0.370$ ). It was not as frequent or as salient as the concept red, because four subjects used a different sign for red, mentioned above as RED $2(\mathrm{~F}=4, \mathrm{mP}=4.5$, $\mathrm{SI}=0.018)$. BLUE ( $\mathrm{SI}=0.276)$, GREEN ( $\mathrm{SI}=0.190)$, YELLOW ( $\mathrm{SI}=0.176)$, BLACK (SI=0.170), WHITE 1 (SI=0.124), PINK/PURPLE (SI=0.103), GRAY ( $\mathrm{SI}=0.091), \mathrm{BROWN}(\mathrm{SI}=0.084)$, WHITE 2 (SI=0.056), PURPLE 1 (SI=0.053), ORANGE $1(\mathrm{SI}=0.037)$ and BROWN/BEIGE $(\mathrm{SI}=0.035)$ followed. Signs mentioned by three or fewer subjects are excluded from the table below (table 6).

According to the mean position, RED 1 ( $\mathrm{mP}=2.3$ ), BLUE ( $\mathrm{mP}=3.5)$, WHITE 2 ( $\mathrm{mP}=4.3)$, GREEN (mP=4.4), YELLOW ( $\mathrm{mP}=5.3)$, WHITE $1(\mathrm{mP}=5.5)$, BLACK $(\mathrm{mP}=5.8)$ and PURPLE $(\mathrm{mP}=6.1)$ were the leading mentions in the list task, leaving out RED 2, as well as the signs for beige and orange, as their frequencies were too low to establish a significant mean position. 
Table 6. List task, signs used more than three times $(F>3)$ : frequencies $(F)$, mean positions (mP), salience indexes (SI) and their respective rank orders (R)

\begin{tabular}{|c|c|c|c|c|c|c|c|}
\hline ESL sign & $\begin{array}{l}\text { Sign gloss } \\
\text { in English }\end{array}$ & $\mathbf{F}$ & $\mathbf{R}$ & $\mathbf{m P}$ & $\mathbf{R}$ & SI & $\mathbf{R}$ \\
\hline RED 1 & red & 43 & 4.0 & 2.33 & 1.0 & 0.370 & 1.0 \\
\hline BLUE & blue & 48 & 2.0 & 3.48 & 2.0 & 0.276 & 2.0 \\
\hline GREEN & green & 42 & 6.0 & 4.43 & 4.0 & 0.190 & 3.0 \\
\hline YELLOW & $\begin{array}{l}\text { yellow (44) } \\
\text { orange (3) }\end{array}$ & 47 & 3.0 & 5.34 & 6.0 & 0.176 & 4.0 \\
\hline BLACK & black & 49 & 1.0 & 5.78 & 9.0 & 0.170 & 5.0 \\
\hline WHITE 1 & white & 34 & 8.5 & 5.50 & 7.0 & 0.124 & 6.0 \\
\hline PINK/ PURPLE & $\begin{array}{l}\text { pink (27) } \\
\text { purple (11) } \\
\text { orange (3) } \\
\text { green (1) }\end{array}$ & 42 & 6.0 & 8.14 & 13.0 & 0.103 & 7.0 \\
\hline GRAY & $\begin{array}{l}\text { gray (39) } \\
\text { purple (3) }\end{array}$ & 42 & 6.0 & 9.24 & 15.0 & 0.091 & 8.0 \\
\hline BROWN & brown & 34 & 8.5 & 8.09 & 12.0 & 0.084 & 9.0 \\
\hline WHITE 2 & white & 12 & 15.0 & 4.25 & 3.0 & 0.056 & 10.0 \\
\hline PURPLE 1 & purple & 16 & 11.5 & 6.06 & 10.0 & 0.053 & 11.0 \\
\hline ORANGE 1 & $\begin{array}{l}\text { orange (16) } \\
\text { beige (1) }\end{array}$ & 17 & 10.0 & 9.12 & 14.0 & 0.037 & 12.0 \\
\hline BROWN/ BEIGE & $\begin{array}{l}\text { brown (11) } \\
\text { beige (3) }\end{array}$ & 14 & 13.0 & 8.07 & 11.0 & 0.035 & 13.0 \\
\hline BLUE DARK & dark blue & 16 & 11.5 & 10.75 & 19.0 & 0.030 & 14.0 \\
\hline BLUE LIGHT 1 & light blue & 13 & 14.0 & 11.31 & 23.0 & 0.023 & 15.0 \\
\hline BEIGE & $\begin{array}{l}\text { beige }(10) \\
\text { creamy (1) }\end{array}$ & 11 & 16.0 & 11.18 & 22.0 & 0.020 & 16.0 \\
\hline ORANGE 2 & $\begin{array}{l}\text { orange (3) } \\
\text { beige (2) }\end{array}$ & 5 & 23.0 & 5.60 & 8.0 & 0.018 & 17.5 \\
\hline RED 2 & red & 4 & 28.5 & 4.50 & 5.0 & 0.018 & 17.5 \\
\hline GREEN DARK & dark green & 10 & 17.0 & 11.60 & 26.0 & 0.017 & 19.0 \\
\hline RED 1 DARK & dark red & 8 & 19.0 & 10.13 & 17.0 & 0.016 & 20.0 \\
\hline BLUE LIGHT 2 & light blue & 9 & 18.0 & 11.78 & 28.0 & 0.015 & 21.0 \\
\hline GREEN LIGHT 1 & light green & 6 & 21.0 & 11.00 & 20.5 & 0.011 & 22.0 \\
\hline GOLD & golden & 6 & 21.0 & 11.67 & 27.0 & 0.010 & 23.0 \\
\hline
\end{tabular}


Table 6. continued

\begin{tabular}{|c|c|c|c|c|c|c|c|}
\hline ESL sign & $\begin{array}{l}\text { Sign gloss } \\
\text { in English }\end{array}$ & $\mathbf{F}$ & $\mathbf{R}$ & $\mathbf{m P}$ & $\mathbf{R}$ & SI & $\mathbf{R}$ \\
\hline SILVER & silvery & 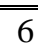 & 21.0 & 12.83 & 29.0 & 0.009 & 24.5 \\
\hline $\begin{array}{l}\text { YELLOW } \\
\text { LIGHT } 2\end{array}$ & light yellow & 5 & 23.0 & 11.00 & 20.5 & 0.009 & 24.5 \\
\hline ORANGE 3 & $\begin{array}{l}\text { orange (3) } \\
\text { pink (1) }\end{array}$ & 4 & 28.5 & 10.00 & 16.0 & 0.008 & 27.0 \\
\hline $\begin{array}{l}\text { GREEN LIGHT } \\
2\end{array}$ & light green & 4 & 28.5 & 10.15 & 18.0 & 0.008 & 27.0 \\
\hline $\begin{array}{l}\text { BROWN LIGHT } \\
\quad 2\end{array}$ & light brown & 5 & 23.0 & 13.20 & 30.0 & 0.008 & 27.0 \\
\hline $\begin{array}{l}\text { YELLOW } \\
\text { LIGHT } 1\end{array}$ & light yellow & 4 & 28.5 & 11.50 & 24.5 & 0.007 & 29.5 \\
\hline GRAY DARK & dark gray & 4 & 28.5 & 11.50 & 24.5 & 0.007 & 29.5 \\
\hline GRAY LIGHT 2 & $\begin{array}{l}\text { light gray (3) } \\
\text { whitish gray (1) }\end{array}$ & 4 & 28.5 & 15.25 & 31.0 & 0.005 & 31.0 \\
\hline
\end{tabular}

Comparing the lists given by three different groups of subjects - deaf signers from signing deaf families, deaf signers from hearing families having access to ESL early in their childhood, and deaf signers from hearing non-signing families, some interesting differences may be observed. Although, as described above, the number of subjects in these groups is too small $(8,7$ and 35 subjects respectively of the total of 50) to draw any conclusions, some of the tendencies are interesting to consider.

As seen in table 7, the salience of the sign RED 1 is much higher among deaf signers from hearing families. This is partly because of the low mean position of RED 1 in the group of deaf people from deaf families but it also has to be noted that, while the vast majority $(90.5 \%, 38$ subjects out of 42$)$ of deaf signers from hearing families used RED 1 in their lists, and RED 2 was mentioned only twice, the proportion of RED 1 among deaf signers from deaf families $(62.5 \%$, 5 subjects out of 8) was lower. Although the total frequency of RED 2 was the same, the proportion of the use of RED 2 in the subgroup of deaf signers from deaf families was much higher (25\%). Combining this result with the average age of subjects using RED 1 (41.5 years of age) and RED 2 (65 years of age), it may be assumed that RED 2 is an older ESL sign used in deaf families, while RED 1 is a newer sign prevalent among younger signers.

Another difference may be observed between the use of the signs WHITE 1 and WHITE 2. While WHITE 1 was quite frequent among both deaf subjects from deaf families and deaf subjects from hearing signing families (80\%, 12 subjects out of 15), only $62.9 \%$ (22 subjects out of 35) of the deaf subjects from hearing non-signing families used the sign, while $28.6 \%$ (10 subjects out of 35) used the sign WHITE 2. 
Table 7. List task, the most frequent signs used ( $\mathrm{F}>25)$. Differences between the lists given by subjects from deaf families, hearing families using ESL and hearing families communicating in Estonian: frequencies (F), mean positions (mP) and salience indexes (SI). Use of the signs RED 2 and WHITE 2 in the three sub-groups

\begin{tabular}{|c|c|c|c|c|c|c|c|c|c|}
\hline \multirow[b]{2}{*}{ ESL sign } & \multicolumn{3}{|c|}{$\begin{array}{l}\text { Subjects from deaf } \\
\text { families }\end{array}$} & \multicolumn{3}{|c|}{$\begin{array}{l}\text { Subjects from } \\
\text { hearing signing } \\
\text { families }\end{array}$} & \multicolumn{3}{|c|}{$\begin{array}{l}\text { Subjects from } \\
\text { hearing non-signing } \\
\text { families }\end{array}$} \\
\hline & $\mathbf{F}$ & $\mathbf{m P}$ & SI & $\mathbf{F}$ & $\mathbf{m P}$ & SI & $\mathbf{F}$ & $\mathbf{m P}$ & SI \\
\hline RED 1 & 5 & 4.20 & 0.149 & 6 & 1.5 & 0.571 & 32 & 2.19 & 0.418 \\
\hline BLUE & 8 & 3.75 & 67 & 7 & 2.86 & 0.350 & 33 & 5 & 0.266 \\
\hline GREEN & 7 & 8.57 & 0.102 & 6 & 3.33 & 0.257 & 29 & 3.66 & 0.227 \\
\hline YELLOW & 8 & 5.00 & 200 & 8 & 6.25 & 0.183 & 31 & .19 & 0.171 \\
\hline BLACK & 8 & 5.25 & 0.190 & 7 & 4.86 & 0.206 & 34 & 6.09 & 0.160 \\
\hline $\begin{array}{l}\text { WHITE } 1 \\
\text { PINK/ }\end{array}$ & 7 & 4.43 & 0.198 & 5 & 6.40 & 0.112 & 22 & 5.64 & 0.112 \\
\hline PURPLE & 6 & 8.17 & 0.092 & 8 & 8.63 & 0.133 & 28 & 8.00 & 0.100 \\
\hline GRAY & 4 & 7.5 & 0.067 & 7 & 2.29 & 0.438 & 31 & 9.23 & 0.096 \\
\hline BROWN & 5 & 7.0 & 0.089 & 7 & 9.00 & 0.111 & 22 & 8.05 & 0.078 \\
\hline WHITE 2 & 1 & 2.0 & 0.063 & 1 & 1.00 & 0.143 & 10 & 4.80 & 0.060 \\
\hline RED 2 & 2 & 3.5 & 0.071 & 0 & - & - & 2 & 5.50 & 0.010 \\
\hline
\end{tabular}

RED 1 was in the first position in the lists of almost half of the subjects. As seen from table 8, there are no significant differences among men and woman respondents. Setting the lists given by the subjects from deaf and hearing signing families against the lists given by the subjects from hearing non-signing families, it might be seen that as RED 1 was not so frequent among the deaf people from deaf families, it's frequency on the first position in the lists is also lower. RED 2, however, is never mentioned first, instead, the frequency of BLUE is higher among the subjects from signing families.

In the list task, the subjects did not use very many finger-spelled Estonian color terms. The sign notated above as PINK/PURPLE was used by the subjects to refer to both pink and purple. The sign was formed by the B hand-shape, either with still or wiggling fingers, with the palm oriented either towards or away from the signer, on the cheek with upward movement. It was assumed that either the wiggling of the fingers or palm orientation would differentiate the meaning of the sign to refer either to pink or purple, but the results of the study did not confirm this. The sign in all its varieties was used in both meanings, referring to a possible composite category of pink and purple in ESL. 
Table 8. List task, ESL signs named first: total frequency of first mention (Total), frequency of first mention among women subjects (Women), men subjects (Men), subjects from deaf and hearing signing families (Signing families), and hearing nonsigning families (Non-signing families)

\begin{tabular}{|c|c|c|c|c|c|c|}
\hline ESL sign & Women & Men & Total & $\begin{array}{l}\text { Signing } \\
\text { families }\end{array}$ & $\begin{array}{c}\text { Non- } \\
\text { signing } \\
\text { families } \\
\end{array}$ & Total \\
\hline RED 1 & 13 & 11 & 24 & 5 & 19 & 24 \\
\hline BLUE & 2 & 4 & 6 & 4 & 2 & 6 \\
\hline BLACK & 2 & 3 & 5 & 2 & 3 & 5 \\
\hline WHITE 1 & 2 & 2 & 4 & 2 & 2 & 4 \\
\hline GREEN & 2 & 1 & 3 & 0 & 3 & 3 \\
\hline $\begin{array}{l}\text { PINK/ } \\
\text { PURPLE }\end{array}$ & 2 & 0 & 2 & 1 & 1 & 2 \\
\hline WHITE 2 & 1 & 1 & 2 & 1 & 1 & 2 \\
\hline YELLOW & 1 & 1 & 2 & 0 & 2 & 2 \\
\hline BROWN & 0 & 1 & 1 & 0 & 1 & 1 \\
\hline ORANGE 2 & 1 & 0 & 1 & 0 & 1 & 1 \\
\hline Total & 26 & 24 & 50 & 15 & 35 & 50 \\
\hline
\end{tabular}

In the list task, the sign PINK/PURPLE was mentioned 42 times. In addition, it was a component of a complex term nine times on the list task. Including the compounds in the discussion here, the sign was used to denote pink in a total of 33 cases. Thirteen times the sign denoted purple, three times it was used for orange and twice for green. Therefore, in most cases (65\%) the sign denoted pink, in $25 \%$ of the cases purple and in $10 \%$ of the cases other colors (figure 29d). Deaf people from signing families mostly used the sign to refer to pink; only one subject (13\% of the cases) used the same sign to refer to purple as well (figure 29a). In the color-naming task, the same subject used the same sign to refer to pink as well as purple. Among the other groups, the sign also referred to other colors, such as orange and green (figure 29b, 29c). The confusion in the use of the color term was greatest among the signers from hearing non-signing families (figure 29c). As also explained above, it is very difficult to detect on the basis of the list task data whether the mouth pattern accompanying the sign PINK/PURPLE showed the sign was used to cover both the area of pink as well as purple, or whether there was no consensus about the meaning of the sign among the subjects. Therefore, the case of PINK/PURPLE is analyzed in depth in the combined analyses of both tasks.

When the term was used to refer to purple, the list either lacked a term for pink or the term for pink was finger-spelled. In some cases, the sign PINK/PURPLE was only one of the different terms given for purple. Three subjects preferred to use the finger-spelled Estonian word l-i-l-l-a for purple $(\mathrm{mP}=7.3)$ and $\mathrm{r}-\mathrm{o}-\mathrm{o}-\mathrm{s}-\mathrm{a}(\mathrm{mP}=9.0)$ for pink in the list task. All the subjects 
finger-spelling the Estonian word for purple were from hearing non-signing families; among the subjects listing a finger-spelled word for pink there was one from a deaf family. Two subjects were from hearing non-signing family. The Estonian equivalent for beige was finger-spelled by one subject (b-e-e-ž, $\mathrm{mP}=10$ ), who was from a deaf family.

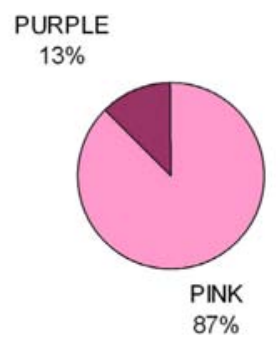

(a) Subjects from deaf signing families

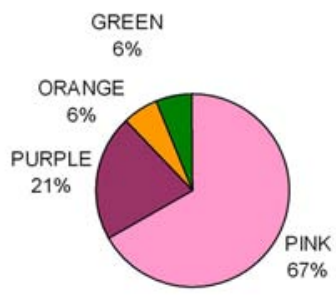

(c) Subjects from hearing non-signing families

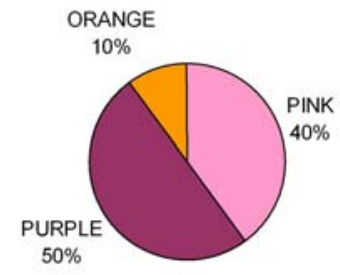

(b) Subjects from hearing signing families GREEN

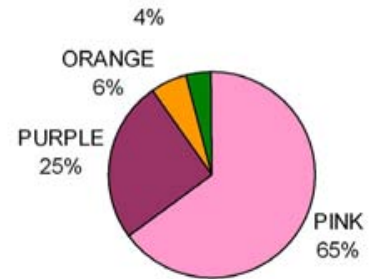

(d) Subjects from different subgroups: total

Figure 29. Use of the sign PINK/PURPLE among the subjects from deaf and hearing families.

The Estonian words for violet and turquoise were both articulated once without any signed counterpart; the subjects only pointed to their lips to show they were using the Estonian word instead of the ESL sign, and once Bordeaux red was articulated in Estonian in the same way.

Similarly to the sign PINK/PURPLE, there were some other signs used to refer to different colors in the list task. These signs were YELLOW, ORANGE, BROWN/BEIGE and GRAY, as shown above. The denotations of these signs, as referred to in the list task, are shown in figure 30. While subjects from deaf signing families were in all cases unanimous in the use of the signs, as seen in the first column of figure 30, among the subjects from hearing families differences appeared - the sign YELLOW (figure 30a) also referred to orange, ORANGE (figure 30b) to beige, BROWN/BEIGE (figure 30c) to beige and GRAY (figure 30d) to purple. 


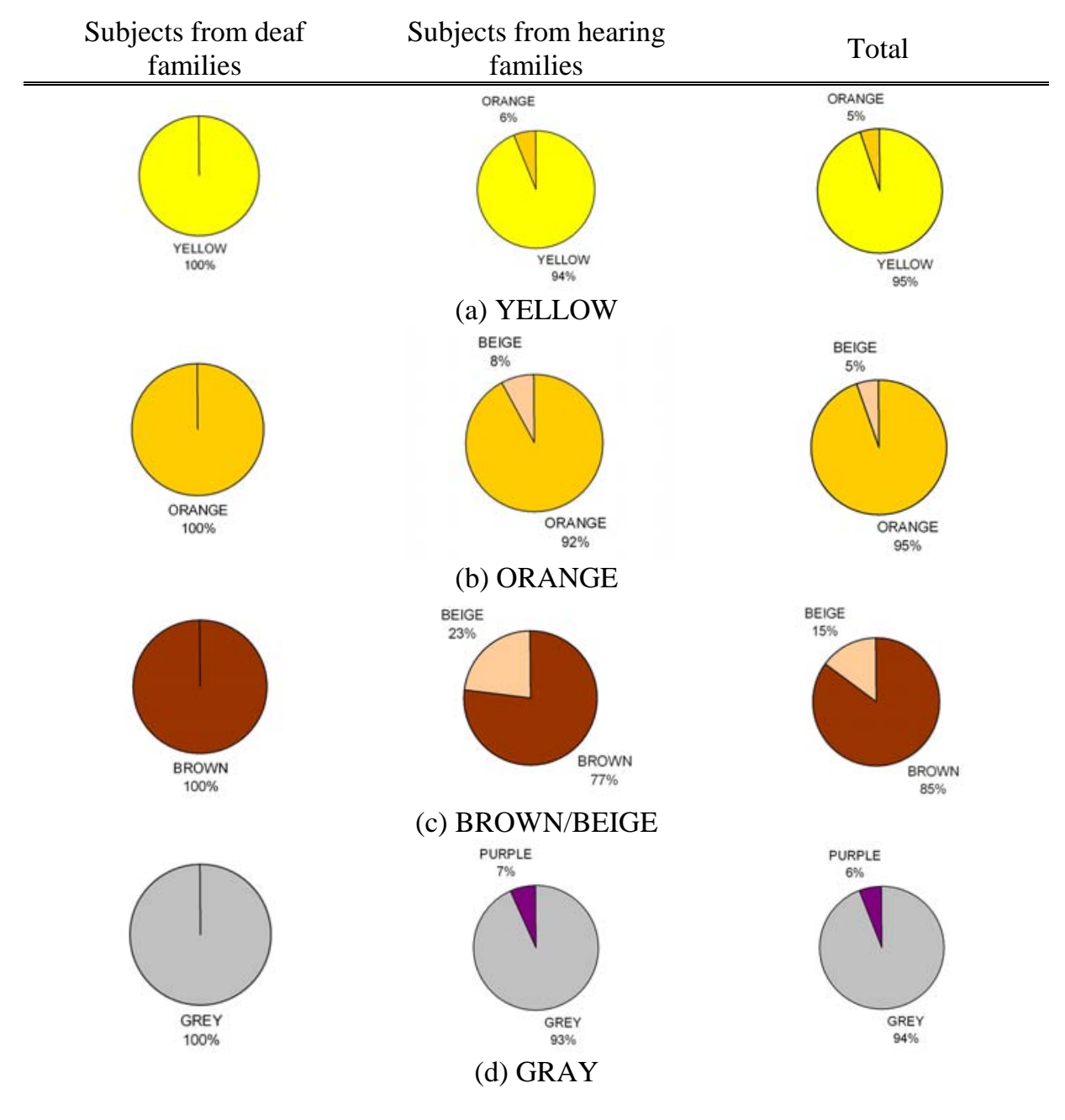

Figure 30. Use of the signs YELLOW, ORANGE, BROWN/BEIGE and GRAY among the subjects from deaf and hearing families.

In the case of the sign YELLOW, all the subjects referring to orange using this sign used the same sign for yellow. For one subject, the sign notated here as YELLOW was only one of several signs for orange; the subject also used other signs for orange. The same was true for the sign ORANGE, used to mean of beige. The subject who referred to beige using the sign ORANGE used the same sign to refer to orange and used different signs for beige. For gray and purple, the subjects using the same sign did so both in the list task and the color-naming task. One subject used different signs for purple, while one of the listed signs coincided with the sign notated as GRAY.

Trying to explain the use of color signs referring to different colors, one of the first assumptions would be that the subjects knew the respective name in 
Estonian but not in ESL and, wishing to refer to the color concept, articulated the Estonian word accompanied by an ESL sign closest, in their opinion, to the concept they were referring to. While yellow, orange, beige and brown are close, the use of the sign GRAY to denote purple, or PINK/PURPLE to denote green is quite inscrutable. One of the explanations would be the slight similarity of the form of the signs (PINK/PURPLE and GRAY are both articulated on the cheek, and GREEN and PINK/PURPLE are both articulated by the 5* handshape).

In terms of the use of GRAY for purple, it should be noted that the sign GRAY was an old ESL sign for purple. However, in the current study, the sign was used by three younger subjects in the age range 30-36 from Tallinn, Pärnu and Võru, all from hearing families. So, there is no obvious connection to any use of old ESL.

In the list task, 19 simple color names were signed by more than three subjects: RED 1, BLUE, GREEN, YELLOW, BLACK, WHITE 1, PINK/ PURPLE, GRAY, BROWN, WHITE 2, PURPLE 1, ORANGE 3, ORANGE 1, BROWN/BEIGE, BEIGE, ORANGE 2, RED 2, GOLD, SILVER and ORANGE 3. The signs GOLD and SILVER have a mean position lower than the position of the mean pause for thinking in listing the color names (11.38). Determining the candidates of basic color terms in ESL, they might also be suspect according to the subsidiary criteria of a basic term provided by Berlin and Kay, as they are also the names of objects characteristically having this color (Berlin \& Kay 1969: 6). Considering the criteria of stability of reference and the occurrence in the idiolects of all subjects, nine terms listed by more than half of all subjects would remain in the list of candidates for basic terms: RED 1, BLUE, GREEN, YELLOW, BLACK, WHITE 1, PINK/PURPLE, GRAY and BROWN. Although WHITE 2 also clearly had a tendency to occur at the beginning of the lists $(\mathrm{mP}=4.25)$, it was only named by 12 subjects and RED 2, which is in the fifth position in the rank of mean positions $(\mathrm{mP}=4.50)$, was only named by four subjects.

\subsection{Results of the color-naming task}

In the color-naming task, of all the possible instances (50 subjects $\mathrm{x} 65$ color tiles $=3.250$ ), in ten cases subjects were not able to name the color square. In 125 instances (3.8\%), the subjects were not able to decide which term described the color tile best and gave two or even three names for one tile. All the names given by the subjects were recorded and transcribed. The total number of names given to 65 different color tiles by 50 subjects was 3,374, including 578 different color concepts expressed using 696 different ESL terms. The number of the terms given was one to five signs, with the average length of all the given names being 1.79 signs. At the same time, only 179 concepts out of 578, and 225 ESL signs out of 696, were named at least twice; most of the 
terms (399 concepts, 69.0\%, and 471 ESL terms, 67.7\%) only occurred once during the task.

A mean of 21.52 different ESL names were given for each tile, which were translated into 15.95 equivalents in Estonian.

In table 9, the most frequent terms used in the tile-naming task are shown together with their total frequencies, number of tiles where they were named at least once and the number of tiles for which they were dominant. The occurrence in the list task is also shown. Terms used fewer than 15 times are not included here.

Table 9. Color-naming task, most frequent terms, frequencies $(F>15)$, number of tiles, dominant terms and the total number of tiles the term was used with

\begin{tabular}{|c|c|c|c|c|c|c|}
\hline No & ESL sign & $\begin{array}{c}\text { Occurence } \\
\text { in the list } \\
\text { task }\end{array}$ & $\begin{array}{c}\text { Total } \\
\text { F }\end{array}$ & $\begin{array}{c}\text { No of } \\
\text { dominant } \\
\text { tiles }\end{array}$ & $\begin{array}{c}\text { No } \\
\text { of } \\
\text { tiles }\end{array}$ & $\begin{array}{c}\text { F/No } \\
\text { of tiles }\end{array}$ \\
\hline 1 & PINK/PURPLE & + & 133 & 4 & 25 & 5.32 \\
\hline 2 & BLUE & + & 130 & 5 & 12 & 10.83 \\
\hline 3 & BLUE DARK & + & 130 & 3 & 15 & 8.67 \\
\hline 4 & GREEN DARK & + & 108 & 4 & 11 & 9.82 \\
\hline 5 & GRAY & + & 100 & 2 & 13 & 7.69 \\
\hline 6 & BROWN & + & 89 & 4 & 11 & 8.09 \\
\hline 7 & GREEN & + & 89 & 4 & 12 & 7.42 \\
\hline 8 & BLACK & + & 88 & 2 & 6 & 14.67 \\
\hline 9 & RED 1 & + & 85 & 4 & 7 & 12.14 \\
\hline 10 & BROWN DARK & + & 85 & 3 & 10 & 8.50 \\
\hline 11 & YELLOW & + & 83 & 2 & 11 & 7.55 \\
\hline 12 & GREEN LIGHT 1 & + & 78 & 4 & 9 & 8.67 \\
\hline 13 & PINK/PURPLE DARK & + & 78 & 2 & 20 & 3.90 \\
\hline 14 & GREEN LIGHT 2 & + & 59 & 0 & 11 & 5.36 \\
\hline 15 & PURPLE 1 & + & 53 & 3 & 12 & 4.42 \\
\hline 16 & PINK/PURPLE LIGHT 1 & + & 50 & 3 & 12 & 4.17 \\
\hline 17 & PURPLE 1 DARK & - & 49 & 2 & 10 & 4.90 \\
\hline 18 & BLUE LIGHT 1 & + & 48 & 1 & 7 & 6.86 \\
\hline 19 & GRAY DARK & + & 47 & 1 & 5 & 9.40 \\
\hline 20 & GRAY LIGHT 1 & + & 46 & 2 & 5 & 9.20 \\
\hline 21 & ORANGE 1 & + & 46 & 3 & 7 & 6.57 \\
\hline 22 & BLUE LIGHT 2 & + & 46 & 1 & 11 & 4.18 \\
\hline 23 & PINK/PURPLE LIGHT 2 & + & 43 & 1 & 17 & 2.53 \\
\hline 24 & GRAY LIGHT 2 & + & 40 & 0 & 8 & 5.00 \\
\hline 25 & WHITE 1 & + & 38 & 1 & 4 & 9.50 \\
\hline 26 & BROWN/BEIGE & + & 37 & 0 & 13 & 2.85 \\
\hline 27 & PURPLE 1 LIGHT 1 & - & 36 & 3 & 10 & 3.60 \\
\hline 28 & YELLOW DARK & - & 31 & 1 & 7 & 4.43 \\
\hline
\end{tabular}


Table 9. continued

\begin{tabular}{|ll|c|r|c|r|r|}
\hline No & ESL sign & $\begin{array}{c}\text { Occurence } \\
\text { in the list } \\
\text { task }\end{array}$ & $\begin{array}{c}\text { Total } \\
\text { F }\end{array}$ & $\begin{array}{c}\text { No of } \\
\text { dominant } \\
\text { tiles }\end{array}$ & $\begin{array}{c}\text { No } \\
\text { of } \\
\text { tiles }\end{array}$ & $\begin{array}{c}\text { F/No } \\
\text { of tiles }\end{array}$ \\
\hline \hline 29 & BROWN LIGHT 2 & + & 31 & 1 & 12 & 2.58 \\
30 & BROWN LIGHT 1 & + & 29 & 0 & 8 & 3.63 \\
31 & RED 1 DARK & + & 27 & 0 & 7 & 3.86 \\
32 & BEIGE & + & 26 & 3 & 7 & 3.71 \\
33 & TINT & + & 24 & 0 & 19 & 1.26 \\
34 & PURPLE 2 DARK & + & 23 & 0 & 9 & 2.56 \\
35 & RED 1 LIGHT 2 & + & 21 & 0 & 9 & 2.33 \\
36 & BLUE GREEN & + & 20 & 0 & 6 & 3.33 \\
37 & WHITE 2 & + & 18 & 0 & 4 & 4.50 \\
38 & BROWN/BEIGE DARK & + & 18 & 0 & 6 & 3.00 \\
39 & TINT DARK & - & 18 & 0 & 14 & 1.29 \\
24 & p-i-n-k (r-O-O-S-a) & + & 17 & 0 & 4 & 4.25 \\
39 & PURPLE 2 & + & 17 & 0 & 11 & 1.55 \\
42 & TINT LIGHT 2 & - & 17 & 0 & 14 & 1.21 \\
\hline
\end{tabular}

The most frequent sign in the tile-naming task was PINK/PURPLE ( $F=133)$. Being a dominant name for four tiles, however, in all cases its dominance frequency stayed below 50\% for each tile. PINK/PURPLE was used to name 25 different tiles and, therefore, its mean frequency was low (5.32). BLUE $(F=130)$ and BLUE DARK $(\mathrm{F}=130)$ follow in the list of total frequencies. The next most frequent simple terms, as seen in table 9, are GRAY $(\mathrm{F}=100)$, BROWN $(\mathrm{F}=89)$, GREEN ( $\mathrm{F}=89)$, BLACK $(\mathrm{F}=88)$, RED $1(\mathrm{~F}=85)$ and YELLOW $(\mathrm{F}=83)$. PURPLE 1 was also used more than 50 times $(\mathrm{F}=53)$ in the color-naming task. Among the most frequent terms, there were also many complex terms, such as BLUE DARK, GREEN DARK, BROWN DARK, GREEN LIGHT 1, PINK/ PURPLE DARK and GREEN LIGHT 2.

The most probable basic color terms, BLACK, WHITE 1, RED 1, YELLOW, GREEN, BLUE, BROWN, GRAY and PINK/PURPLE, were used with a total frequency of 835 , which is $24.7 \%$ of the total number of signs named during the task.

The total frequencies of WHITE 1 and WHITE 2 were quite low, as there was actually only one white tile used in the survey. Both signs were used for four different tiles, and for one tile WHITE 1 was also the dominant name $(\mathrm{DF}=33)$. BEIGE was used with a total frequency of 26 for seven tiles, of which for three tiles it was a dominant name. For four tiles, the Estonian color term roosa (pink) was finger-spelled (r-o-o-s-a). PURPLE 2 was mentioned 17 times to name 11 different tiles.

In 19 instances, the sign TINT or HUE, together with mouthing a respective color word in Estonian, was used to name 17 different tiles. The sign is identical 
to the sign LIGHT 1, similar to the color sign BEIGE, but articulated with the 5 hand-shape instead of the B hand-shape; and was used together with the Estonian color words green, yellow, blue, brown, purple, light purple or light blue. In an additional 25 instances, the same sign accompanied an Estonian color word in the compounds with the signs LIGHT or DARK. In the compounds, the sign was usually accompanied by the Estonian word for purple, green or blue. This way of describing color tiles using Estonian words was used by five subjects, three from Pärnu and two from the Tartu region, all from hearing families, between the ages of 64 and 73, which leads us to assume that influence from Estonian might be greater than normal among these subjects. None of them, however, used this method in the list task. In most cases, the color name expressed in this way was missing in the list task; only in two cases did a different color sign exist in the list task, while the sign HUE or TINT was used to describe more complicated compounds. In one case, a subject used the same sign for yellow, green and blue and, in the list task, only listed the signs for red, white black and brown.

Excluding all the complex terms, the most frequent simple color signs in terms of total frequency and tile ratio in the color-naming task were BLACK, RED 1, BLUE, WHITE 1, BROWN, GRAY, YELLOW, GREEN, ORANGE 1, PINK/PURPLE, WHITE 2 and PURPLE 1 (figure 31).

In 35 cases out of 65, the dominant name given to a tile was a simple term. These simple terms included 12 different color names, and their highest dominance frequencies for one tile are shown in table 10. BLACK $(\mathrm{F}=41)$, YELLOW (F=37), GRAY ( $\mathrm{F}=35)$, WHITE 1 ( $\mathrm{F}=33$ ), BLUE ( $\mathrm{F}=29)$, RED 1 $(\mathrm{F}=27)$ and GREEN $(\mathrm{F}=27)$ were named by more than half of the subjects. PINK/PURPLE ( $\mathrm{F}=21)$, ORANGE $(\mathrm{F}=19)$, BROWN $(\mathrm{F}=16)$, PURPLE 1 $(\mathrm{F}=13)$ and BEIGE $(\mathrm{F}=8)$ were also dominant names, but their frequencies were quite low, as the respective tiles were named using very many different names.

Considering only the tiles for which a color name was used by at least half of the subjects (DI $1 / 2$ ), there were only seven simple dominant color signs in the tile-naming task: BLACK, RED 1, BLUE, WHITE 1, GRAY, YELLOW and GREEN (table 11). According to the specificity indexes, consensus among the subjects using these terms was highest for BLACK ( $\mathrm{SI}=0.93)$, WHITE 1 (SI=0.87), YELLOW (SI=0.8) and RED $1(\mathrm{SI}=0.61)$. 


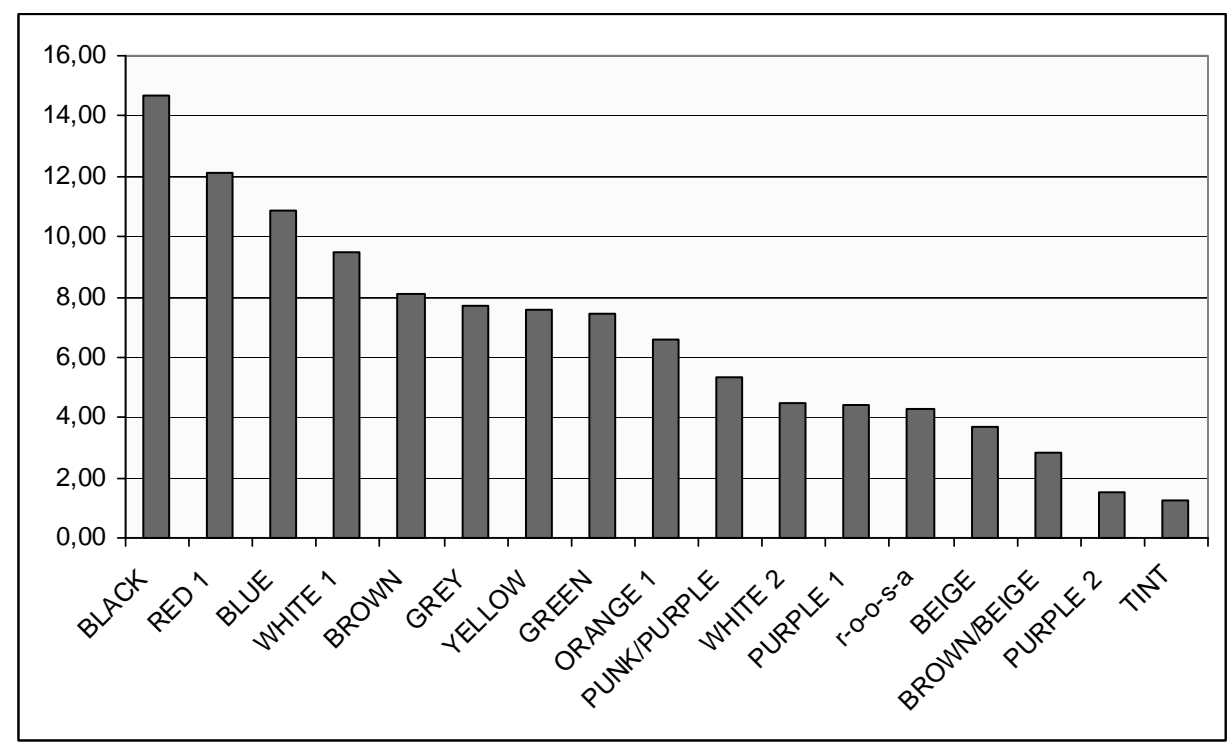

Figure 31. Most frequent mono-lexemic terms in the color-naming task according to mean frequencies (total $\mathrm{F} /$ number of tiles).

Table 10. Dominant mono-lexemic terms in the tile-naming task

\begin{tabular}{|l|l|r|l|}
\hline Color code & Dominant name in ESL & F & Gloss in English \\
\hline BLACK & BLACK & 41 & black \\
Y & YELLOW & 37 & yellow \\
GRAY 4 & GRAY & 35 & gray \\
WHITE & WHITE 1 & 33 & white \\
BGB & BLUE & 29 & blue \\
RO & RED 1 & 27 & red \\
G & GREEN & 27 & green \\
ROR T3 & PINK/PURPLE & 21 & pink \\
OYO & ORANGE 1 & 19 & orange \\
YO S3 & BROWN & 16 & brown \\
VRV & PURPLE 1 & 13 & purple \\
YOY S2 & BEIGE & 8 & beige \\
\hline
\end{tabular}

As a rule, dominant color terms were also among the most frequent names given to the tiles, with two significant exceptions: PINK/PURPLE was the most frequent name in the color-naming task, with a total frequency of 133 . It was a dominant name for four different tiles, named by 14-21 subjects (28-42\% of the subjects).

In total, PINK/PURPLE was used to name 25 different tiles, showing that its meaning was not as clearly specified. Another exception was WHITE 1, the 
dominant name for one tile, with a quite high specificity index but a very low total frequency $(\mathrm{F}=38)$, as it was only used for four different tiles.

Table 11. Color-naming task, most frequent terms, frequencies/number of tiles $(F / T>5)$, total frequencies $(\mathrm{F})$, dominance frequencies (DF), dominance indexes (DI 1/2) and specificity indexes

\begin{tabular}{|rlrrrrr|}
\hline No & ESL sign & F/T & F & DF & DI 1/2 & SI (DF/F) \\
\hline \hline 1 & BLACK & 14.67 & 88 & 82 & 2 & 0.93 \\
2 & RED 1 & 12.14 & 85 & 52 & 2 & 0.61 \\
3 BLUE & 10.83 & 130 & 54 & 2 & 0.42 \\
4 & GREEN DARK & 9.82 & 108 & 66 & 2 & 0.61 \\
5 & WHITE 1 & 9.50 & 38 & 33 & 1 & 0.87 \\
6 & GRAY DARK & 9.40 & 47 & 31 & 1 & 0.66 \\
7 & GRAY LIGHT 1 & 9.20 & 46 & - & - & - \\
8 & BLUE DARK & 8.67 & 130 & 85 & 3 & 0.65 \\
9 & GREEN LIGHT 1 & 8.67 & 78 & - & - & - \\
10 & BROWN DARK & 8.50 & 85 & 26 & 1 & 0.31 \\
11 & BROWN & 8.09 & 89 & - & - & - \\
12 & GRAY & 7.69 & 100 & 35 & 1 & 0.35 \\
13 & YELLOW & 7.55 & 83 & 66 & 2 & 0.80 \\
14 & GREEN & 7.42 & 89 & 27 & 1 & 0.30 \\
15 & BLUE LIGHT 1 & 6.86 & 48 & - & - & - \\
16 & ORANGE 1 & 6.57 & 46 & - & - & - \\
17 & GREEN LIGHT 2 & 5.36 & 59 & - & - & - \\
18 & PINK/PURPLE & 5.32 & 133 & - & - & - \\
\hline
\end{tabular}

Contrasting the dominant color names in ESL with the Estonian dominant color names (table 12), it may be seen that, while dominant names for black, yellow, gray, blue and red are used with quite similar frequencies in Estonian and ESL, names for white, green, orange and pink show some differences in their frequencies. The Estonian terms shown are from the basic color terms survey by Sutrop (Sutrop 2002). As the number of the subjects participating in the survey on Estonian was 80, the frequencies appearing in the ESL survey are here multiplied by 0.625 (50/80) to make the results comparable.

The differences are, to a large extent, explained by the tendencies also mentioned above. In nine cases, subjects using ESL used a different sign (WHITE 2) for white. In five cases, the Estonian word roosa for pink was finger-spelled (r-o-o-s-a), instead of using the ESL sign. And, besides the main sign ORANGE, eight different signs for orange were used, most of them occurring only once for one tile. In one instance, the Estonian word oranž for orange was also finger-spelled (o-r-a-n-ž). 
Table 12. Distribution of the most frequent terms and their frequencies in the tilenaming task, ESL and Estonian. The Estonian terms from the basic color terms survey Sutrop (Sutrop 2002). To make the frequencies comparable the frequencies appearing in ESL survey are here multiplied by 0.625 (50/80)

\begin{tabular}{|c|c|c|c|c|}
\hline $\begin{array}{l}\text { Color } \\
\text { Aid } \\
\text { Code } \\
\end{array}$ & & $\begin{array}{l}\text { Most frequent terms } \\
\text { ESL } \\
\text { Estonian } \\
\end{array}$ & & $\mathbf{F}$ \\
\hline $\mathrm{Y}$ & & YELLOW & yellow & 37 \\
\hline & & YELLOW LIGHT 1 & light yellow & 3 \\
\hline & & kollane & yellow & 32.5 \\
\hline & $\mathrm{S} 2$ & BROWN & brown & 10 \\
\hline & & GREEN BROWN & greenish-brown & 4 \\
\hline & & roheline & green & 7.5 \\
\hline YOY & & YELLOW & yellow & 29 \\
\hline & & YELLOW DARK & dark yellow & 13 \\
\hline & & kollane & yellow & 8.8 \\
\hline & $\mathrm{T} 4$ & YELLOW LIGHT 1 & light yellow & 9 \\
\hline & & YELLOW LIGHT 2 & light yellow & 6 \\
\hline & & kollane & yellow & 13.8 \\
\hline & $\mathrm{S} 2$ & BEIGE & beige & 8 \\
\hline & & BROWN LIGHT 2 & light brown & 4 \\
\hline & & hallikas-roheline & grayish-green & 6.9 \\
\hline $\mathrm{YO}$ & & YELLOW DARK & dark yellow & 12 \\
\hline & & ORANGE 1 & orange & 9 \\
\hline & & oranž & orange & 11.3 \\
\hline & T3 & BEIGE & beige & 6 \\
\hline & & YELLOW & yellow & 4 \\
\hline & & oranž & orange & 13.1 \\
\hline & S3 & BROWN & brown & 16 \\
\hline & & BROWN DARK & dark brown & 12 \\
\hline & & roheline & green & 10.6 \\
\hline OYO & & ORANGE 1 & orange & 19 \\
\hline & & PINK/PURPLE & pink, purple & 4 \\
\hline & & oranž & orange & 35 \\
\hline $\mathrm{O}$ & & ORANGE 1 & orange & 9 \\
\hline & & RED 1 LIGHT 1 & light red & 3 \\
\hline & & oranž & orange & 17.5 \\
\hline & S1 & BROWN & brown & 13 \\
\hline & & BROWN LIGHT 1 & light brown & 8 \\
\hline & & pruun & brown & 15 \\
\hline & S3 & BROWN DARK & dark brown & 21 \\
\hline & & BROWN & brown & 11 \\
\hline & & pruun & brown & 36.9 \\
\hline
\end{tabular}


Table 12. Continued

\begin{tabular}{|c|c|c|c|c|}
\hline \multicolumn{2}{|l|}{\begin{tabular}{|l|} 
Color \\
Aid \\
Code \\
\end{tabular}} & \multicolumn{2}{|l|}{$\begin{array}{l}\text { Most frequent terms } \\
\text { ESL } \\
\text { Estonian }\end{array}$} & $\mathbf{F}$ \\
\hline \multirow[t]{10}{*}{ ORO } & & RED 1 & red & 10 \\
\hline & & $\begin{array}{l}\text { RED } 1 \text { LIGHT } 1 \\
\text { punane }\end{array}$ & $\begin{array}{l}\text { light red } \\
\text { red }\end{array}$ & $\begin{array}{r}6 \\
21.3 \\
\end{array}$ \\
\hline & T3 & BEIGE & beež & 4 \\
\hline & & $\begin{array}{l}\text { ORANGE LIGHT } 1 \\
\text { ORANGE } 1\end{array}$ & $\begin{array}{l}\text { light orange } \\
\text { orange }\end{array}$ & $\begin{array}{l}4 \\
4\end{array}$ \\
\hline & & roosa & pink & 8.1 \\
\hline & S3 & BOWN LIGHT 2 & light brown & 5 \\
\hline & & BEIGE & beige & 4 \\
\hline & & PINK/PURPLE LIGHT 1 & pink, purple & 4 \\
\hline & & PINK/PURPLE LIGHT 2 & pink, purple & 4 \\
\hline & & lillakas-hall & purplish-gray & 5 \\
\hline \multirow[t]{9}{*}{$\mathrm{RO}$} & & RED 1 & red & 27 \\
\hline & & RED DARK & dark red & 6 \\
\hline & & punane & red & 27.5 \\
\hline & T3 & PINK/PURPLE & pink, purple & 15 \\
\hline & & PINK/PURPLE LIGHT 1 & light pink, light purple & 4 \\
\hline & & roosa & pink & 16.9 \\
\hline & S3 & BROWN DARK & dark brown & 26 \\
\hline & & PRUUN & brown & 14 \\
\hline & & must & black & 17.5 \\
\hline \multirow[t]{6}{*}{ ROR } & & RED 1 & red & 25 \\
\hline & & RED DARK & dark red & 8 \\
\hline & & punane & red & 28.8 \\
\hline & T3 & PINK/PURPLE & pink, purple & 21 \\
\hline & & r-o-o-s-a & pink & 5 \\
\hline & & roosa & pink & 28.8 \\
\hline
\end{tabular}


Table 12. Continued

\begin{tabular}{|c|c|c|c|c|}
\hline \multicolumn{2}{|l|}{$\begin{array}{l}\text { Color } \\
\text { Aid } \\
\text { Code } \\
\end{array}$} & \multicolumn{2}{|l|}{$\begin{array}{l}\text { Most frequent terms } \\
\text { ESL } \\
\text { Estonian } \\
\end{array}$} & $\mathbf{F}$ \\
\hline ROR & "S3 & $\begin{array}{l}\text { PINK/PURPLE LIGHT } 1 \\
\text { PINK/PURPLE LIGHT } 2 \\
\text { lilla }\end{array}$ & $\begin{array}{l}\text { light pink, light purple } \\
\text { light pink, light purple } \\
\text { purple }\end{array}$ & $\begin{array}{r}\mathbf{8} \\
5 \\
11.9\end{array}$ \\
\hline $\mathrm{R}$ & & $\begin{array}{l}\text { RED } 1 \\
\text { PINK/PURPLE DARK } \\
\text { punane }\end{array}$ & $\begin{array}{l}\text { red } \\
\text { dark pink, dark purple } \\
\text { red }\end{array}$ & $\begin{array}{r}12 \\
7 \\
13.1\end{array}$ \\
\hline & $\mathrm{T} 4$ & $\begin{array}{l}\text { PINK/PURPLE } \\
\text { PINK/PURPLE LIGHT } 1 \\
\text { r-o-o-s-a } \\
\text { roosa }\end{array}$ & $\begin{array}{l}\text { pink, purple } \\
\text { light pink, light purple } \\
r-o-o-s-a \\
\text { pink }\end{array}$ & $\begin{array}{r}14 \\
6 \\
6 \\
21.9\end{array}$ \\
\hline & S3 & $\begin{array}{l}\text { BROWN DARK } \\
\text { BROWN } \\
\text { must }\end{array}$ & $\begin{array}{l}\text { dark brown } \\
\text { brown } \\
\text { black }\end{array}$ & $\begin{array}{r}17 \\
7 \\
15\end{array}$ \\
\hline RVR & & $\begin{array}{l}\text { PINK/PURPLE DARK } \\
\text { PINK/PURPLE } \\
\text { lilla }\end{array}$ & $\begin{array}{l}\text { dark pink, dark purple } \\
\text { pink, purple } \\
\text { purple }\end{array}$ & $\begin{array}{r}9 \\
7 \\
12.5\end{array}$ \\
\hline & $\begin{array}{l}\text { S1 } \\
\text {. }\end{array}$ & $\begin{array}{l}\text { PURPLE 1 } \\
\text { PINK/PURPLE } \\
\text { lilla }\end{array}$ & $\begin{array}{l}\text { purple } \\
\text { pink, purple } \\
\text { purple }\end{array}$ & $\begin{array}{r}7 \\
5 \\
25\end{array}$ \\
\hline & S3 & $\begin{array}{l}\text { PINK/PURPLE LIGHT } 1 \\
\text { PINK/PURPLE LIGHT } 2 \\
\text { PURPLE } 1 \text { LIGHT } 1 \\
\text { roosa }\end{array}$ & $\begin{array}{l}\text { light pink, light purple } \\
\text { light pink, light purple } \\
\text { light purple } \\
\text { pink }\end{array}$ & $\begin{array}{r}\mathbf{8} \\
\mathbf{8} \\
\mathbf{8} \\
14.4 \\
\end{array}$ \\
\hline $\mathrm{RV}$ & & $\begin{array}{l}\text { PURPLE 1 } \\
\text { PINK/PURPLE } \\
\text { lilla } \\
\end{array}$ & $\begin{array}{l}\text { purple } \\
\text { pink, purple } \\
\text { purple }\end{array}$ & $\begin{array}{r}10 \\
8 \\
26.9 \\
\end{array}$ \\
\hline & $\mathrm{T} 2$ & $\begin{array}{l}\text { PINK/PURPLE } \\
\text { PURPLE } 1 \\
\text { r-o-o-s-a } \\
\text { lilla }\end{array}$ & $\begin{array}{l}\text { pink, purple } \\
\text { purple } \\
\text { pink } \\
\text { purple }\end{array}$ & $\begin{array}{r}17 \\
4 \\
4 \\
25\end{array}$ \\
\hline VRV & & $\begin{array}{l}\text { PURPLE } 1 \\
\text { PINK/PURPLE DARK } \\
\text { lilla }\end{array}$ & $\begin{array}{l}\text { purple } \\
\text { dark pink, dark purple } \\
\text { purple }\end{array}$ & $\begin{array}{r}13 \\
7 \\
21.3 \\
\end{array}$ \\
\hline & S3 & $\begin{array}{l}\text { PURPLE } 1 \text { LIGHT } 1 \\
\text { PINK/PURPLE LIGHT } 1 \\
\text { roosa }\end{array}$ & $\begin{array}{l}\text { light purple } \\
\text { light pink, light purple } \\
\text { pink }\end{array}$ & $\begin{array}{r}13 \\
6 \\
17.5\end{array}$ \\
\hline
\end{tabular}


Table 12. Continued

\begin{tabular}{|c|c|c|c|c|}
\hline \multicolumn{2}{|c|}{$\begin{array}{l}\text { Color } \\
\text { Aid } \\
\text { Code } \\
\end{array}$} & \multicolumn{3}{|l|}{$\begin{array}{l}\text { Most frequent terms } \\
\text { ESL } \\
\text { Estonian } \\
\end{array}$} \\
\hline & & PURPLE 1 DARK & dark purple & 13 \\
\hline & & PINK/PURPLE DARK & dark pink, dark purple & \\
\hline & & PINK/PURPLE & pink, purple & 5 \\
\hline & & PURPLE 1 & purple & 5 \\
\hline & & tumelilla & dark purple & 19.4 \\
\hline \multirow[t]{7}{*}{ VBV } & & PURPLE 1 DARK & dark purple & 11 \\
\hline & & PINK/PURPLE DARK & dark pink, dark purple & 7 \\
\hline & & tumelilla & dark purple & 13.8 \\
\hline & T4 & PINK/PURPLE LIGHT 1 & light pink, light purple & 6 \\
\hline & & PURPLE 1 LIGHT 1 & light purple & 6 \\
\hline & & PURPLE 1 & purple & 4 \\
\hline & & lilla & purple & 9.4 \\
\hline \multirow[t]{6}{*}{ BV } & & BLUE DARK & dark blue & 30 \\
\hline & & BLUE & blue & 6 \\
\hline & & tumesinine & dark blue & 26.3 \\
\hline & S2 & BLUE DARK & dark blue & 27 \\
\hline & & PURPLE 1 DARK & dark purple & 8 \\
\hline & & sinine & blue & 10.6 \\
\hline \multirow[t]{6}{*}{ BVB } & & BLUE DARK & dark blue & 28 \\
\hline & & BLUE & blue & 13 \\
\hline & & sinine & blue & 17.5 \\
\hline & S3 & GRAY & gray & 18 \\
\hline & & GRAY LIGHT 1 & light gray & 7 \\
\hline & & helelilla & light purple & 21.3 \\
\hline \multirow[t]{6}{*}{ B } & & BLUE & blue & 23 \\
\hline & & BLUE DARK & dark blue & 15 \\
\hline & & sinine & blue & 31.9 \\
\hline & $\mathrm{T} 1$ & BLUE & blue & 25 \\
\hline & & BLUE DARK & dark blue & 4 \\
\hline & & sinine & blue & 21.3 \\
\hline \multirow[t]{6}{*}{ BGB } & & BLUE & blue & 29 \\
\hline & & BLUE LIGHT 2 & light blue & 4 \\
\hline & & sinine & blue & 31.9 \\
\hline & T3 & BLUE LIGHT 1 & light blue & 21 \\
\hline & & BLUE LIGHT 2 & light blue & 17 \\
\hline & & helesinine & light blue & 20 \\
\hline
\end{tabular}


Table 12. Continued

\begin{tabular}{|c|c|c|c|c|}
\hline \begin{tabular}{|l|} 
Color \\
Aid \\
Code \\
\end{tabular} & & $\begin{array}{l}\text { Most frequent terms } \\
\text { ESL } \\
\text { Estonian } \\
\end{array}$ & & $\mathbf{F}$ \\
\hline BG & & BLUE & blue & 18 \\
\hline & & BLUE DARK & dark blue & 5 \\
\hline & & sinine & blue & 14.4 \\
\hline & $\mathrm{T} 1$ & BLUE & blue & 10 \\
\hline & & BLUE LIGHT 1 & light blue & 8 \\
\hline & & sinine & blue & 14.4 \\
\hline & $\mathrm{S} 2$ & GREEN DARK & dark green & 16 \\
\hline & & BLUE GREEN & blueish-green & 7 \\
\hline & & rohekassinine & greenish-blue & 11.3 \\
\hline GBG & & GREEN DARK & dark green & 9 \\
\hline & & GREEN & green & 9 \\
\hline & & BLUE GREEN & blueish-green & 4 \\
\hline & & roheline & green & 28.8 \\
\hline & S2 & BLUE LIGHT 2 & light blue & 7 \\
\hline & & BLUE LIGHT 1 & light blue & 6 \\
\hline & & helesinine & light blue & 18.8 \\
\hline G & & GREEN & green & 27 \\
\hline & & GREEN DARK & dark green & 6 \\
\hline & & roheline & green & 37.5 \\
\hline & S3 & GREEN DARK & dark green & 34 \\
\hline & & GREEN & green & 5 \\
\hline & & tumeroheline & dark green & 23.8 \\
\hline GYG & & GREEN & green & 22 \\
\hline & & GREEN DARK & dark green & 4 \\
\hline & & roheline & green & 35 \\
\hline & $\mathrm{T} 4$ & GREEN LIGHT 1 & light green & 21 \\
\hline & & GREEN LIGHT 2 & light green & 14 \\
\hline & & roheline & green & 16.9 \\
\hline & S1 & GREEN & green & 13 \\
\hline & & GREEN LIGHT 2 & light green & 6 \\
\hline & & roheline & green & 11.3 \\
\hline YG & & GREEN LIGHT 1 & light green & 14 \\
\hline & & GREEN LIGHT 2 & light green & 8 \\
\hline & & roheline & green & 27.5 \\
\hline & S3 & GREEN DARK & dark green & 32 \\
\hline & & tumeroheline & dark green & 18.1 \\
\hline
\end{tabular}


Table 12. Continued

\begin{tabular}{|c|c|c|c|c|}
\hline \multicolumn{2}{|l|}{\begin{tabular}{|l|} 
Color \\
Aid \\
Code \\
\end{tabular}} & \multicolumn{3}{|l|}{$\begin{array}{l}\text { Most frequent terms } \\
\text { ESL } \\
\text { Estonian } \\
\end{array}$} \\
\hline \multirow[t]{7}{*}{ YGY } & & " GREEN LIGHT 1 & light green & 16 \\
\hline & & GREEN LIGHT 2 & light green & 7 \\
\hline & & roheline & green & 24.4 \\
\hline & \multirow[t]{3}{*}{ S3 } & GREEN LIGHT 1 & light green & 13 \\
\hline & & GREEN LIGHT 2 & light green & 12 \\
\hline & & heleroheline & light green & 23.8 \\
\hline & & Unsystematic hues & & \\
\hline \multirow{5}{*}{\multicolumn{2}{|c|}{ Red Rose }} & PINK/PURPLE DARK & dark pink, dark purple & 12 \\
\hline & & RED 1 DARK & dark red & 5 \\
\hline & & RED 1 & red & 5 \\
\hline & & PINK/PURPLE & pink, purple & 5 \\
\hline & & roosa & pink & 7.5 \\
\hline \multirow{4}{*}{\multicolumn{2}{|c|}{ Sienna Brown }} & BROWN & brown & 14 \\
\hline & & BROWN LIGHT 1 & light brown & 8 \\
\hline & & BROWN LIGHT 2 & light brown & 8 \\
\hline & & pruun & brown & 36.3 \\
\hline \multicolumn{5}{|c|}{ Achromatic hues } \\
\hline \multirow{3}{*}{\multicolumn{2}{|c|}{ White }} & WHITE 1 & white & 33 \\
\hline & & WHITE 2 & white & 9 \\
\hline & & valge & white & 41.9 \\
\hline \multirow{3}{*}{\multicolumn{2}{|c|}{ Black }} & BLACK & black & 41 \\
\hline & & BLACK DARK & dark black & 4 \\
\hline & & must & black & 44.4 \\
\hline \multicolumn{5}{|l|}{ Grays } \\
\hline \multirow{4}{*}{\multicolumn{2}{|c|}{1}} & GRAY LIGHT 1 & light gray & 18 \\
\hline & & GRAY LIGHT 2 & light gray & 12 \\
\hline & & hall & gray & 20 \\
\hline & & helehall & light gray & 20 \\
\hline \multirow{3}{*}{\multicolumn{2}{|c|}{2}} & GRAY LIGHT 1 & light gray & 19 \\
\hline & & HALL & gray & 13 \\
\hline & & hall & gray & 35.6 \\
\hline \multirow{3}{*}{\multicolumn{2}{|c|}{4}} & GRAY & gray & 35 \\
\hline & & GRAY DARK & dark gray & 6 \\
\hline & & hall & gray & 34.4 \\
\hline \multirow{3}{*}{\multicolumn{2}{|c|}{6}} & GRAY DARK & dark gray & 31 \\
\hline & & GRAY DARK & gray & 18 \\
\hline & & tumehall & dark gray & 21.9 \\
\hline
\end{tabular}


Table 12. Continued

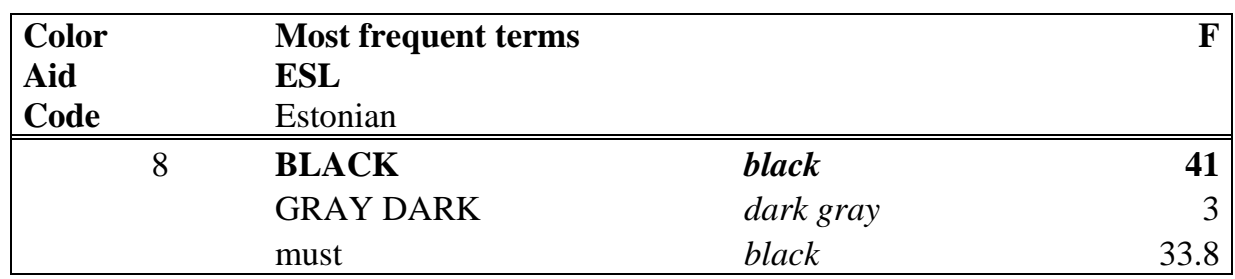

To compare the distribution of ESL color terms in Ostwald's color space with some other languages, ESL dominant color terms are hereby contrasted to the survey by Uusküla (2006), who has examined the distribution of color terms in Ostwald's color space in different languages, including Estonian, Finnish, Hungarian, Russian, Czech and English, using the same methodology for data collection. In her study, Uusküla concluded that the best examples of color, or "focal points”, vary in different languages.

Table 13. Distribution of color terms in ESL, compared to languages described by Uusküla (2008b: 37)

\begin{tabular}{|c|c|c|c|}
\hline $\begin{array}{l}\text { Color } \\
\text { category }\end{array}$ & $\begin{array}{l}\text { Color aid code } \\
\text { of best } \\
\text { examples }\end{array}$ & $\begin{array}{l}\text { Color name in } \\
\text { ESL }\end{array}$ & $\begin{array}{l}\text { Languages having the same } \\
\text { focal points }\end{array}$ \\
\hline yellow & $\mathrm{Y}$ & YELLOW & $\begin{array}{l}\text { Czech, English, Estonian, } \\
\text { Finnish, Hungarian and } \\
\text { Russian }\end{array}$ \\
\hline orange & OYO & ORANGE 1 & $\begin{array}{l}\text { Czech, Estonian, Finnish, } \\
\text { Hungarian and Russian }\end{array}$ \\
\hline brown & YO S3 & BROWN & Finnish and Hungarian \\
\hline red & RO & RED 1 & $\begin{array}{l}\text { Czech, Finnish, Hungarian and } \\
\text { Russian }\end{array}$ \\
\hline pink & ROR T3 & PINK/PURPLE & Czech, Estonian and Russian \\
\hline purple & VRV & PURPLE 1 & $\begin{array}{l}\text { Czech, Finnish, Hungarian and } \\
\text { Russian }\end{array}$ \\
\hline blue & BGB & BLUE & $\begin{array}{l}\text { Estonian, Hungarian and } \\
\text { Russian }\end{array}$ \\
\hline green & G & GREEN & $\begin{array}{l}\text { Estonian, Finnish, Hungarian } \\
\text { and Russian }\end{array}$ \\
\hline gray & GRAY 4 & GRAY & $\begin{array}{l}\text { Czech, Finnish, Hungarian and } \\
\text { English }\end{array}$ \\
\hline
\end{tabular}

There are several color terms in one language equivalent to color terms in the other language, while in other cases one term in one language does not correspond to terms used in the other language (Uusküla 2006: 152). Comparing the descriptions by Uusküla (2008b: 37) with the focal points of colors in ESL (table 13), it may be seen that the best examples of ESL color signs coincide the 
most with the focal point areas in Hungarian, Russian and Finnish, and less with the terms in English and Estonian. The focal point areas for yellow, orange, pink, blue and green coincide in ESL and Estonian, while with Hungarian, the focal point areas coincide in all shown cases.

The differences in focal point areas in Estonian and ESL on CIE coordinates (Davies et al 1992: 1098-1099) are shown in figure 32.

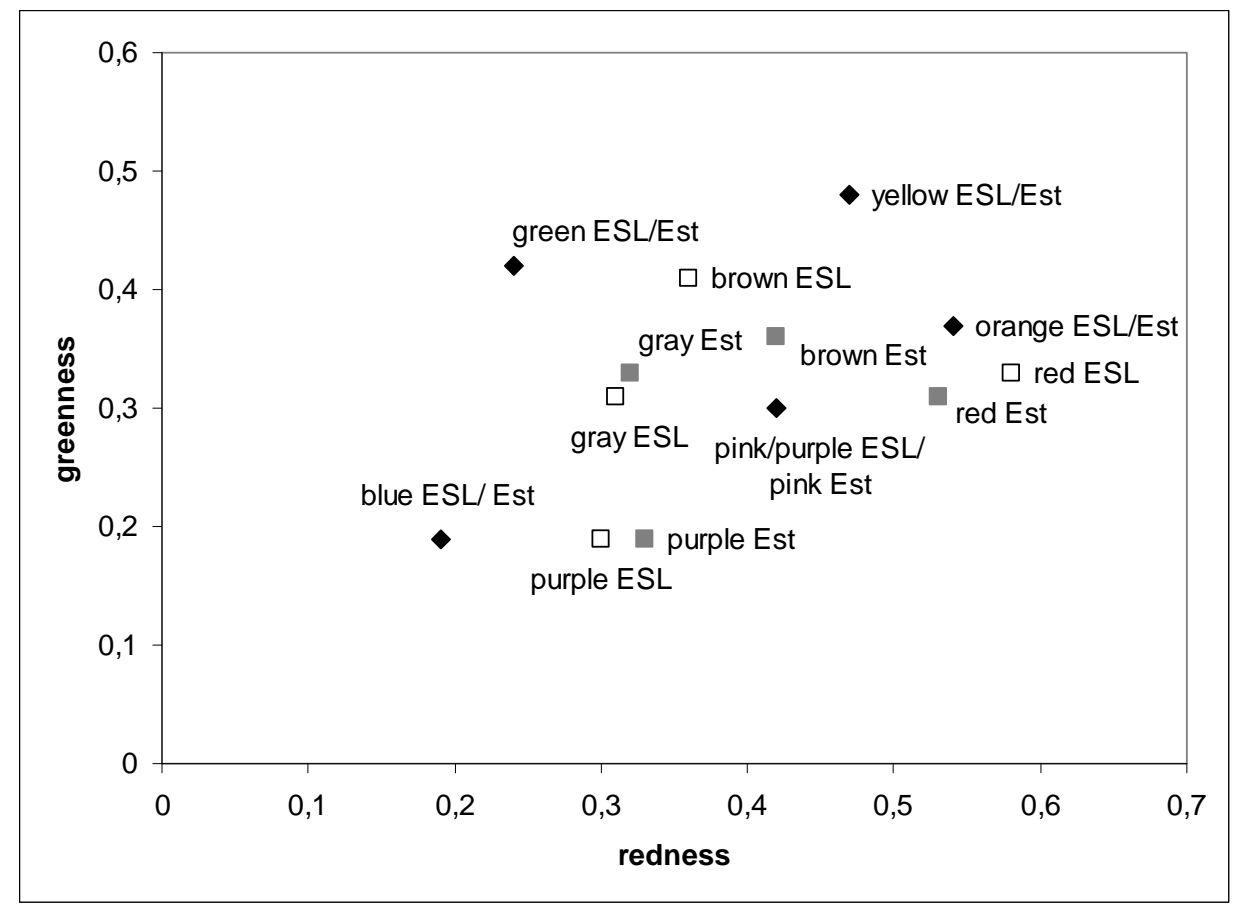

Figure 32. Focal point areas of ESL and Estonian on CIE coordinates.

The differences between Estonian color terms and ESL color terms may arise from the way these different groups of subjects tend to characterize color tiles. From the study of Estonian color terms, it may be seen that there was a mean of 9.82 different names given to each tile (Sutrop 2002: 65). In the study of ESL color terms, the number was 21.52, although the number of subjects participating in the survey was much smaller. The average length of one term in ESL in the color-naming task was 1.79. In 1202 cases out of 3374 (i.e. $35.6 \%$ of all the names given), the name given to a tile was a simple term. In most of the cases, the name given was a compound, consisting of two, three or more signs.

The signs DARK (see the example (c) below) and LIGHT (example (d)) were used often to describe the color tiles, as well as the signs MIDDLE (example (e)), BRIGHT (example (f)), OLD (example (g)) and CLEAN (example (h)). The frequencies of the sign DARK were higher, as for light two different signs, LIGHT 1 and LIGHT 2 were used. 


\begin{tabular}{|c|c|c|c|}
\hline \multirow[b]{2}{*}{ (c) } & ESL color name & Color aid code & $\mathbf{F}$ \\
\hline & $\begin{array}{l}\text { GREEN DARK } \\
\text { dark green }\end{array}$ & G S3 & 34 \\
\hline \multirow{8}{*}{ (d) } & $\begin{array}{l}\text { GRAY DARK } \\
\text { dark gray }\end{array}$ & GRAY-6 & 31 \\
\hline & $\begin{array}{l}\text { BLUE DARK } \\
\text { dark blue }\end{array}$ & BV & 30 \\
\hline & $\begin{array}{l}\text { BROWN DARK } \\
\text { dark brown }\end{array}$ & RO S3 & 26 \\
\hline & $\begin{array}{l}\text { GRAY LIGHT } 1 \\
\text { light gray }\end{array}$ & GRAY-2 & 19 \\
\hline & $\begin{array}{l}\text { GRAY LIGHT } 2 \\
\text { light gray }\end{array}$ & & 12 \\
\hline & $\begin{array}{l}\text { GREEN LIGHT } 1 \\
\text { light green }\end{array}$ & YGY S3 & 13 \\
\hline & $\begin{array}{l}\text { GREEN LIGHT } 2 \\
\text { light green }\end{array}$ & & 12 \\
\hline & $\begin{array}{l}\text { PURPLE } 1 \text { LIGHT } 1 \\
\text { light purple }\end{array}$ & VRV S3 & 13 \\
\hline (e) & $\begin{array}{l}\text { GREEN MIDDLE } \\
\text { middle green }\end{array}$ & GYG S1 & 4 \\
\hline (f) & $\begin{array}{l}\text { GREEN BRIGHT } \\
\text { bright green }\end{array}$ & YGY & 4 \\
\hline \multirow[t]{3}{*}{ (g) } & OLD PINK/PURPLE & ORO S3 & 2 \\
\hline & dusky pink & ROR S3 & 2 \\
\hline & & RVR S3 & 2 \\
\hline \multirow[t]{2}{*}{ (h) } & CLEAN RED & ROR & 2 \\
\hline & clear red & RO & 1 \\
\hline
\end{tabular}

Among the more infrequent adjectival attributes were the signs NORMAL (i), USUAL (j), WEAK (k), TIRED (l), FRESH (m), STRONG (n) and SHARP (o), which were used to describe different shades of colors.

\section{ESL color name}

(i) BLUE NORMAL normal blue

(j) USUAL BROWN usual brown

(k) GREEN WEAK MIDDLE BORDER DOWNWARD darker weak green

(l) TIRED PINK/PURPLE dusky pink

(m) FRESH TRANSPARENT LIGHT GREEN fresh transparent light green

(n) CLEAN DARK STRONG DARK BLACK clear strong dark black

(o) SHARP GREEN sharp green

\author{
Color aid code \\ BVB \\ B T1 \\ BGB \\ O S1 \\ G \\ ORO S3 \\ YGY S3 \\ BLACK \\ GYG
}


Some of the descriptions given are quite complicated:

ESL color name

(p) GRAY PLUS WHITE TOGETHER MIX DARK a dark mix of gray and white

(r) LIGHT YELLOW A_LITTLE ADD RED light yellow with a little red added

(s) LIGHT GREEN PLUS WHITE TOGETHER MIX DARK darker light green mixed with white
Color aid

code

GRAY-2

YO T3

GYG T4

\subsection{Etymology of the ESL color terminology}

As seen in the above analyses, the most dominant name in the list task was BLACK (figure 33). Comparing the frequencies of color concepts and ESL signs used in the list task, it may be seen that it is the only sign used for black in the current study. The sign has two variants: it may be articulated with one upward movement or with a repeated movement. It might be assumed that the first variant would denote deep black and the repeated movement blackish shades, but the results of the current study did not show the difference in meaning of these two variants.

Detecting the motivation of the sign BLACK is quite problematic. It seems to be an arbitrary native ESL sign for which there are no similar signs in neighboring sign languages. At the same time, it has been stated by Laiapea that the etymology of the sign may be associated with the transfer of the relationship between black and dirty in Estonian, both marked by the same word, must, and the sign BLACK might therefore be motivated by a dirty nose (Hollman 2008: 859). It is also possible that the sign is motivated by the method used to help the deaf students feel the airflow while articulating nasal sounds described also in chapter 3.4, as the Estonian counterpart must starts with nasal $m$.

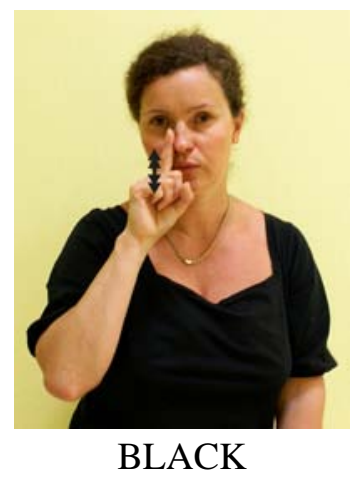

Figure 33. ESL color signs: BLACK. 
For white, there were two signs used by the subjects of the current study. WHITE 1 is formed by the $\mathrm{F}$ hand form on the back of the non-dominant hand with a forward movement (figure 34a). It is in all probability a native ESL sign with no formally similar counterparts in neighboring sign languages. It may be assumed that the formation of the sign is motivated by the white skin of the hands.

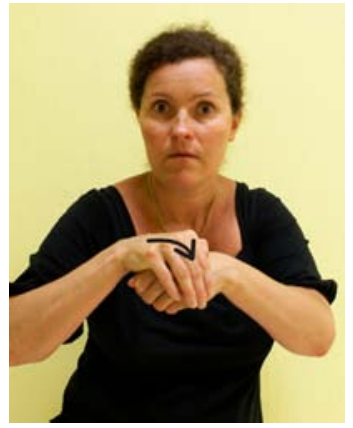

(a) WHITE 1

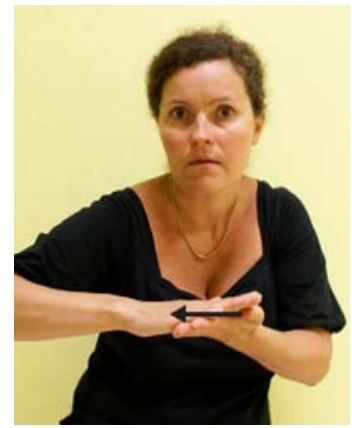

(b) WHITE 2 / CLEAN

Figure 34. ESL color signs: WHITE 1, WHITE 2.

WHITE 2 (figure 34b) is probably an extension of the meaning of the ESL sign CLEAN, identical to WHITE 2. As seen in the previous analyses, WHITE 2 was not as salient as WHITE 1 . In the list task, WHITE 2 was mainly used by elderly subjects from the Pärnu region, while WHITE 1 prevailed in the data given by younger subjects from different regions (figure 35).

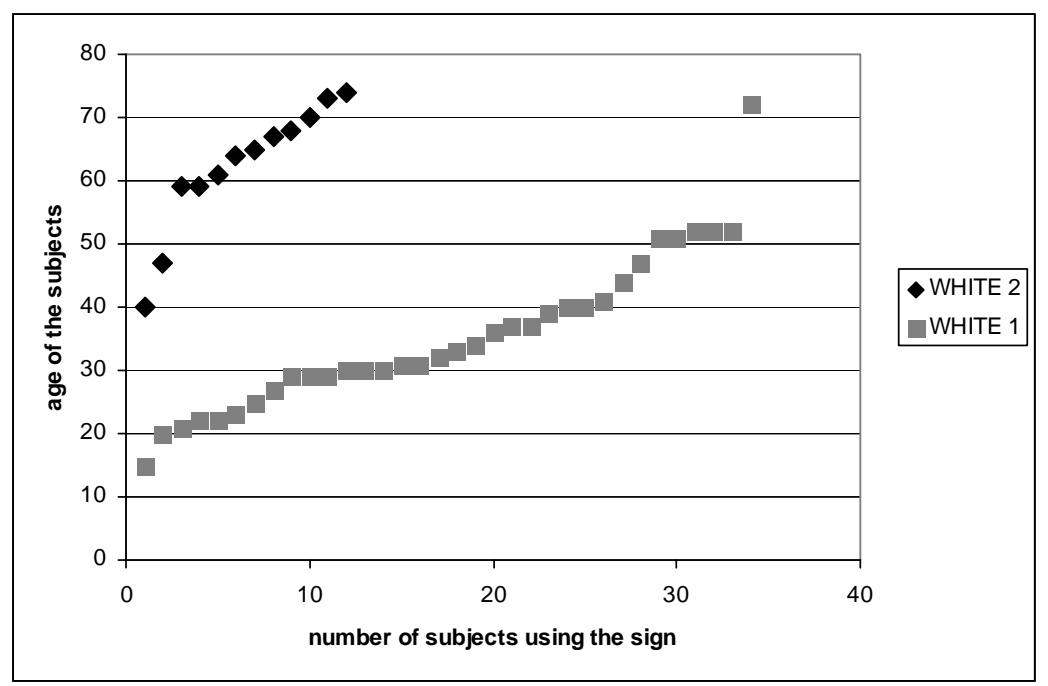

Figure 35. Age of the subjects using the signs WHITE 1 and WHITE 2 in the list task 


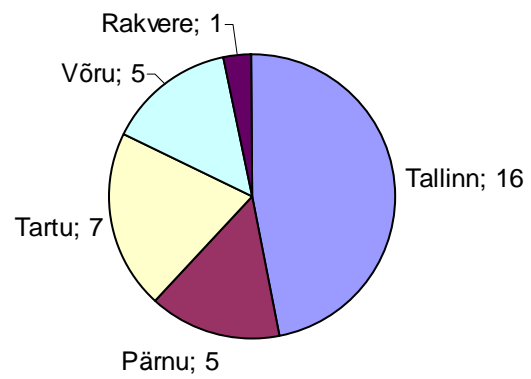

(a) WHITE 1

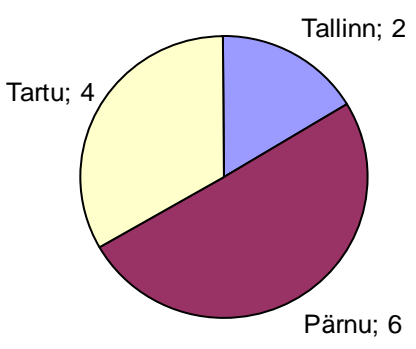

(b) WHITE 2

Figure 36. Use of the signs WHITE 1 and WHITE 2 in the list task by subjects from different regions.

As seen in figure 35, WHITE 2 was used by the subjects in the age range 40 to 74 , with an average age of 62.3 years, while the age of the subjects using WHITE 1 was 15 to 72 years, with the average being 35.4 years. Half of the subjects using WHITE 2 were from the Pärnu region, while WHITE 1 prevailed in the Tallinn region (figure 36). The proportion of WHITE 1 was somewhat higher among the subjects from deaf families (87.5\%) than among the subjects from hearing families (71.1\%).

RED 1 was articulated on the cheek (figure 37a), mainly with the ESL A hand-shape (figure 37c), although sometimes with the ESL F (figure 37d) or S hand-shape (figure 37e). The sign might be motivated by the blush, especially when articulated with the F hand shape. ESL RED 1 is very similar to the sign PINK (VAALEANPUNAINEN) in Finnish SL but, as mentioned above, it is mostly articulated with a different hand-shape. It was the most salient term in the list task and followed the sign BLACK in the color-naming task. It was also very salient compared to RED 2 (figure 37b), articulated on the lips with the index finger, a sign which is similar to the sign RED in many other sign languages, including Russian SL and ASL, and it was probably derived from pointing to the lips, typically representing the red color, although in ESL it is difficult to say if it is derived from pointing or if it is an influence from other sign languages, for example from Russian SL. 


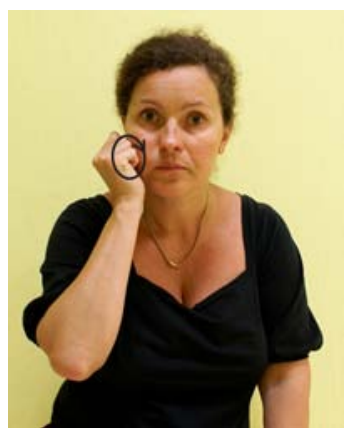

(a) RED 1

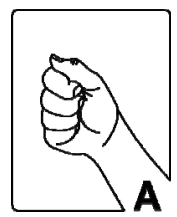

(c)

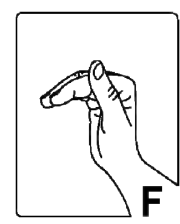

(d)

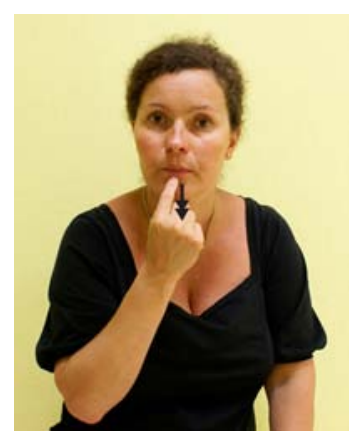

(b) RED 2

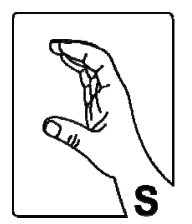

(e)

Figure 37. ESL color signs: RED 1, RED 2.

In the current study, RED 2 was quite rare. The sign was used mainly by the elderly subjects, with an average age of 60, from different regions of Estonia. RED 2 prevailed in the lists of subjects from deaf signing families, while RED 1 was used by the subjects from the hearing families. In ESL, the same sign accompanied by a different mouth pattern was used to denote both wine and ruby. According to the explanations by the ESL users, the infrequency of RED 2 might also be related to the fact that the use of either RED 1 or RED 2 is dependent on the object having the red color. While RED 1 would most commonly be used for an abstract color tile, the sign RED 2 would most likely be used for fluids.

GREEN was articulated in three different variants, a two-handed sign formed with a divisive downward movement in neutral space (GREEN a, figure $38 a$ ), with a round upward movement in the neutral space (GREEN b, figure $38 \mathrm{~b}$ ) or with a divisive downward movement in front of the face (GREEN c, figure $38 \mathrm{c}$ ). A wiggling movement of the fingers was also characteristic of the sign in all its variants. 


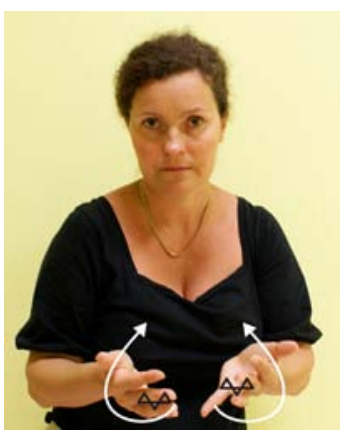

(a) GREEN a

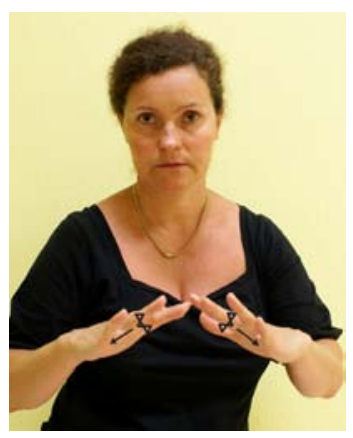

(b) GREEN b

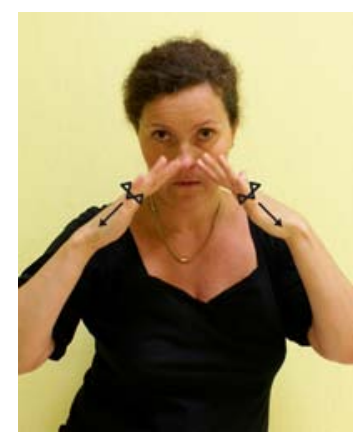

(c) GREEN c

Figure 38. ESL color signs: three variants of the sign GREEN.

As the oldest variants of the sign are probably two-handed signs articulated in the neutral space, either with a round upward movement (figure 38a), or a divisive downward movement (figure 38b), the first identical to the sign CHRISTMAS, and the second similar to the sign SPRUCE (formed by repeated downward movement, no wiggling of the fingers), it may be assumed that the sign is motivated by the green Christmas tree. The sign with all its variants was basically the only sign for green in ESL, as it was almost as salient as the concept green. Different variants used seem to illustrate precisely the principles of diachronic change in sign form described by Frishberg. The location of the sign has moved up. The newest variant is signed in front of the face and is becoming a one-handed sign.

GREEN a was mostly used by the elderly subjects. In the list task, the average age of the subjects using this variant was 59.7 years, while GREEN b was used by the subjects with an average age of 36.8 and GREEN c by the subjects who were 30.0 years old on average (see figure 39 for the age distribution of the subjects using different variants of the sign GREEN in the list task).

In both the list task and the color-naming task the percentage of variant a was lower than that of the others (22.5\%). In most cases, this variant was signed two-handed; in the color-naming task, the sign was articulated with one hand in $9.9 \%$ of the cases. The most frequent variant of the sign GREEN was, however, the sign with an upward location, articulated with simpler diagonal movement (figure 38b). This sign was mostly used by the middle-aged subjects from different regions. This was also mainly a two-handed sign, in the list task formed only with two hands and in the color-naming task formed by one hand in $6.4 \%$ of the cases. Younger subjects from all regions used the third variant of the sign - the location of the sign was in front of the face (figure 38c). To free the mouth, the sign is obviously changing to a single-handed sign (figure 40). In the color-naming task, in $39.5 \%$ of all the cases the sign was used it was formed by one hand only. 


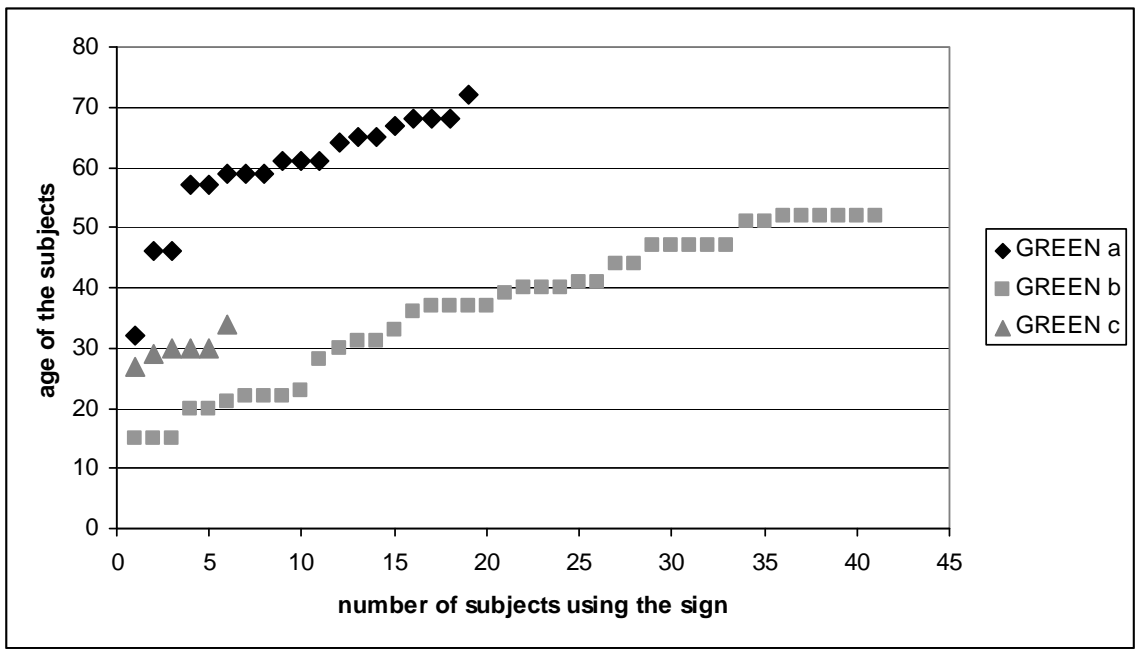

Figure 39. Age of the subjects using GREEN a, GREEN b or GREEN c in the list task.

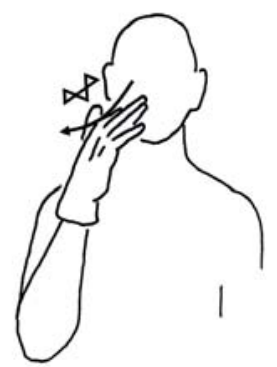

Figure 40. ESL color signs: one-handed variant of the sign GREEN c.

A comparison of the ESL lexicon to Russian SL, according to Swadesh's list mentioned above, also includes some color terms. The study describes five color terms - black, white, red, green and yellow. According to Taniroo (2007: 23), only the sign YELLOW (figure 41) is identical in both sign languages.

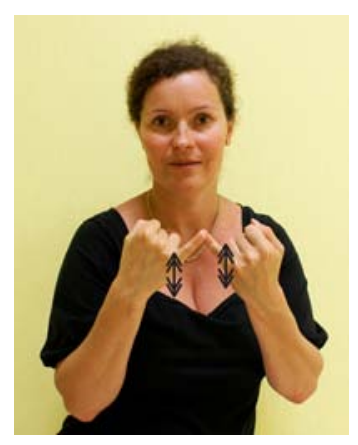

Figure 41. ESL color signs: YELLOW. 
In the Estonian context, the sign seems to be arbitrary, with no clear motivation or initialization but, considering the obvious influence from Russian SL or even an implicit influence from French SL and ASL, ESL YELLOW may have originated from an initialized sign (the $\mathrm{Y}$ hand-shape from the English yellow or $\mathrm{J}$ hand-shape from the French jaune). Although ASL YELLOW is a one-handed sign, in ESL and Russian SL the sign is definitely formed by two hands. It might be assumed that ESL YELLOW, of Russian, American or French provenance, has moved from its original location to a more central location and, characteristic of a sign formed in front of the body, has become a two-handed sign.

YELLOW is articulated in two basic variants - with crossed I or Y hand forms and repeated movements towards and away from the signer, or with I or Y hand forms moving alongside, upward and downward (figure 42a). A rarer variety was articulated on the non-dominant hand (figure 42b).

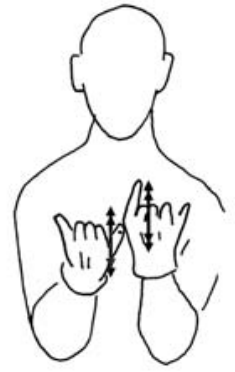

(a) YELLOW b

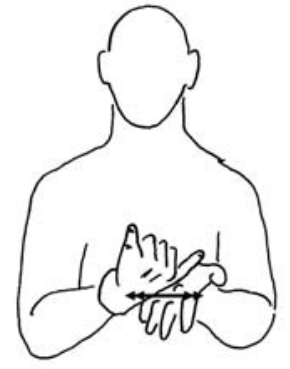

(b) YELLOW c

Figure 42. ESL color signs: different variants of the sign YELLOW.

According to the current study, the ESL sign BLUE (figure 43) was also identical to the respective sign in Russian SL. In addition, YELLOW, although very salient, outperforming even the signs BLACK and WHITE 1 in the list task and, also being dominant in the color-naming task, is probably also a loan from Russian SL. Both signs are, however, very salient terms in ESL, with very small variations, and are practically the only terms for yellow and blue in ESL, which leads to the assumption that they can't be very recent loans. In the current study, BLUE was articulated by the same hand-shape, either in the neutral space (figure 43a) or in front of the face (figure 43b,c). 


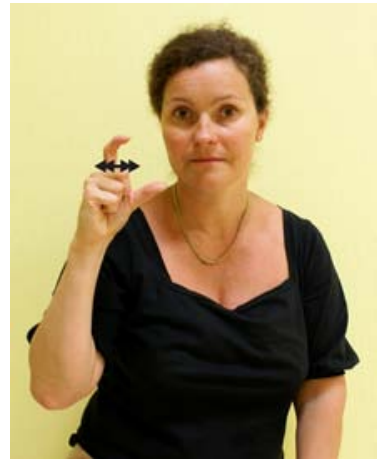

(a) BLUE a

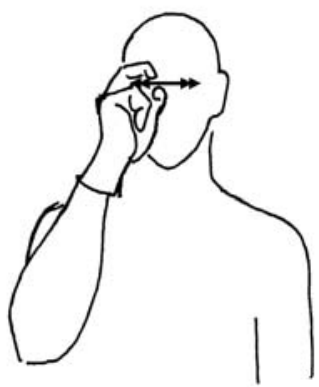

(b) BLUE b

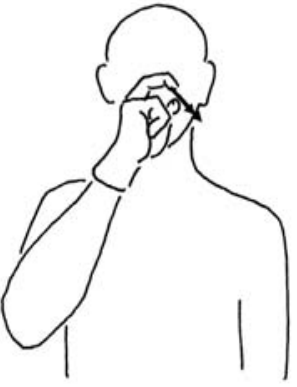

(c) BLUE c

Figure 43. ESL color signs: three variants of the sign BLUE.

GRAY (figure 44) is also very clearly a basic color term in ESL, being in all probability a native sign, very salient and practically the only sign for gray in ESL. According to the expert opinion of Laiapea, the sign might be motivated by the beard typically being gray (Hollman 2008: 859). The sign is articulated in two variants: one with one touching movement on the cheek, the other with a repeated movement but, as in the case of BLACK, there was no difference in their meaning as gray or grayish in the current study.

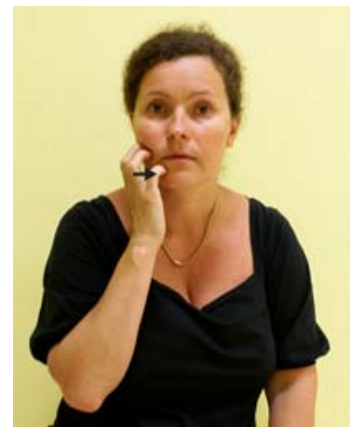

Figure 44. ESL color signs: GRAY.

The ESL sign which, in the current study, was used to denote both pink and purple also meets all the requirements of a basic color term. It outperformed, in salience, GRAY and BROWN in the list task and was a dominant name for four tiles in the color-naming task. 

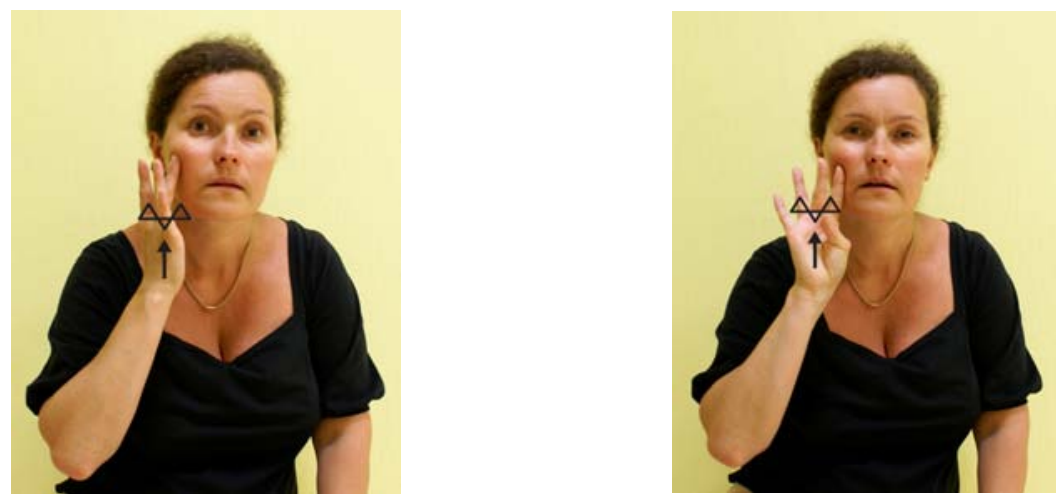

Figure 45. ESL color signs: different variants of the sign PINK/PURPLE denoting the composite category of pink and purple.

The sign here named as PINK/PURPLE is probably also a native ESL sign. Probably motivated from the blush, similarly to RED 1, the sign is articulated in many different varieties: with wiggling fingers and the palm oriented either towards or away from the signer, and with still fingers and the palm oriented either towards or away from the signer (figure 45). In some cases, the sign is articulated in the neutral space, not on the cheek.

BROWN (figure 46a) is probably derived from an extension of the meaning of the sign COFFEE (figure 46b). BROWN is articulated with two hands touching each other while, according to the ESL dictionary of 1988, the sign COFFEE is formed with a larger movement and with no contact between the two signing hands. In some Russian SL dictionaries, the same sign for brown may be found, although the main sign for brown in Russian SL is different.

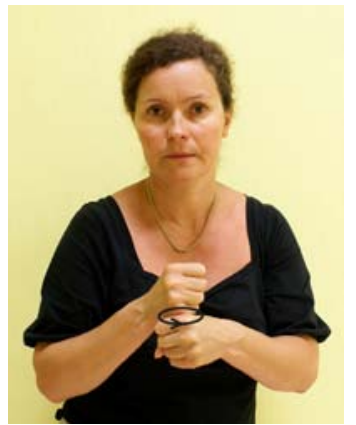

(a) BROWN

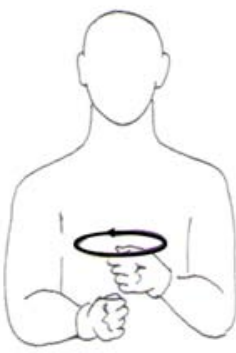

(b) COFFEE

Figure 46. ESL signs (a) BROWN and (b) COFFEE.

BROWN may also be articulated with a back and forth movement instead of a circular movement. The sign for coffee is obviously motivated by the movement 
of coffee-grinding, but it is difficult to determine if the extension of the meaning of the color brown was developed in ESL or if it is a loan or influence from another sign language having the same sign for coffee.

The ESL signs ORANGE 1 (figure 47a), PURPLE 1 (figure 47b) and BEIGE (figure 47c) are typical examples of initialization. ORANGE 1 is articulated with the ESL O hand-shape (figure 47d) from the Estonian word oranž for orange. PURPLE is articulated with the same movement and in the same location, but with the L hand-shape (figure 47e) from the Estonian word lilla for purple. Although BEIGE is articulated with a B hand-shape (figure 47f; the Estonian word beež for beige), it may also be assumed that the sign is derived from the ESL sign LIGHT (articulated with two B hand-shapes in neutral space). For all these colors, many other signs were also used in the current study, but the most salient of them were the initialized signs.

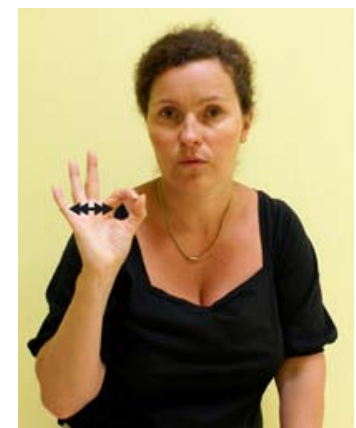

(a) ORANGE 1

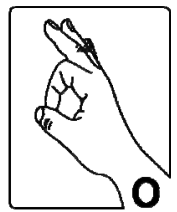

(d)

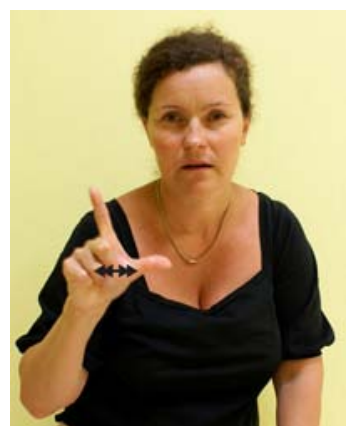

(b) PURPLE 1

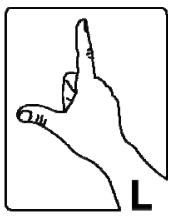

(e)

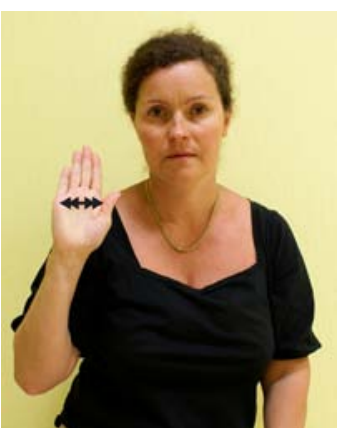

(c) BEIGE

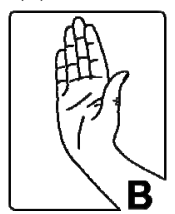

(f)

Figure 47. Initialized signs ORANGE 1, PURPLE 1 and BEIGE.

As mentioned above, WHITE 2, BLACK, RED 2, and the oldest variant of GREEN (GREEN a) are articulated lower in the neutral space with upward movement. YELLOW, BLUE and BROWN are also presented in the ESL dictionary of 1988. It may be assumed that the signs included in the dictionary are more widespread than others and this may be the case for some signs, such as BLACK, GREEN, YELLOW, BLUE and BROWN. At the same time, the representation in the dictionary has not hindered a generation of probable new signs, such as RED 1 and WHITE 1 not mentioned in the dictionary and very salient in ESL according to the study; nor the change in the formation of signs as described in the case of GREEN. 


\subsection{Combined results and discussion}

According to the list task data, the most probable candidates for basic color terms in ESL are RED 1, BLUE, GREEN, YELLOW, BLACK, WHITE 1, PINK/PURPLE, GRAY and BROWN. These terms are the most salient in the list task and were named by more than half of the subjects $(\mathrm{F}=34-49)$, followed by WHITE 2, although it was in third place in terms of its mean position but listed only by 12 subjects, and PURPLE 1 was listed by 17 subjects.

Comparing the salience of different concepts and ESL signs named in the list task, it may be concluded that more salient concepts, such as red, blue, green, yellow, black, white, gray and brown, are mostly denoted by one dominant sign. Among the nine probable candidates there were three signs which were the only signs mentioned for the respective color concepts, these signs being BLACK, BLUE and GRAY. For the other colors, at least one different sign was also mentioned during the list task. There were two different signs for red (RED 1 and RED 2), white (WHITE 1 and WHITE 2) and brown (BROWN, BROWN/ BEIGE), but one of them was clearly the most frequent. At the same time, the frequencies of different signs for orange, purple and beige were distributed more evenly, while none of the signs was used frequently enough to be a candidate for a basic term, according to the list task.

The most frequent terms in the color-naming task were PINK/PURPLE, BLUE, BLUE DARK, GREEN DARK, GRAY, BROWN, GREEN, BLACK, RED 1, BROWN DARK and YELLOW (total F>80). However, considering the number of tiles for which a sign was used (F/number of tiles) and leaving out such complex terms as GREEN DARK and BLUE DARK, the probable candidates for basic color terms according to the color-naming task would be BLACK, RED1, BLUE, WHITE 1, BROWN, GRAY, YELLOW, GREEN, ORANGE 1 and PINK/PURPLE.

The basicness of BROWN, ORANGE 1 and PINK/PURPLE is suspicious, because even though they were dominant names for some tiles, their dominance frequencies were always less than 25 (21 for PINK/PURPLE, 19 for ORANGE 1 and 16 for BROWN). BROWN and PINK/PURPLE were, however, salient according to the list task and their total frequencies in the color-naming task were higher. PINK/PURPLE was the most frequent sign in the color-naming task $(\mathrm{F}=133)$ and BROWN $(\mathrm{F}=89)$ outperformed even the signs BLACK, RED 1 and YELLOW. ORANGE 1, to the contrary, was mentioned only by 17 subjects in the list task and its total frequency in the color-naming task was only 46.

The case for PINK/PURPLE may be questionable because there seemed to be no clear consensus among the subjects on which color the term actually referred to. As shown above, in the list task the sign was mostly accompanied by the mouth pattern for pink (with a frequency of 27), and in some cases (with a frequency of 11) the mouth pattern for purple accompanied the sign. The sign was used as a dominant name for four tiles (table 14), while PURPLE 1, although having very low frequencies, was a dominant name for three tiles. In 
all the cases, PURPLE 1 was dominant. PINK/PURPLE or PINK/PURPLE DARK followed as the second most frequent name for the tile (table 12).

Table 14. ESL signs PINK/PURPLE and PURPLE 1 as dominant names for the color tiles, together with the respective frequencies compared to the dominant names in Estonian (Sutrop 2002). To make the frequencies comparable, the frequencies appearing in the ESL survey are here multiplied by $0.625(50 / 80)$

\begin{tabular}{|l|l|l|}
\hline Color aid code & Dominant name in ESL & Dominant name in Estonian \\
\hline RO T3 & PINK/PURPLE (15) & pink (17) \\
ROR T3 & PINK/PURPLE (21) & pink (29) \\
R T4 & PINK/PURPLE (14) & pink (22) \\
RVR S1 & PURPLE 1 (7) & purple (25) \\
RV & PURPLE 1 (10) & purple (27) \\
RV T2 & PINK/PURPLE (17) & purple (25) \\
VRV & PURPLE 1 (13) & purple (22) \\
\hline
\end{tabular}

While the sign PINK/PURPLE was used to refer to pink as well as purple, there were no subjects who used the sign to refer to purple only and who had a different name for pink. Two subjects finger-spelled the Estonian word for pink to differentiate between the colors pink and purple. The subjects for whom the term covered both pink and purple, did not use any other names for either pink or purple. Only one also used the sign PURPLE 1 to name the tiles V and VBV T4, while for the other tiles shown in table 9 PINK/PURPLE or the compounds RED LIGHT, RED BLUE TOGETHER and CHERRY COLOR were used.

Considering all the cases where the signs PINK/PURPLE, PURPLE 1 and PURPLE 2 were used to describe the color tile both as a simple term or part of a compound in the area of color space where either PINK/PURPLE or PURPLE 1 was the dominant name, it may be seen that in the red area of the color space and in the transition area of red and orange (R T4, RO T3, ROR T3), mostly PINK/PURPLE was used, PINK/PURPLE being more frequent in cases of brighter variants (RO T3, ROR T3 and R T4) and less frequent in cases of darker variants of each color (ROR S3, RVR S1). In the transition area of red and violet, the proportion of the sign PINK/PURPLE decreased significantly (RVR S1, RVR S3, RV, VRV), while brighter tints still tended to be named as PINK/PURPLE (RV T2). In the transition area of violet and blue, PURPLE 1 or PURPLE 2 was dominantly used, even in the case of brighter tints (VBV T4), although PINK/PURPLE was also used by some of the subjects (figure 48). 


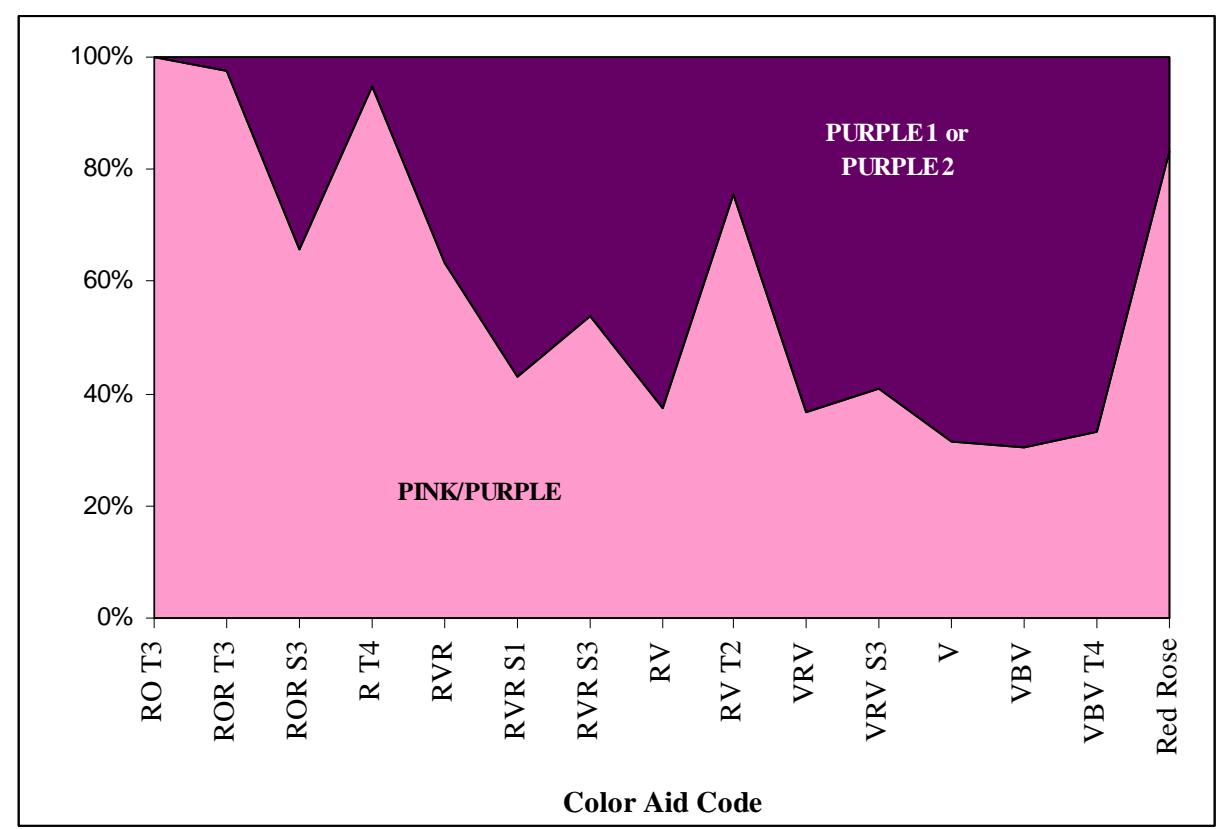

Figure 48. Use of the signs PINK/PURPLE, PURPLE 1 and PURPLE 2 in the colornaming task.

As seen in the discussion above, the sign PINK/PURPLE covered both pink and purple, similarly to the term grue, which covers the areas of green and blue. Differentiating from PINK/PURPLE, PURPLE 1 is most probably the next color term that will become basic in ESL. At the same time, the use of PINK/PURPLE for a wide range of tiles is not necessarily explained by a lack of consensus among the subjects, but by the area of the color space it covers.

Although the ESL signs BLUE and YELLOW are obviously loans from Russian SL, their affiliation with the basic terms is definitely not questionable because of their salience in both tasks. Therefore, there is no need to apply the secondary criteria of a basic term.

The initialized signs ORANGE 1 and PURPLE 1 are not basic in ESL because of their low frequencies in both tasks, but this is not due to the influence of Estonian. It is most probable that ORANGE 1 and PURPLE 1 will be the next to become basic color terms in ESL.

Motivation either from a blush or white skin may be found in the formation of the signs RED 1 and WHITE 1, but both of the signs are lexicalized color terms clearly distinguished from pointing signs. In the signs BLACK, GRAY and GREEN, the motivation, even if it was once there, is not so clearly seen any more. The process of going through a change to lose its transparent motivation is clearly seen in the case of GREEN. 
Drawing on the discussion above, it may be concluded that ESL has nine basic color terms: BLACK, WHITE 1, RED 1, YELLOW, GREEN, BLUE, GRAY, BROWN and PINK/PURPLE. Therefore, ESL corresponds to stage VII of Berlin and Kay. The arguments against the validity of the definition of a basic term were not supported by the results of the current study. Initialized signs did appear quite low in the hierarchy, and signs obviously derived from pointing movements have changed formally and differentiate clearly from pointing (Hollman \& Sutrop 2009). 


\section{SUMMARY}

Estonian Sign Language (ESL) is used by approximately 1,400-1,500 Estonian deaf people and their families. ESL is described in Ethnologue under the Language Code eso.

As in the case of many other sign languages, the history of ESL is also considered to be related to the establishment of the first Estonian deaf school in 1866. Although the oral teaching method was used in the school, it was a perfect place for deaf people from all over Estonia to come together to develop their own sign language. After more than a century of the oral tradition in deaf education, ESL research began in the 1980s, and since the early 1990s ESL has been used as the teaching language in the educational system for deaf children.

ESL is now a developing language which is taught in universities and other schools as a second language, and interpreting services from and into ESL are provided for its users. During the last two decades, three small ESL dictionaries have been written (Toom 1988, 1990, Kivisild and Toom 1990); they contain approximately 700 signs that form the basic vocabulary of ESL. Some general overviews of sign languages and ESL have been published (Laiapea 1992, 2001, 2007). More specific descriptions have focused on noun phrases (Miljan 2000), adjectives (Miljan 2001), numbers (Miljan 2003) and expressing time relations in ESL (Trükmann 2006), as well as the classification and etymology of name signs (Paales 2002). Since March 2007, ESL has been recognized as a separate language by the Estonian Language Law, which defines ESL as an independent language and signed Estonian as a form of Estonian. The law also stipulates that the state encourage the use and development of ESL and signed Estonian.

Since Berlin and Kay published their Basic Color Terms in 1969, color terms have been the focus of numerous studies. Relying on a sample of ninety-eight languages from different language groups, Berlin and Kay concluded that, in a language which has a fully developed color system, there are eleven basic color categories: white, black, red, green, yellow, blue, brown, purple, pink, orange and gray. A language encodes these basic categories in a certain order. At stage I in the evolution of lexical color categories, two terms, the term for black and all dark hues, and the term for white and all light hues, appear. At stage II, the third category emerges which includes all reds, oranges, yellows, browns, pinks and purples. At stage III, the scope of white and black reduces again and the category of green, yellow or grue appears, followed by the category blue at stage V, brown at stage VI and pink, purple, orange and gray at stage VII. Therefore, a language with two basic color terms is a stage I language, and with three basic terms a stage II language. A stage VI language has seven basic color terms and a stage VII language has eight to eleven.

A basic color term is defined by Berlin and Kay as (1) a mono-lexemic term whose meaning is not predictable from the meaning of its parts; (2) a term whose signification is not included in that of any other color term; (3) a term whose application is not restricted to a narrow class of objects and (4) a term 
which is psychologically salient for subjects. For handling doubtful cases, additional criteria are provided. The definition of a basic term has been reviewed by several authors, and in the latest definitions the emphasis has shifted from formal aspects to psychological salience and semantic basicness (Sutrop 2002, Uusküla 2008b).

Basic color terms in sign languages have not been widely and empirically studied. However, the existing studies show that lexicalization of basic color terms follows the same pattern found in spoken languages. Different studies mention sign languages with only two basic color terms: terms for black and white (e.g. Providence Island SL and Al-Sayyid Bedouin SL). Sign languages with three basic color terms (e.g. ASL and Ban Khor SL) have added the term for red. Four-term systems have terms for yellow (Mainland Chinese SL) or grue (French SL). Auslan, which also includes pink, is a nine-term system (Woodward 1989, 150, Nonaka 2004: 750, Fox: 2007: 77).

The studies of basic color terms in sign languages highlight the problem of defining a basic color term in sign languages. Several authors refer to numerous color terms derived from pointing to body parts or borrowed from spoken languages through initialization, and state that only arbitrary color signs should be considered basic according to the definition provided by Berlin and Kay. The current study does not support this challenge, as the secondary criteria should be applied only in a situation where the status of a term is not clear after analyzing it with the help of the four primary criteria, i.e. if the term is basic according to the primary criteria, the secondary criteria do not matter. Therefore, lexicalized and salient color signs, obviously having their motivation base in referential pointing, are considered basic. Loans from other sign languages are also considered basic if they meet the primary criteria. Initialized color signs in ESL appear low in the hierarchy (stage VII, PURPLE 1, ORANGE 1 and BEIGE) only at stage VII in the color hierarchy. Signs apparently derived from pointing to respective body parts (the cheeks or lips for RED 1 and RED 2, and the beard for GRAY) are fully lexicalized and salient terms and there is no reason to doubt their basicness.

A survey of basic color terms in ESL was carried out in summer 2005. The research consisted of three tasks, following Davies and Corbett's field method developed further by Sutrop (2001, 2002), and used also for the basic color term survey in Estonian (Sutrop 2000b: 147-148; 2002, 58):

(1) The list task, where the subjects were asked to name as many colors in ESL as they could.

(2) The City University color vision test for assessing the subjects' ability to see color (Fletcher 1980).

(3) The color-naming task. This task involved showing the subjects 65 different color squares, one square at a time, in random sequence. The subjects were asked to name the colors of the tiles.

All the tasks were carried out indoors and in natural daylight. Both the list task and the color-naming task were video-recorded. The collected data was notated 
using the Estonian Sign Language transcription system (Paabo, Födisch \& Hollman 2009).

The subjects participating in the survey were selected from four different regions, following the proportions of the actual number of deaf people living in these areas. A total of 50 subjects were interviewed, 20 of them from Tallinn, 13 from Pärnu, 11 from Tartu, five from Võru and one from Rakvere. Among the subjects, there were 24 men and 26 women, between the ages of 15 and 74, with an average age of 43 years.

Thirty-eight subjects (76\%) were profoundly deaf, and twelve (24\%) had some residual hearing, or identified themselves as hearing-impaired rather than deaf. All of the subjects communicated in ESL, but only eight (16\%) were from deaf families. Thirty-five subjects (70\%) were from totally hearing families, and had started to learn ESL at the age of two to fourteen.

All of the subjects had normal color vision (controlled by the City University color vision test).

In the list task, the 50 subjects named a total of 681 color terms, among them 109 different ESL signs. Fifty-one signs were mentioned only once during the task. The most salient signs named in the list task were RED 1, BLUE, GREEN, YELLOW, BLACK, WHITE 1, PINK/PURPLE, GRAY, BROWN, WHITE 2, PURPLE, ORANGE 1 and BROWN/BEIGE. WHITE 2, PURPLE, ORANGE 1 and BROWN/BEIGE were, however, used by less than half of the subjects.

In the color-naming task, the mean number of names given to 65 different color tiles by 50 subjects was 3.374, including 696 different ESL terms. Only 225 signs were named at least twice; most of the terms only occurred once during the task. The most salient ESL signs in the color-naming task were BLACK, RED 1, BLUE, a compound sign, DARK GREEN and WHITE 1. After some other compounds, such simple signs as BROWN, GRAY, YELLOW and GREEN, were also quite frequently used. Excluding all the compounds, the most frequent simple color terms in the color-naming task were BLACK, RED 1, BLUE, WHITE 1, BROWN/BEIGE, GRAY, YELLOW, GREEN, ORANGE, PINK/PURPLE, WHITE 2 and PURPLE.

In twelve cases out of 65, a mono-lexemic color term was dominantly used to name a tile by at least half of the subjects - BLACK, YELLOW, GRAY, WHITE 1, BLUE, RED 1 and GREEN.

Considering the first four criteria of a basic term given by Berlin and Kay, the candidates for basic color terms in ESL are BLACK, WHITE 1, RED 1, GREEN, YELLOW, BLUE, BROWN, GRAY and PINK/PURPLE.

The ESL signs for the first three color categories, as well as the sign for green, seem to be native ESL signs, having a putative motivation base but being fully lexicalized. BLACK seems to be an arbitrary native ESL sign which has no similar signs in neighboring sign languages, and whose motivation might be associated with the transfer of the relationship between black and dirty in Estonian, both marked by the same word, or by the method used to help deaf students feel the airflow while articulating nasal sounds, as the Estonian counterpart must starts with a nasal $m$. 
WHITE 1 is also, in all probability, a native ESL sign, with no similar signs in neighboring sign languages. It may refer to the white skin of the hands. WHITE 2 is not a basic term, as it is not as salient and has a different meaning, clean, as well. RED 1 is articulated on the cheek. The sign might be motivated by a blush and is very similar to the sign for pink. It was the most salient term according to the list task and followed the sign BLACK in the color-naming task. It was also very salient compared to RED 2, articulated on the lips with the index finger, a sign which is similar to the sign RED in many other sign languages, including ASL, and was probably derived from a pointing sign. RED 2 is, according to the current study, quite rare and mostly used by elderly people.

GREEN is articulated with two hands, either with a divisive downward movement or a round upward movement. It may be assumed that GREEN in ESL is derived from the sign for spruce or Christmas, but now differs from them in at least one parameter. There is no similar sign in neighboring sign languages and it was basically the only sign for green in ESL. Different variants of GREEN appearing in the study illustrate precisely the principles of diachronic change, as the older variants are two-handed signs articulated in the neutral space, while the later variants have moved up in front of the face and become one-handed.

In the case of YELLOW and BLUE, although the signs are very salient, outperforming even the signs BLACK and WHITE 1 in the list task and being dominant also in the color-naming task, the same signs are also used in Russian SL. Considering the obvious influence from Russian SL or even an implicit influence from French SL and ASL, ESL YELLOW may have originated from an initialized sign (the $\mathrm{Y}$ hand-shape from the English yellow or the $\mathrm{J}$ handshape from French jaune). Both signs are formed with very small variations and are practically the only terms for yellow and blue in ESL, which leads to the assumption that they cannot be very recent loans and might therefore be considered basic.

GRAY is also very clearly a basic color term in ESL, being in all probability a native sign, very salient and practically the only sign for gray in ESL. The sign might be motivated by the beard typically being gray. 

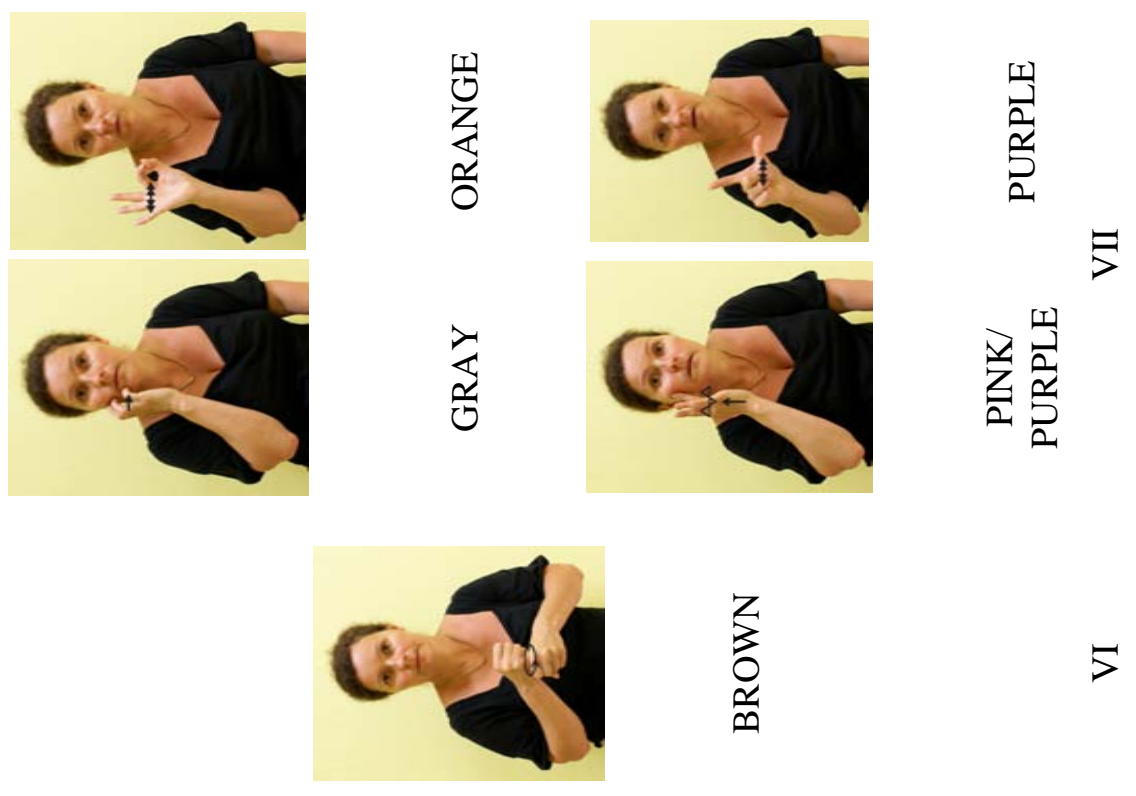

言

5

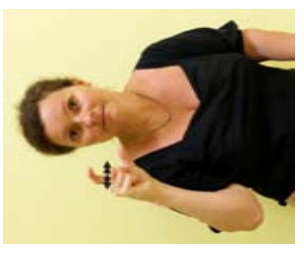

吕

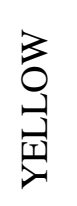
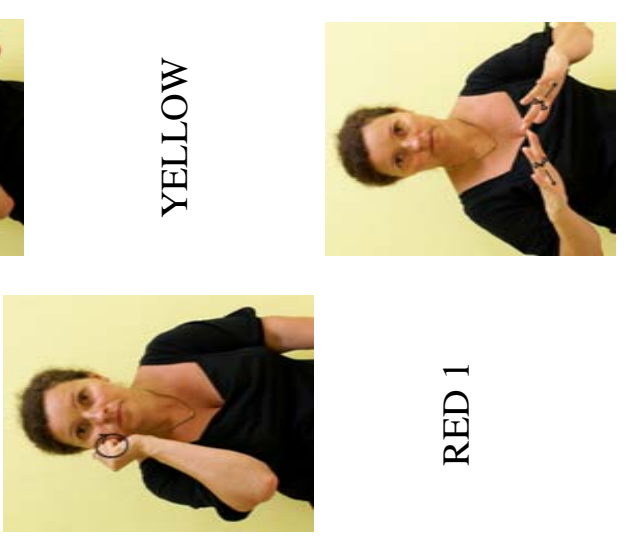

臬

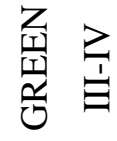
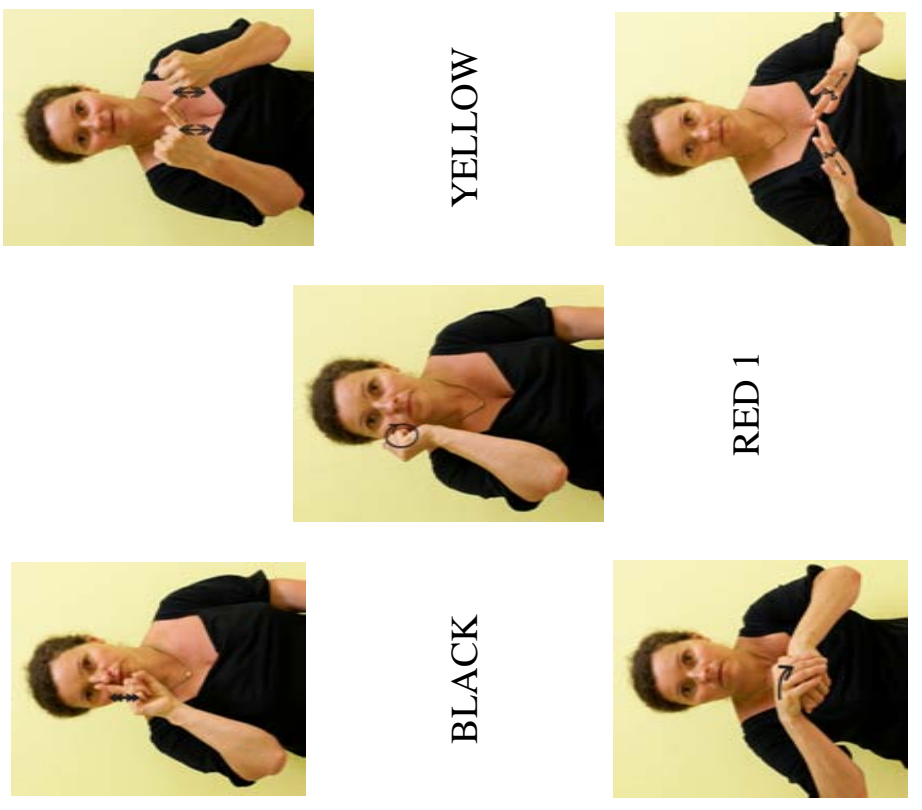

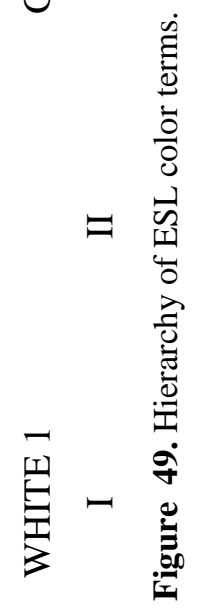


BROWN seems to be a native ESL sign, similar to the ESL sign for coffee, and differing from it by one phoneme (hands touching each other). A Russian origin for brown is also possible.

The ESL sign which, in the current study, was used to denote both pink and purple also meets all the requirements of a basic color term. It outperformed, in salience, GRAY and BROWN in the list task and was a dominant name for four tiles in the color-naming task. The sign here named as PINK/PURPLE is probably also a native ESL sign and, according to the results of the current study, obviously covers the composite category of pink and purple.

ORANGE 1, PURPLE 1 and BEIGE are typical examples of initialization. All of them are articulated by the hand-shape of the initial letter of the respective color word in Estonian.

Comparing the salience of different concepts and ESL signs named in the list task it may be concluded that more salient concepts, such as red, blue, green, yellow, black, white, gray and brown, are mostly denoted by one dominant sign. There are at least two different signs each for red, white and brown, but one of them is clearly the most frequent. At the same time, the frequencies of different signs for orange, purple and beige are distributed more evenly.

Drawing on the above discussion, it may be assumed that ESL is a stage VII language and has nine basic color terms: BLACK, WHITE, RED, YELLOW, GREEN, BLUE, GRAY, BROWN and PINK/PURPLE. The terms YELLOW and BLUE, although quite high in the hierarchy and very salient in both the list task and color-naming task, are probably not native ESL signs.

The arguments against the validity of the definition of a basic term were not supported by the results of the current study. Initialized signs appeared quite low in the hierarchy, and signs obviously derived from pointing movements were rare.

The study showed that the universalistic theory of basic color terms is applicable to the sign language studied, which was conducted with a sufficient number of subjects (50). In some idiolects, the tendency to use mouth patterns following Estonian was observed and in some cases the correspondence of the mouth pattern and the color signs was questionable. However, focusing on the signs, it may be seen that the basic color term hierarchy (figure 49) is clearly displayed by the data collected. 


\section{KOKKUVÕTE}

Pärast seda, kui Brent Berlin ja Paul Kay 1969. aastal värvinimede universaalid sõnastasid, on värvinimesid uuritud ja kirjeldatud väga paljudes keeltes. Berlini ja Kay teooria kohaselt on täielikult väljaarenenud põhivärvinimede süsteemiga keeles kokku 11 põhivärvinime: valge, must, punane, roheline, kollane, sinine, pruun, lilla, roosa, oranž ja hall. Seejuures ilmuvad värvide põhinimed keelde kindlas järjekorras (Berlin \& Kay 1969: 2-3). Viipekeeltes on põhivärvinimesid suhteliselt vähe käsitletud, kuid olemasolevad uurimused kinnitavad, et viipekeelte puhul kehtivad samad seaduspärasused mis suulistes keeltes (Woodward 1989: 148, Nonaka 2004: 750, Nyst 2007: 96).

Käesolev doktoritöö keskendub põhivärvinimedele eesti viipekeeles. Töö eesmärgiks on välja selgitada eesti viipekeele põhivärvinimed ning Berlini ja Kay põhivärvinimede teooria kehtivus eesti viipekeeles. Uurimistöö on jaotatud viieks peatükiks. Sissejuhatusele järgneb ülevaade viipekeeltest ja kurtide kogukondadest, pikemalt peatutakse viipekeelte leksikal ja leksikaalsetel muutustel. Kolmandas peatükis käsitletakse pikemalt eesti viipekeelt, eesti viipekeele ajalugu, fonoloogiat ja leksikat. Neljandas peatükis tutvustatakse põhivärvinimede teooriat ja viipekeelte põhivärvinimede uuringuid. Viiendas peatükis antakse ülevaade eesti viipekeele värvinimede uuringust, eesti viipekeele põhivärvinimedest ja nende võimalikust etümoloogiast. Alljärgnevas kokkuvõttes käsitletakse lühidalt viipekeeli ja nende muutumist, sealhulgas eesti viipekeelt, põhivärvinimede teooriat, värvinimede uuringuid erinevates viipekeeltes ja värvinimesid eesti viipekeeles.

\section{I. Viipekeeled ja nende muutumine}

Eestis elab ligikaudu 1400-1500 kurti. Suhtlemisel kasutavad nad eesti viipekeelt. Eesti viipekeel kuulub maailmas ametlikult tunnustatud keelte hulka ning on registreeritud maailma keelte andmebaasis Ethnologue, kus selle rahvusvaheline kood on eso (vt ka Sutrop 2000a). Eestis määratleb eesti viipekeele staatuse 2007. aasta 1. märtsist kehtima hakanud keeleseaduse redaktsioon, kus tunnustatakse eesti viipekeelt iseseisva keelena, mille kasutamist ja arengut riik soodustab. Viibeldud eesti keelt (eesti viipekeele viipeid ja sõrmendeid kasutades visualiseeritud eesti keelt) defineeritakse seejuures kui eesti keele esinemiskuju.

Viipekeelsed kogukonnad, sealhulgas eesti kurtide kogukond, on keeleliselt väga heterogeensed. Suurem osa kurte lapsi sünnib kuuljate peredesse, kus viipekeel ei ole esimeseks keeleks. Erinevatel andmetel on kuuljate peredest pärit kurtide laste osakaal 90-95\% (Anderson 2006: 137, Kyle \& Woll 1995: 25, Laiapea 2007: 97, Toom 2003: 185). Nii õpib suur osa kurtidest lastest viipekeele mitte oma vanematelt, vaid eakaaslastelt ja õpetajatelt ning üldjuhul avaneb ligipääs viipekeelele sel juhul ka hiljem. Ehkki enamasti jääb kurdi esimeseks keeleks siiski eesti viipekeel, mõjutab seda eesti keel. Mõju tugevus 
sõltub õpetusmetoodikast, kodusest keelest, kasutatavatest kuulmisabivahenditest, kuulmislanguse sügavusest, kuulmistaju arendamisest ning paljudest muudest teguritest ja nende koosmõjust. Viipekeelse kogukonna tuumiku moodustavad aga kurtide vanemate kurdid lapsed, kes on viipekeele omandanud oma vanematelt, kandes samas ühelt põlvkonnalt teisele edasi ka kurtide kultuurilisi väärtushinnanguid.

Esimene Eesti kirjalik allikas, milles leiavad mainimist kurdid ja sõrmekeele-pookstavid 'sõrmendid', on F. R. Kreutzwaldi ajakirja „Ma-ilm ja mõnda”, mis seal sees leida on“ 4. anne 1849. aastast. Artiklis tutvustatakse kurte ning antakse põhjalik ülevaade sõrmendtähestiku kasutamisest.

Jumal on meile kõrvakuulmist ja keeleliikumist jutustamise tarvis kinkinud, aga seda suurt õnne ei ole igamehele osaks saanud. Leitakse maa peal mõnda õnnetumat looma, kes lukkupandud kõrvadega ilmale tulnud ja kelle kõrv inimese rääkimise häält iial ei kuule, kes sellepärast ka mingisugust sõna teise järel ei või rääkima õppida; niisugused viletsad inimesed nimetatakse kurdiks,

kirjutab Kreutzwald ja julgustab lugejaid sõrmendamist kindlasti õppima ja lastele õpetama, et oma kurtide sõprade ja sugulastega suhelda (Kreutzwald 1849: 124, faksiimileväljaanne 2003). Viipekeelt artiklis siiski ei mainita.

Viipekeeltest ning eesti viipekeelest räägitakse sageli just kurtide hariduse kontekstis. Eesti esimene kurtide kool rajati 1866. aastal Vändras. Kuigi õpetus toimus eesti keeles, oli kool siiski kohaks, kuhu koondus viipekeelse keskkonna tekkimiseks piisaval hulgal kurte. Omavahelise suhtluse keeleks jäi eesti viipekeel veel pikkadeks aastakümneteks. Eesti viipekeele teaduslik uurimine sai alguse 1980. aastate lõpus, mil eesti viipekeelt hakati kirjeldama Tartu Ülikoolis (aastatel 1989-1990) ja Porkuni Kurtide Kooli viipekeele keskuses (aastatel 1991-1992). 1988. aastal ilmus esimene eesti viipekeele sõnastik „Kõnelevad käed” ja 1990. aastal lisandusid sellele „Abimaterjale eesti viipekeele omandamiseks” ning „Eesti kristlikud viiped”. Eesti viipekeel kurtide õpetuskeelena võeti kasutusele 1994. aastal.

Viipekeelte dokumenteeritud ajalugu kogu maailmas on suhteliselt lühike ning seetõttu on viipekeelte muutumise ja arengu kirjeldused sageli vaid oletuslikud. Pidades silmas esimese eesti viipekeele sõnaraamatu hilist ilmumisaega, on selge, et ka eesti viipekeeles kasutatavate viibete päritolu kohta on praegu äärmiselt keeruline oletusi teha. Siiski, nende viipekeelte baasil, mille ajalugu on mõnevõrra pikemalt dokumenteeritud, on välja toodud nii mõnedki viipekeelte leksika muutumise seaduspärasused. Nancy Frishberg (1975) kõrvutas ameerika viipekeelt eri perioodidel: 1) prantsuse teadlaste kirjeldusi 19. sajandi algusest ja keskelt; 2) Joseph Schuyler Longi käsiraamatus toodud materjali 1918. aastast ning 3) Frishbergi kaasaegset viipekasutust William C. Stokoe 1965. aastal ilmunud sõnaraamatu alusel. Frishberg tuli järeldusele, et ikoonilised viiped muutuvad ajas järjest arbitraarsemaks. Viipe üksikute parameetrite (käekuju, viipe moodustuskoht, liigutus, peopesa ja sõrmede suund) osas tähendab see tendentsi muutuda ökonoomsuse ja lihtsuse suunas nii viibete 
moodustamisel kui ka nende tajumisel. Ta tõi välja järgmised seaduspärasused viibete muutumises:

(a) kahekäeviibetes omandavad mõlemad käed ühesuguse käekuju;

(b) viipe moodustuskoht

a. näol nihkub tsentrist perifeeriasse, kahekäeviibe muutub seejuures ühekäeviipeks;

b. kaelast allpool nihkub üles ja keha keskosa poole, ühekäeviiped muutuvad seejuures kahekäeviibeteks;

(c) liitviibete osade käekujud või liigutused sulanduvad ühte, moodustuskohad lähenevad ning liitviiped lühenevad;

(d) leksikaalne informatsioon koondub kätesse (Frishberg 1975: 711).

Nii nagu kõikides teistes keeltes uusi sõnu, tekib ka viipekeeltes pidevalt uusi viipeid, millest osa jääb kasutusse ja osa kaob. Viiped tekivad olemasolevate viibete baasil nende tähendusvälja laienedes ning muutudes, olemasolevate viibete kombineerimisel liitviibeteks ning viipetuletuse kaudu. Viipekeeled laenavad viipeid teistest viipe- ning kõnekeeltest. Viimaste puhul on kahe erineva väljendusviisi vahel sillaks sõrmendamine. Kõnekeele sõna sõrmendatakse nn algustähtviibete abil (ingl initialized signs), kus viibe moodustatakse vastava sõna esitähe sõrmendi käekujuga.

Ruumilis-visuaalsete keeltena kasutavad viipekeeled kindlasti ära ka võimalust visuaalselt motiveeritud viibete loomiseks, kus referendi ja teda tähistava viipe vormi vahel on ilmselge sarnasus. See omakorda on üheks põhjuseks, miks erinevates viipekeeltes on sarnaste viibete osakaal suhteliselt kõrge. Samal ajal on viipekeeltes ka palju arbitraarseid viipeid ning viipeid, mis on küll kord ikoonilise viipena keelde tekkinud, kuid mille vorm on nii muutunud, et motiveeritust võib tõestada veel vaid diakrooniliste uurimustega (Laiapea 2007: 45).

Püüdes suhestada eesti viipekeelt teiste viipekeeltega, võiks ajaloole toetudes arvata, et kuna kurtide haridust Eestis mõjutas algul peamiselt saksa traditsioon ning hilisem aeg viis siinsed kurdid lähemalt kokku vene kurtide kogukonnaga, on eesti viipekeeles tajutav saksa ja/ või vene viipekeele mõju. Vene viipekeelt arvatakse omakorda kuuluvat prantsuse ja ameerika viipekeelte harru, tuginedes samuti eelkõige ajaloole (Zeshan 2005: 559). Kuigi vastavasisulised uurimused peaaegu puuduvad, kinnitab oletust vene viipekeele mõjust eesti viipekeelele neid võrrelnud Liisi Taniroo bakalaureusetöö, kus kokkulangevaid viipeid oli 200st 123 ehk 61,5\% (Taniroo 2007: 23).

\subsection{Põhivärvinimede teooria}

Berlini ja Kay värvinimede teooria kohaselt (Berlin \& Kay 1969) ilmuvad värvide põhinimed keelde kindlas järjekorras. Teooria põhipostulaadiks on, et täielikult väljaarenenud põhivärvinimede süsteemiga keeles on kokku 11 põhivärvinime: valge, must, punane, roheline, kollane, sinine, pruun, lilla roosa, oranž ja hall. Seejuures esinevad põhivärvinimed keeles kindlate seaduspärasuste alusel: 
1. Kõikides keeltes on olemas värvinimed „must” ja „valge”.

2. Kui keeles on kolm värvinime, on olemas värvinimi „punane”.

3. Kui keeles on neli värvinime, siis sisaldab keel nimetusi kas „rohelise” või „kollase” jaoks (aga mitte mõlema jaoks).

4. Kui keeles on viis värvinime, siis sisaldab keel nimetusi nii „rohelise” kui ka „kollase” jaoks.

5. Kui keeles on kuus värvinime, on olemas värvinimi „sinine”.

6. Kui keeles on seitse värvinime, sisaldab keel nimetust „pruuni” jaoks.

7. Kui keeles on kaheksa või rohkem värvinime, on olemas värvinimed „lilla”, „roosa”, „oranž” ja „hall” või nende kombinatsioon. (Berlin \& Kay 1969: 2-3)

Põhivärvinime defineerisid Berlin ja Kay nelja põhikriteeriumiga: (1) see peab olema monolekseemne, s.t selle tähendus ei tohi olla tuletatav komponentide tähendustest, (2) selle tähendus ei tohi sisalduda ühegi teise värvinime tähenduses, (3) see peab olema kasutatav milliste tahes objektide kirjeldamiseks ning (4) see peab olema psühholoogiliselt esilduv (Berlin \& Kay 1969: 2-3, 12). Juhul, kui mainitud kriteeriumite alusel tekib siiski kahtlus põhivärvinime staatuse osas, rakendatakse lisakriteeriumeid: (5) kahtlusalusel vormil peaks olema samasugune levikupotentsiaal varasemate põhivärvinimedega; (6) värvinimi, mis tähistab ühtlasi sellevärvilist objekti, tuleks põhinimede hulgast välja arvata, kui esimesed neli kriteeriumi ei ole täidetud; (7) hilised laenud on kahtlased ja (8) värvinimi peaks olema morfoloogiliselt lihtne (Berlin \& Kay 1969: 6-7).

Põhivärvinime definitsiooni on hiljem korduvalt täiendatud ja parandatud. Diskussioone on tekitanud põhivärvinime kui semantilise üksuse defineerimine formaalsete ja ajalooliste kriteeriumite kaudu (Crawford 1982: 324). Urmas Sutrop (2002) pakub välja definitsiooni, mis arvestab nii psühholoogilist esiletulekut kui ka vormilisi aspekte:

Põhivärvinimi on psühholoogiliselt esiletulev, enamasti morfoloogiliselt lihtne omasõna, mis kuulub prototüüpsete värvinimedega samasse sõnaliiki ning millel on nendega sama grammatiline potentsiaal. Põhivärvinimi on kognitiivsel põhitasemel kasutatav kõigis asjakohastes situatsioonides. (Sutrop 2002: 40, Bogatkin-Uusküla \& Sutrop 2005)

Mari Uusküla (2008b) seab kahtluse alla monolekseemsuse nõude põhivärvinime definitsioonis, kuivõrd see jätab välja morfoloogiliselt keerulised, kuid semantiliselt lihtsad põhinimed, ning formuleerib definitsiooni alljärgnevalt:

Põhivärvinimi on semantiliselt ühtne ja psühholoogiliselt esilduv, väljendub kõikide keelekasutajate idiolekti(de)s ning esineb katseloeteludes esimes(t)ena nimetatud värvinimede hulgas. Värvitahvlitele nime andes kasutavad keelejuhid põhivärvinime üksmeelselt. Põhivärvinime tähendus ei sisaldu ühegi teise põhivärvi nimetuses. Kui värvinimi täidab psühholoogilise esilduvuse kriteeriumi, ehkki kirjeldab teatud suletud klassi objekte, võib selle arvata põhivärvinimeks. (Uusküla 2008b: 65) 
Seega on hilisemates definitsioonides põhirõhk nihkunud vormiliselt lihtsuselt pigem semantilisele ja psühholoogilisele esilduvusele.

Berlini ja Kay sõnastatud teooriat illustreerib joonis 1 (Berlin \& Kay 1969: 4). Sünkrooniliselt tähendab see, et kui keeles on olemas kirjeldatud hierarhias paremal asetsev värvinimi, on kindlasti olemas ka kõik hierarhias vasakul asetsevad värvinimed. Diakrooniliselt on keel, mis praegu on põhivärvinimede arvu poolest ühes arengujärgus, kindlasti läbinud kõik sellele staadiumile eelnenud arengujärgud (Berlin \& Kay 1969: 15).

Kuus aastat pärast värvinimede universaalide sõnastamist täiendas Kay teooriat ja tutvustas täiendustest lähtuvalt ka uut põhivärvinimede evolutsiooni skeemi (joonis 2). Vastavalt uuele skeemile võib sinine leksikaliseeruda sinirohelise kategooria näol ka enne või samal ajal rohelisega, mitte ainult pärast rohelise leksikaliseerumist, nagu algsest skeemist nähtus. Siiski ei ole sinine ega roheline kunagi olemas eraldi värvinimedena enne, kui ka kollane on saavutanud põhivärvinime staatuse (Kay 1975: 260-261).

Oma esialgses uurimuses märgivad Berlin ja Kay unikaalse värvinimede süsteemi poolest ära vene ja ungari keele, kuna vene keeles on ilmselt kaks põhinime sinise ja ungari keeles punase tähistamiseks (Berlin \& Kay 1969: 36, 99). Ka Kay ja McDaniel (1978) mainivad vene keelt kui erandit, kuid peavad seda pigem juhuseks, öeldes, et goluboj 'helesinine' on üksnes võimalik kaheteistkümnes põhivärvinimi, olles põhinimi osale vene keele kõnelejatest, kuid mitte kõigile (Kay \& McDaniel 1978: 640). Ian Daviese ja Greville Gorbett' (1994) järgi aga vastab goluboj kõikidele põhivärvinime kriteeriumitele. Nimetatud uurimusele toetudes on vene keeles 12 põhivärvinime (Davies \& Gorbett 1994: 87).

Ungari keelele lisaks on arvatud, et ka tšehhi keeles võib olla kaks põhinime punase tähistamiseks. Uusküla (2008a, 2008b) uurimused kinnitavad siiski, et mõlemas keeles on täpselt 11 põhivärvinime, ungari vörös ja tšehhi rudá põhivärvinime kriteeriumitele ei vasta (Uusküla \& Sutrop 2007: 121, Uusküla 2008a: 25, Uusküla 2008b: 34). 


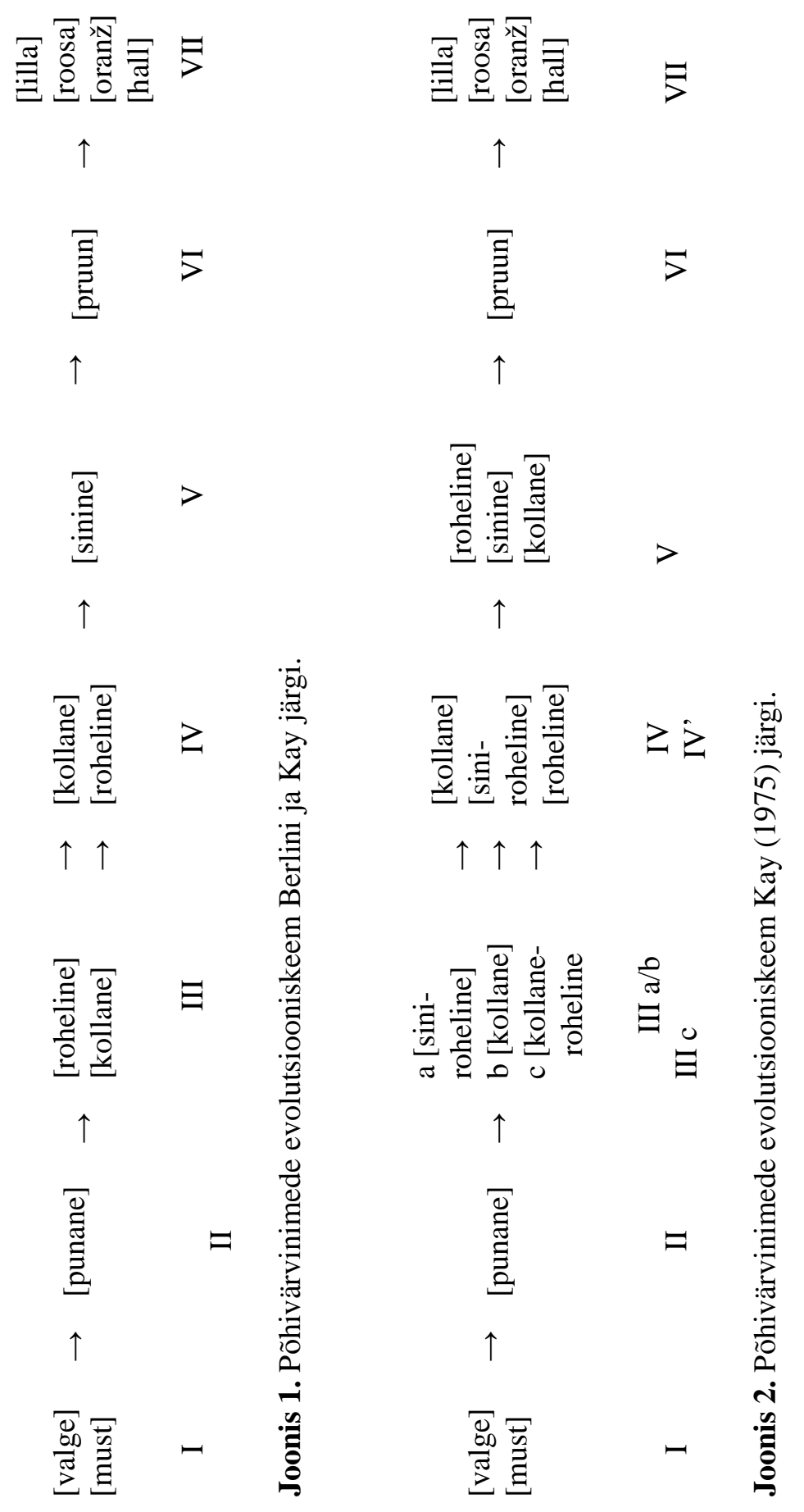




\subsection{Põhivärvinimed viipekeeltes}

Põhivärvinimesid on viipekeeltes suhteliselt vähe uuritud. James Woodward (1989), kes võrdles värvinimesid kümnes viipekeeles, tuli järeldusele, et viipekeeltes kehtivad samad universaalid mis suulistes keeltes. Woodwardi kirjeldatud kahe põhivärvinimega viipekeeltes on olemas viiped VALGE ja MUST (Providencia saare viipekeeles). Kolme põhivärvinimega viipekeeltes lisandub neile viibe PUNANE (ameerika viipekeeles). Hiina viipekeeles on Woodwardi andmetel kasutusel neli põhivärvinime: MUST, VALGE, PUNANE ja KOLLANE. Prantsuse viipekeeles on neljandaks põhivärvinimeks GRUE 'sini-roheline'. Hong Kongi viipekeele põhivärvinimede süsteem koosneb kuuest värvinimest, sisaldades viipeid MUST, VALGE, PUNANE, KOLLANE, ROHELINE ja SININE. India ja Saudi-Araabia viipekeeltes lisandub eelpool nimetatud viibetele PRUUN. Jaapani ja Taiwani viipekeeltes on kaheksa (lisandub LILLA) ning austraalia viipekeeles auslanis on üheksa põhivärvinime (lisandub ROOSA). Viipekeeltes, kus on põhivärvinimesid vähem, kasutatakse Woodwardi sõnul värvide kirjeldamiseks liitviipeid, laenamist, tuletamist ja teisi strateegiaid. Providencia saare viipekeeles osutatakse vastavat värvi objektile või kasutatakse vastavat objekti tähistavat viibet: näiteks osutatakse punasest värvusest rääkides punasele objektile või kasutatakse viibet VERI. Ameerika viipekeel laenab värvinimed ROHELINE ja SININE inglise keelest, kasutades vastava inglisekeelse sõna esimese tähe käekuju. (Woodward 1989: 149-151)

Victoria Nyst (2007), kes on uurinud ja kirjeldanud adamorobe ${ }^{5}$ viipekeelt, sõnastas ka võimalused värvinimede tekkeks viipekeeltes:

1. tuletamine: tüüpiliselt teatud värvi kandva objekti viipe tähenduse laienemine, viitamaks selle värvile;

2. osutamine: viitamine konkreetselt olemas olevale objektile ümbritsevas keskkonnas. Mitmes viipekeeles moodustatakse värvinimi osutusega kehaosale, mis tüüpiliselt seda värvi on (kulmud, hambad, huuled);

3. suulise keele sõnade artikuleerimine: vastava suulise keele sõna artikuleerimisel tekkiva suupildi kasutamine koos üldistava värviviipega;

4. Initsialiseeritud viiped: viibete moodustamine kohaliku suulise keele vastava sõna esimese tähe sõrmendiga;

5. Arbitraarsed viiped: viiped, milles puudub eespool mainitud motiveeritus (Nyst 2007: 91-92).

Viipekeeltes on levinud ka kohaliku suulise keele värvinimede sõrmendamine (Woodward 1989: 151).

Margalit Foxi (2007) kirjeldatud Al-Sayyidi küla ${ }^{6}$ beduiinide viipekeeles on kaks põhivärvinime: MUST ja VALGE (Fox 2007: 77). Ban Khori ${ }^{7}$ põlisviipe-

\footnotetext{
5 Isoleeritud viipekeel, mida kasutatakse Adamorobe külas Ghana idaosas. Külas elas 2001. aastal 1356 inimest, kurtide osakaal elanikkonnas oli 2\% (Nyst 2007: 17, 24-25)

$6 \quad$ Isoleeritud beduiinide kogukond Iisraelis, külas on ligikaudu 3500 elanikku, kellest ligi 150 on kurdid (Fox: 2007: 7)
} 
keeles (Nonaka 2004) ja adamorobe viipekeeles (Nyst 2007) on kolm põhivärvinime: MUST, VALGE ja PUNANE. Teiste värvinimede väljendamiseks kasutatakse Ban Khori viipekeeles kahte erinevat strateegiat: kui vastavat värvi objekt on vahetus läheduses olemas, osutatakse sellele, kui mitte, kasutatakse ühte kolmest olemasolevast põhivärvinimest. Kõik kolm põhivärvinime moodustatakse osutamisega kehaosadele: juustele musta, hammastele valge ja huultele punase puhul. Kuigi ajalooliselt on tegemist ikooniliste viibetega, on need kolm viibet täielikult leksikaliseerunud (Nonaka 2004: 750-751). Adamorobe viipekeele kolm põhivärvinime moodustatakse kõik ühesuguse käekuju ja liigutusega, viipeid eristab üksteisest vaid suupilt. Viipe reduplikatsiooniga on võimalik väljendada värvi intensiivsuse astet. Viiped KOLLANE ja ROHELINE aga baseeruvad sellevärvilise objekti viibetel (BANAAN PEHME või RASV KANA kollase tähenduses ning LEHED või BANAAN KÕVA vastavalt rohelise tähenduses). Kui pehme banaan kollase tähenduses on kasutusel ainult adamorobe viipekeeles, siis kana rasv kollase tähenduses ning lehed ja kõva banaan vastavalt rohelise tähenduses on kasutusel ka kohalikus suulises keeles akani keeles. Viiped sinise, lilla, halli ja pruuni tähistamiseks Nysti andmetel puuduvad (Nyst 2007: 95-96).

Mitu viipekeelte põhivärvinimesid käsitlenud autorit mainivad, et Berlini ja Kay põhivärvinime definitsioon võib viipekeelte puhul osutuda problemaatiliseks. Näiteks seatakse kahtluse alla initsialiseeritud viibete põhinime staatus, kuivõrd neid on võimalik pidada laenudeks suulistest keeltest. Lähtudes sellest, et ameerika viipekeele viiped SININE, KOLLANE ja ROHELINE moodustatakse vastava inglisekeelse sõna esitähe sõrmendiga, järeldab Woodward, et ameerika viipekeel on kolme põhivärvinimega keel, milles on omaviiped vaid musta, valge ja punase tähistamiseks (Woodward 1989: 146, 150). Initsialiseeritud viibete teket ameerika viipekeeles ja teistes prantsuse viipekeelest mõjutatud viipekeeltes selgitab üks strateegiatest, mida Abbe de l'Epeé, 1770. aastal avatud Pariisi kurtide kooli rajaja ja õpetaja, kasutas nn süstematiseeritud viibete (pr signes méthodiques) loomiseks: viipe moodustamine vastava prantsusekeelse sõna esitähe sõrmendiga. Kuna prantsuse viipekeel on ameerika viipekeelt tugevasti mõjutanud, olid nii prantsuse kui ka ameerika viipekeeltes 19. sajandi keskel olemas viiped rohelise, kollase, sinise, pruuni, roosa, oranži ja lilla tähistamiseks, nagu see on omane Berlini ja Kay kirjeldatud VII staadiumi keeltele (Stokoe 1978: 65, Stokoe 1987: 10).

Teiseks peetakse vastavalt eespool mainitud kuuendale põhinime kriteeriumile problemaatiliseks viipeid, mis on tuletatud osutusest tüüpiliselt sellevärvilisele objektile. Stokoe (1987) vastandab ameerika viipekeele värviviiped VALGE, MUST ja PUNANE initsialiseeritud viibetele ning kirjeldab esimesi kui algupäraseid viipeid, mis moodustatakse viipekeeltele omaste vähim markeeritud käekujudega vastavalt osutusega kulmudel (MUST), rinnal (VALGE) või huultel (PUNANE), kuid möönab samas, et needki kolm värvinime ei

7 Küla Tai kirdeosas, 2741 elaniku hulgas on 16 kurti, nii kuuljad kui ka kurdid külaelanikud viiplevad (Nonaka 2009: 213-214) 
pruugi olla käsitletavad põhinimedena kõige otsesemas tähenduses, kuivõrd on tegemist osutusega mustadele kulmudele, punastele huultele või valgele kraele (Stokoe 1987: 11). Ka Nyst väidab, et põhivärvinimedena peaks käsitama ainult arbitraarseid viipeid ning kuivõrd mitmes viipekeeles on esimesed kolm värviviibet värvinimede hierarhias tuletatud osutusest kehaosadele, mis tüüpiliselt seda värvi on, ei ole tegemist põhinimedega otseses tähenduses (Nyst 2007: 92). Ban Khori viipekeeles moodustatakse kõik kolm värvinime osutusega vastavalt juustele musta, hammastele valge ja huultele punase tähenduses. Samas on kõik kolm värvinime leksikaliseerunud ning kuigi viiped võivad ajalooliselt olla tuletatud osutusest, ei ole enam tegemist osutamisega (Nonaka 2004: 751).

Vaadeldes Berlini ja Kay põhinime definitsiooni, võib aga öelda, et igasugune vastuolu tegelikult puudub, kuivõrd kõikidel eespool kirjeldatud juhtudel on tegemist monolekseemsete psühholoogiliselt esiletulevate värvinimedega, mis sobivad kõikide objektide kirjeldamiseks ning on neis keeltes väidetavalt täielikult leksikaliseerunud. Seetõttu ei olegi põhjust neile värvinimedele põhinime definitsiooni lisakriteeriumeid rakendada.

\subsection{Põhivärvinimed eesti viipekeeles}

Eesti viipekeele värvinimede kolmeosaline uurimus korraldati 2005. a suvel, kasutades Ian Daviese ja Greville Corbett' välimeetodit (Davies \& Corbett 1994: 69-72; 1995: 25-27; Davies, Corbett \& Margalef 1995: 22-26; Sutrop 1995: 798-799; Sutrop 2000b, 147-148; 2002, 58). Loetelukatses paluti keelejuhil nimetada nii palju värvinimesid, kui talle meelde tuli. Seejärel kontrolliti City University testiga keelejuhi värvinägemisvõimet (Fletcher 1998). Nimeandmiskatses näidati keelejuhile juhuslikus järjekorras 65 värvitahvlit ning paluti nimetada, mis värvi need on.

Kõik testid viidi läbi loomulikus ja võimalikult hajutatud päevavalguses, ilma tugevate varjude ja otsese päikesevalguseta. Nii loetelukatse kui ka nimeandmiskatse salvestati videole ning seejärel transkribeeriti hilisemaks analüüsiks, kasutades Paabo, Födischi ja Hollmani (2009) kirjeldatud eesti viipekeele transkriptsiooni süsteemi. Taustinformatsiooni saamiseks täideti iga keelejuhi kohta lühike ankeet, kuhu märgiti tema vanus, sugu, elukoht ja päritolu, haridus ja haridustee (missuguses kurtide koolis õppinud), amet, kuulmispuude sügavus (kurtus, nürmus), esimene keel ning vanus, millal keelejuht hakkas õppima eesti viipekeelt.

Uurimuses osalesid kurdid erinevatest Eestimaa piirkondadest: Tallinnast ja Tartust kui kahest suuremast kurtide keskusest, kus on olemas kurtide koolid ja klubid ning seeläbi ka võimalused avaramaks viipekeelseks suhtluseks; Pärnust, mida peetakse piirkonnaks, kus on säilinud kõige algupärasem eesti viipekeel; ning Võrust ja Rakverest kui suhteliselt väikestest kurtide keskusest, kus kurtide vähesuse tõttu võib eeldada, et ka nende keelekasutus on kõige enam eesti keelest mõjutatud. Kokku intervjueeriti 50 kurti, sealhulgas 24 meest ja 26 naist 
vanuses 15-74 aastat. Kuigi pool uurimuses osalenutest olid kogu oma elu elanud ühes ja samas linnas, olid ainult kaks keelejuhti õppinud kohalikus kurtide koolis. Ülejäänud, olles küll elanud ühes ja samas kohas, olid oma kooliaastad siiski veetnud kuulmispuuetega laste koolides Tartus või Porkunis. Ainult üks keelejuht oli hoolimata oma kuulmispuudest õppinud tavakoolis. Keelejuhtide hulgas oli erineva haridustaustaga mitmesuguste ametite esindajaid: õmblejaid, õpetajaid, tislereid, üliõpilasi, kingseppi, pastoreid, maalikunstnik, filmioperaator, raamatukogutöötaja, koduperenaisi jt. Enamik (76\%) uurimuses osalenutest olid täiesti kurdid, 24\% kuulmisjäägiga või identifitseerisid end pigem vaegkuulja kui kurdina. Kõik küsitletud kasutasid suhtlemisel eesti viipekeelt, kuid vaid $16 \%$ olid kurtide vanemate lapsed. Lisaks sellele oli 14 protsendil uurimuses osalenud kuuljate vanemate kurtidest lastest olnud ligipääs eesti viipekeelele enne kuulmispuuetega laste õppeasutusse õppima asumist, eelkõige seetõttu, et nende peres kasvas ka kurte õdesid-vendi. Ülejäänud 70\% puutusid viipekeelega esimest korda kokku 2.-14. eluaastal kurtide lasteaeda või kooli õppima asudes. Kuigi enamik käesolevas uurimuses osalenutest ei olnud pärit kurtide kogukonna nn tuumast, esindasid nad sellest hoolimata eespool kirjeldatud tüüpilist, oma taustalt ja keelekasutuselt väga heterogeenset viipekeelset kurtide kogukonda.

Loetelukatses nimetasid 50 keelejuhti kokku 681 värvinime. Üks küsitletutest nimetas ainult 4, kaks keelejuhti seevastu 25 värvinime, keskmiselt loetles üks keelejuht 13,62 erinevat värvinime, millest keskmiselt 11,38 värvinime nimetati enne esimest pikemat mõttepausi. Seejuures nimetasid viipekeelsetest kurtide peredest pärit keelejuhid keskmiselt rohkem värvinimesid kui viipekeelt mitte valdavate kuuljate peredest pärit kurdid. Keelejuht, kes ei suutnud meenutada rohkem kui 4 värvinime, oli pärit kuuljate perest ega osanud öelda, millal ta viipekeelt õppima oli hakanud. Ta õppis vaegkuuljate koolis, mistõttu võib arvata, et enne kooli tal ilmselt viipekeelega kokkupuudet ei olnud. Järgmises katses ei olnud tal värvitahvlitele nime andmisega mingeid raskusi, kuid fakt, et ta kasutas ka nime andmisel rohkem eestikeelseid sõnu kui eesti viipekeele viipeid, kinnitab oletust, et eesti keel oli jäänud tema esimeseks keeleks ka pärast eesti viipekeele ära õppimist. Keelejuhid, kes nimetasid 25 värvinime, olid samuti kuuljate perest pärit: 68-aastane õmbleja Pärnust, kes oli juba varakult oma kurdi vennaga eesti viipekeeles suhelnud, ning 37-aastane kunstikõrgharidusega maalikunstnik. 681 värvinime sisaldas 109 erinevat viibet (sealhulgas liitviiped), mis tähistasid kokku 70 erinevat värvust. 
Tabel 1. Kõige esiletulevamad viiped loetelukatses koos sageduse (F) ja keskmise positsiooniga (mP)

\begin{tabular}{|l|l|l|r|r|r|}
\hline Nr & Viibe & Viipe eestikeelne vaste & \multicolumn{1}{|c|}{ F } & \multicolumn{1}{c|}{ mP } & Esiletulek \\
\hline \hline 1 & PUNANE 1 & punane & 43 & 2,326 & 0,370 \\
2 & SININE & sinine & 48 & 3,479 & 0,276 \\
3 & ROHELINE & roheline & 42 & 4,429 & 0,190 \\
4 & KOLLANE & kollane (44), oranž (3) & 47 & 5,340 & 0,176 \\
5 & MUST & must & 49 & 5,776 & 0,170 \\
6 & VALGE 1 & valge & 34 & 5,500 & 0,124 \\
7 & ROOSA/LILLA & roosa (27), lilla (11), & 42 & 8,143 & 0,103 \\
& & oranž (3), roheline (1) & & & \\
8 & HALL & hall (39), lilla (3) & 42 & 9,238 & 0,091 \\
9 & PRUUN & pruun & 34 & 8,088 & 0,084 \\
10 & VALGE 2 & valge & 12 & 4,250 & 0,056 \\
11 & LILLA 1 & lilla & 16 & 6,063 & 0,053 \\
12 & ORANŽ 1 & oranž (16), beež (1) & 17 & 9,118 & 0,037 \\
13 & PRUUN/BEEŽ & pruun (11), beež (3) & 14 & 8,071 & 0,035 \\
14 & BEEŽ & beež (10), kreem (1) & 11 & 11,182 & 0,020 \\
15 & ORANŽ 2 & oranz (3), beež (2) & 5 & 5,600 & 0,018 \\
16 & PUNANE 2 & punane & 4 & 4,500 & 0,018 \\
\hline
\end{tabular}

Kõige sagedamini esinev viibe nimetamiskatses oli MUST $(\mathrm{F}=49)$, sellele järgnesid SININE ( $\mathrm{F}=48)$, KOLLANE ( $\mathrm{F}=47,44$ korral kollase tähenduses, 3 korral oranži tähenduses), PUNANE $1(\mathrm{~F}=43)$, ROHELINE $(\mathrm{F}=42)$ ja HALL $(\mathrm{F}=42)$. Viibe ROOSA/LILLA $(\mathrm{F}=42)$ oli küll samamoodi sage, kuid seda kasutatati koos eestikeelsete sõnade roosa ja lilla ning isegi oranž samaaegse artikuleerimisega. Sageduse alusel järgnesid VALGE 1 ( $\mathrm{F}=34)$ ja PRUUN $(\mathrm{F}=34)$. 51 viibet nimetati loetelukatses vaid ühel korral. Esimene pikem vahe sageduste vähenemisel värviviibete pingereas loetelukatses on üheksanda (PRUUN, F=34) ja kümnenda (ORANŽ 1, F=17) värviviipe vahel.

Kõige esiletulevamaks viipeks (tabel 1) loetelukatses oli PUNANE 1. See oli küll väiksema sagedusega ning mitte nii esilduv kui mõiste punane, sest neli keelejuhti kasutasid teistsugust viibet, PUNANE 2. Esilduvuse poolest järgnesid SININE, ROHELINE, KOLLANE, MUST, VALGE 1, ROOSA/LILLA, HALL, PRUUN, VALGE 2, LILLA 1, ORANŽ 1 ja PRUUN/BEEŽ.

Keskmise positsiooni alusel oli nimetatute seas esikohal PUNANE 1, talle järgnesid SININE, VALGE 2, ROHELINE, KOLLANE, VALGE 1, MUST ja LILLA 1. PUNANE 1 oli esimesel kohal peaaegu pooltel küsitletutest (tabel 2). 
Tabel 2. Loetelukatses esimesena nimetatud viiped

\begin{tabular}{|l|r|}
\hline Viibe & Sagedus (F) \\
\hline \hline PUNANE 1 & \\
SININE & \\
MUST & 6 \\
VALGE 1 & 5 \\
ROHELINE & 4 \\
ROOSA/LILLA & 3 \\
VALGE 2 & 2 \\
KOLLANE & 2 \\
PRUUN & 2 \\
ORANŽ 1 & 1 \\
\hline Kokku & 1 \\
\hline
\end{tabular}

Loetelukatses eestikeelseid värvinimesid kuigi palju ei sõrmendatud. Võib arvata, et värvid, mille puhul keelejuhid üldjuhul kasutavad eestikeelset nimetust, jäeti loetelukatses lihtsalt välja toomata. Vaid kolm keelejuhti sõrmendasid eestikeelseid värvinimesid lilla ja roosa, üks keelejuht sõrmendas värvinime beež. Ühel korral artikuleeriti eestikeelsed värvinimed türkiis ja violett ilma viibet moodustamata. Keelejuhid osutasid lihtsalt huultele ja artikuleerisid eestikeelse sõna. Ühel korral artikuleeriti samamoodi bordoopunane.

Seega võib öelda, et kõige tõenäolisemad põhivärvinime kandidaadid eesti viipekeeles on loetelukatse tulemuste põhjal PUNANE 1, SININE, ROHELINE, KOLLANE, MUST, VALGE 1, ROOSA/LILLA, HALL ja PRUUN. Nimetatud viiped olid kõige esiletulevamad ja esinesid vähemalt poolte keelejuhtide loeteludes.

Nimeandmiskatses ei osanud keelejuhid värvitahvlile nime anda kümnel korral kõikidest võimalikest juhtudest. 125 juhul (3,8\%) ei osanud keelejuhid otsustada, missugune nimi kirjeldab värvitahvlit kõige täpsemini, ning nad andsid ühele tahvlile kaks või isegi kolm nime. Kokku andsid 50 keelejuhti 65 erinevale värvitahvlile 3374 nime, sealhulgas 578 erinevat värvusele viitavat nime, mida tähistasid 696 erinevat viibet. Vaid 225 viibet esinesid nimeandmiskatses vähemalt kahel korral. Keskmiselt anti ühele värvitahvlile 21,52 erinevat nime, mida tõlgiti keskmiselt 15,95 eestikeelseks vasteks. Seitsme tahvli puhul 65-st andsid värvitahvlile ühesuguse nime enam kui pooled keelejuhid - nende dominantsete nimede hulka kuuluvad MUST, KOLLANE, HALL, VALGE 1, SININE, PUNANE 1 ja ROHELINE (tabel 3). 
Tabel 3. Dominantsed värvitahvlite nimetused

\begin{tabular}{|rlr|}
\hline Värvitahvli kood & Eesti viipekeele viibe & Sagedus \\
\hline \hline BLACK & MUST & 41 \\
Y & KOLLANE & 37 \\
GRAY 4 & HALL & 35 \\
WHITE & VALGE 1 & 33 \\
BGB & SININE & 29 \\
RO & PUNANE 1 & 27 \\
G & ROHELINE & 27 \\
ROR T3 & ROOSA/LILLA & 21 \\
OYO & ORANŽ 1 & 19 \\
YO S3 & PRUUN & 16 \\
VRV & LILLA 1 & 13 \\
YOY S2 & BEEŽ & 8 \\
\hline
\end{tabular}

Värvinimesid, millega nimetas ühte tahvlit vähemalt pool keelejuhtidest ( $\mathrm{F}>25$, DI 1/2), on nimetamiskatses ainult seitse: MUST, PUNANE 1, SININE, VALGE 1, HALL, KOLLANE ja ROHELINE. Seejuures oli viibete MUST (SI=0,93), VALGE 1 (SI=0,87), KOLLANE $(\mathrm{SI}=0,8)$ ja PUNANE 1 (SI=0,61) kasutamisel keelejuhtide konsensus kõige suurem (tabel 4).

Jättes loetelust välja viiped, mis ei vasta põhivärvinime esimesele kriteeriumile, on nimeandmiskatse tulemuste põhjal kõige esiletulevamad värvinimed nende esinemise kogusageduse ja värvitahvlite arvu, mille puhul neid nimetati, suhte alusel MUST, PUNANE 1, SININE, VALGE 1, PRUUN, HALL, KOLLANE, ROHELINE, ORANŽ 1 ja ROOSA/LILLA. Viibet PRUUN/BEEŽ nimetati küll kokku 37 korral, kuid tervelt 13 erineva värvitahvli puhul, seejuures ei olnud viibe ühelgi korral värvitahvli dominantseks nimetuseks. Sama võib öelda valge teise viipe kohta: mitte ühelgi juhul ei ole tegemist dominantse nimetusega. 17 korral sõrmendatud eestikeelne värvinimi r-o-o-s-a langeb põhivärvinime kandidaatide hulgast välja juba seetõttu, et tegemist on eestikeelse värvinimega. Lilla sageduselt teist viibet LILLA 2 kasutati nimeandmiskatses kokku 17 korral 11 värvitahvli puhul. 
Tabel 4. Kõige sagedasemad värvinimed nimeandmiskatses: kogusagedus/värvitahvlite arv (F/T $>5)$, kogusagedus (F), sagedus dominantsete värvitahvlite puhul (DF), dominantsusindeks (DI $1 / 2$ ) ja spetsiifilisusindeks (SI)

\begin{tabular}{|r|l|r|r|r|r|r|}
\hline Nr & Eesti viipekeele viibe & F/T & F & DF & DI 1/2 & $\begin{array}{r}\text { SI } \\
\text { (DF/F) }\end{array}$ \\
\hline \hline 1 & MUST & 14,67 & 88 & 82 & 2 & 0,93 \\
2 & PUNANE 1 & 12,14 & 85 & 52 & 2 & 0,61 \\
3 & SININE & 10,83 & 130 & 54 & 2 & 0,42 \\
4 & ROHELINE TUME & 9,82 & 108 & 66 & 2 & 0,61 \\
5 & VALGE 1 & 9,50 & 38 & 33 & 1 & 0,87 \\
6 & HALL TUME & 9,40 & 47 & 31 & 1 & 0,66 \\
7 & HALL HELE 1 & 9,20 & 46 & - & - & - \\
8 & SININE TUME & 8,67 & 130 & 85 & 3 & 0,65 \\
9 & ROHELINE HELE 1 & 8,67 & 78 & - & - & - \\
10 & PRUUN TUME & 8,50 & 85 & 26 & 1 & 0,31 \\
11 & PRUUN & 8,09 & 89 & - & - & - \\
12 & HALL & 7,69 & 100 & 35 & 1 & 0,35 \\
13 & KOLLANE & 7,55 & 83 & 66 & 2 & 0,80 \\
14 & ROHELINE & 7,42 & 89 & 27 & 1 & 0,30 \\
15 & SININE HELE 1 & 6,86 & 48 & - & - & - \\
16 & ORANŽ 1 & 6,57 & 46 & - & - & - \\
17 & ROHELINE HELE 2 & 5,36 & 59 & - & - & - \\
18 & ROOSA/LILLA & 5,32 & 133 & - & - & - \\
\hline
\end{tabular}

Kuigi PRUUN, ORANŽ 1 ja ROOSA/LILLA on samuti dominantsed värvitahvlite nimetused, jääb nende nimetamissagedus kõikide tahvlite puhul alla 25. ROOSA/LILLA on seejuures kogusageduselt nimeandmiskatses kõige enam esinev viibe $(F=133)$ ning ROOSA/LILLA ja PRUUN on esiletulevad ka loetelukatse tulemuste põhjal. Viipe PRUUN kogusagedus on nimeandmiskatses isegi suurem kui viibete MUST, PUNANE 1 ja KOLLANE sagedus. ORANŽ 1 seevastu esineb vaid 17 keelejuhi loeteludes ja selle kogusagedus nimeandmiskatses on vaid 46 .

Kahe katse tulemusi kokku võttes võib öelda, et kõige esiletulevamateks värvinimedeks, mis vastavad ka teistele põhivärvinime kriteeriumitele, on eesti viipekeeles viiped MUST, VALGE 1, PUNANE 1, SININE, KOLLANE, ROHELINE, PRUUN, HALL ja ROOSA/LILLA. Nimeandmiskatses olid dominantseteks värvinimedeks ka initsialiseeritud viiped ORANŽ 1, LILLA 1 ja BEEŽ, mis kõik moodustatakse vastavalt O, L ja B sõrmendiga, kuid loetelukatses nimetati neid oluliselt vähem kui teisi värvinimesid.

Viibete MUST (joonis 3a) ja HALL (joonis 3b) kogusagedus on nimetamiskatses sama suur kui mõistete must ja hall sagedus, millest võib järeldada, et need viiped on ainsad selles tähenduses kasutatavad viiped. 


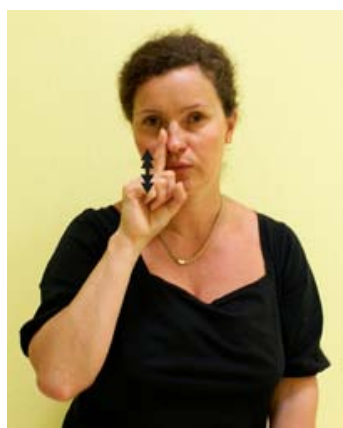

(a) MUST

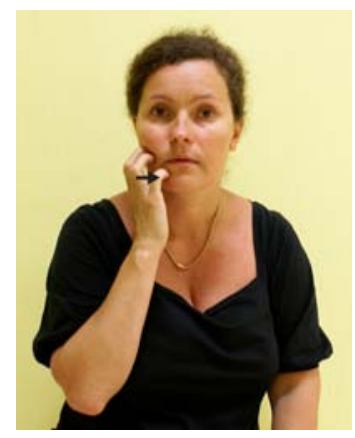

(b) HALL

Joonis 3. Eesti viipekeele viiped MUST ja HALL.

Teadaolevalt puuduvad nimetatud viibetel ka naaberviipekeeltes vormilt ja tähenduselt sarnased vasted. MUST esineb käesolevas uurimuses kahes variandis: ühekordse ja korduva liigutusena. Võiks arvata, et ühekordne liigutus annab viipele sügavmusta ja korduv liigutus mustja tähendusvarjundi, kuid see oletus käesoleva uurimuse tulemustele toetudes kinnitust ei leidnud.

Viibet MUST võiks pidada ilma selge algupärata omaviipeks, kuid motiveerituse puudumine võib samas osutuda vaieldavaks. Viibet on seostatud ka eesti keelele omase musta ja määrdunud tähendusseose ülekandega ja viitega mustale või väärdunud ninale. Samas on võimalik ka motiveeritus eesti keele häälikuõpetuses kasutatavast metoodikast, kus vibratsiooni tunnetamiseks nasaalide hälldamisel asetatakse nimetissõrm ninale.

Viibe HALL esineb kahes variatsioonis, korduva ja ühekordse liigutusena. Siingi ei leidnud käesoleva uurimuse tulemuste põhjal kinnitust ühekordse liigutuse tähendusvarjund hall ja korduva liigutuse hallikas. Viibe võib olla motiveeritud habemest, mis on tüüpiliselt halli värvi.

Viibe VALGE 1 (joonis 4a) ei esine nii sageli kui viibe MUST, sest kasutusel on ka teine viibe VALGE 2 (joonis $4 \mathrm{~b}$ ). Siiski on esimene neist oluliselt esiletulevam. Viibe ei sarnane vene, soome ega ameerika viipekeele viibetega VALGE ning tema teket eesti viipekeelde seostatakse osutusega käeselja valgele nahale. VALGE 2 puhul on ilmselt tegemist tähenduse laienemisega. Sama viibe kannab eesti viipekeeles tähendust puhas. Valge tähenduses kasutasid seda käesolevas uurimuses enamasti vanemad kurdid Pärnu piirkonnast. VALGE 1 kasutajad olid seevastu nooremad keelejuhid erinevatest Eestimaa paikadest. 


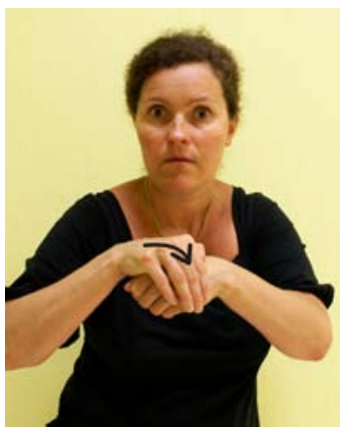

(a) VALGE 1

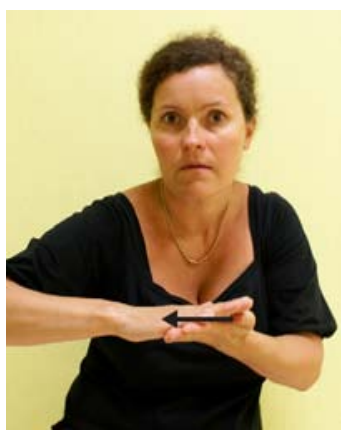

(b) VALGE 2 / PUHAS

Joonis 4. Eesti viipekeele viiped VALGE 1 ja VALGE 2.

Punase nimedena on eesti viipekeeles samuti kasutusel kaks viibet. PUNANE 1 (joonis 5a), mis moodustatakse A, F või S käekujuga põsel, on nimetamiskatses kõige esiletulevam viibe ning nimeandmiskatses viipe MUST järel teisel kohal. Viibelduna F käekujuga on viibe väga sarnane soome viipekeele viipega ROOSA (VAALEANPUNAINEN) ning arvatavasti motiveeritud osutusest põsepunale. Osutusega huultele on eesti viipekeel tuletanud ilmselt teise punase viipe (joonis 5b), mis on käesoleva uurimuse tulemustele toetudes siiski väga harv. Viibet PUNANE 2 kasutasid enamasti vanemad inimesed (keskmiselt 60 aasta vanused) erinevatest Eestimaa piirkondadest. Sama viibe samas tähenduses on kasutusel ka vene ja ameerika viipekeeltes, mistõttu ei ole võimalik päris kindlalt öelda, kas viipe sarnasus on tingitud loomulikust tendentsist tähistada punast värvust osutusega huultele kui selle värvi tüüpilistele kandjatele või on see keelte omavahelise mõju tulemus.

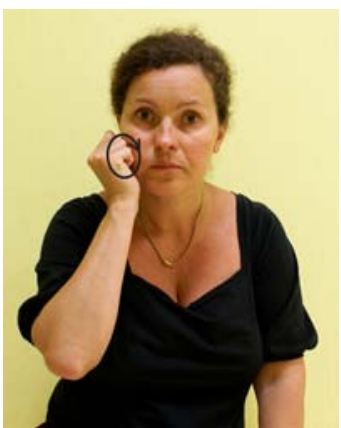

(a) PUNANE 1

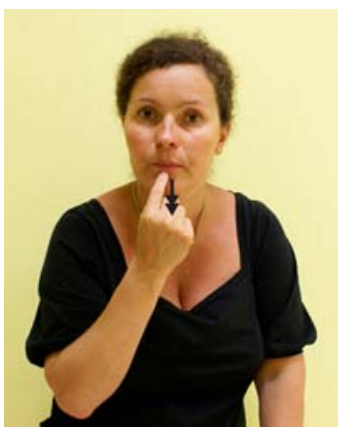

(b) PUNANE 2

Joonis 5. Eesti viipekeele viiped PUNANE 1 ja PUNANE 2. 
Eesti viipekeeles tähistab sama viibe ka veini ja veinipunast. Arvatakse ka, et kahe erineva punase viipe kasutus sõltub värvi kandjast: kui abstraktset värvi tahvliga seostub eelkõige PUNANE 1, siis näiteks jookide iseloomustamisel kasutatakse rohkem varianti PUNANE 2. Ühelt poolt selgitaks see käesolevas uuringus PUNANE 2 vähest esinemist, kuid samas välistaks selle võimaliku käsitlemise põhivärvinimena ka sagedasema esinemise puhul, kuna vastavalt Berlini ja Kay põhinime definitsioonile peab põhivärvinime saama kasutada kõikide objektide kirjeldamiseks. Käesolevas uuringus anti siiski viibet PUNANE 2 värvitahvlitele nimeks sagedamini, kui seda nimetati loetelukatses.

Kahe katse tulemuste põhjal on esiletulevad ning peaaegu ainsad viiped nende värvide tähistamiseks eesti viipekeeles ka värvinimed KOLLANE (joonis 6a) ja SININE (joonis 6b). Mõlema viipe puhul on ilmselgelt tegemist laenudega vene viipekeelest. Eespool mainitud eesti ja vene viipekeele viibete võrdlev uuring Swadeshi nimekirja alusel sisaldab andmeid ka nende kahe keele mõne värvinime kohta. Swadeshi nimekirjas on 5 põhivärvinime: must, valge, punane, roheline ja kollane. Taniroo tulemustele toetudes on neist eesti ja vene viipekeeles identne vaid viibe KOLLANE (Taniroo 2007: 23). Käesoleva uurimuse tulemuste põhjal ühtib vene viipekeele sõnaraamatu variandiga ka eesti viipekeele SININE.

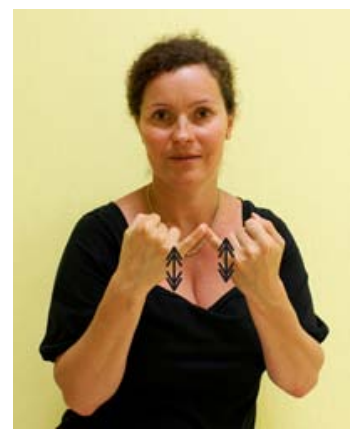

(a) KOLLANE

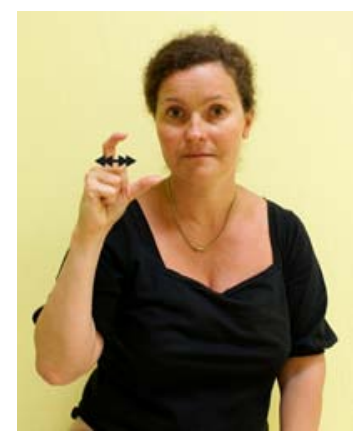

(b) SININE

Joonis 6. Eesti viipekeele viiped KOLLANE ja SININE.

Viipe KOLLANE käekuju, liigutus ja moodustuskoht viitavad seejuures ameerika viipekeele viipele KOLLANE (Y käekuju viipest YELLOW või J käekuju prantsuse viipekeele viipest JAUNE). Kuigi ameerika viipekeeles on tegemist ühekäeviipega, on eesti ja vene viipekeele KOLLANE kindlasti kahekäeviibe. Võib oletada, et eesti viipekeele KOLLANE on prantsuse - ameerika viipekeelte algupäraga, oma algselt moodustuskohalt küljel keha keskossa liikunud ja nagu neutraalruumis moodustatavatele viibetele omane kahekäeviipeks muutunud viibe.

Viibe ROHELINE (joonis 7) esineb kolmes variandis - neutraalruumis liigutusega ülevalt alla ja liigutusega alt üles ning liigutusega ülevalt alla näo ees. 


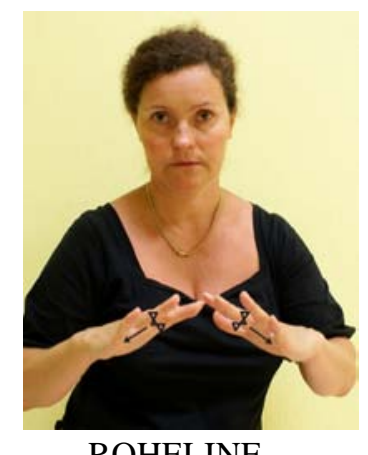

Joonis 7. Eesti viipekeele viibe ROHELINE.

Eesti viipekeele viibe ROHELINE oma erinevate variantidega näib täpselt illustreerivat Frishbergi (1975) kirjeldust viipe vormi diakroonilisest muutumisest.

Kuna viipe ROHELINE oletatavasti kõige algupärasem variant (neutraalruumis kaarja liigutusega alt üles moodustatud kahekäeviibe) on identne viipega JÕULUD, võib oletada, et viibe on algselt olnud motiveeritud rohelisest jõulukuusest. Viibet kasutasid enamasti Pärnust ja Tartust pärit vanemad kurdid (keskmine vanus 61 aastat). Mõlemas katses oli selle viipevariandi osakaal teistega võrreldes kõige väiksem (22,5\%). Viibe moodustati enamasti kahe käega, nimeandmiskatses artikuleeriti viipe seda varianti vaid 9,9 protsendil juhtudest ühe käega. Kõige sagedasem oli aga viipe ROHELINE variant, mille moodustuskoht on liikunud ülespoole ning mis artikuleeritakse lihtsama diagonaalse liigutusega ülevalt alla (vt joonis 6). Seda viibet kasutasid keskealised kurdid (keskmise vanusega 42 aastat) erinevatest piirkondadest. Tegu oli enamasti kahekäeviipega, loetelukatses moodustati viibe kõikidel juhtudel kahe käega, vaid 6,4 protsendil juhtudest moodustati viibe nimeandmiskatses ühe käega. Erinevate piirkondade nooremad kurdid (keskmise vanusega 27 aastat) kasutasid enim aga kolmandat varianti - viibe on liikunud näo ette ning on oletatavasti muutumas ühekäeviipeks: 39,5 protsendil juhtudest moodustati nimeandmiskatses viibe juba ühe käega.

Viibe PRUUN (joonis 8a) on eesti viipekeelde tekkinud ilmselt tüüpiliselt seda värvi kandva objekti viipe tähenduse laienemise kaudu. Peaaegu identne on eesti viipekeele viibe KOHV (joonis 8b), mis 1988. aasta sõnaraamatu põhjal moodustatakse paari väikese erinevusega (käte asend üksteise kohal, mitte peal; liigutus on suurema ulatusega; viipe PRUUN puhul võib ringliigutus olla asendatud ka edasi-tagasi liigutusega). Kuigi viibe KOHV omakorda on siiani äratuntavalt motiveeritud tüüpilisest kohvi jahvatamise liigutusest, on väga raske öelda, kas tegemist on eesti viipekeele viipega. Sama viibe kohvi tähenduses on kasutusel ka näiteks ameerika, soome ja mitmes teises viipekeeles. Vene viipekeeles aga tähendab viibe just pruuni, mistõttu võib eesti viipekeeles 
kasutusel olev PRUUN olla ka juba laienenud tähendusega laen vene viipekeelest.

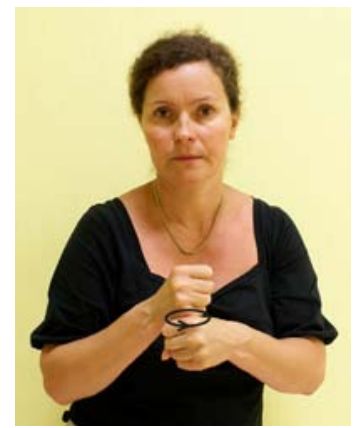

(a) PRUUN

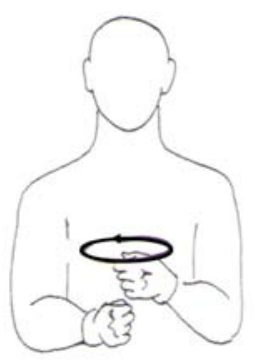

(b) KOHV

Joonis 8. Eesti viipekeele viiped PRUUN ja KOHV.

Sagedast kasutust leidis uuringu tulemuste põhjal ka viibe ROOSA/LILLA (joonis 9), mida keelejuhid kasutavad kas roosa, lilla või mõlema tähistamiseks.

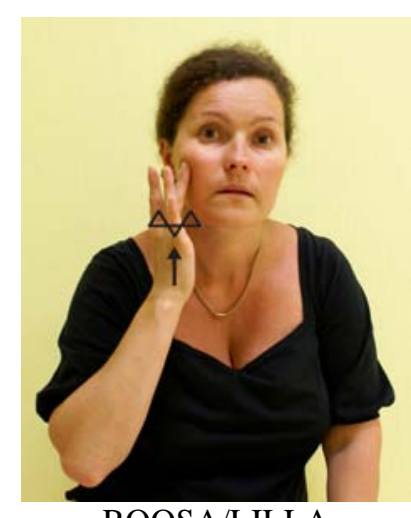

ROOSA/LILLA

Joonis 9. Eesti viipekeele viiped ROOSA/LILLA.

Viibet ROOSA/LILLA kasutatakse mõlema katse tulemuste põhjal nii roosa kui ka lilla tähenduses, kusjuures ükski keelejuht ei kasuta viibet ainult lilla tähenduses, nimetades seejuures roosat mõne muu viipega. Vaid kaks keelejuhti sõrmendavad eestikeelse sõna $r$-o-o-s- $a$, et neid kahte nime eristada. Keelejuhid, kes kasutavad viibet nii roosa kui ka lilla tähistamiseks, ei kasuta üldjuhul muid viipeid, vaid ühel juhul nimetatakse kahe värvitahvli puhul (V ja VBV T4) viibet LILLA 1, teistel juhtudel kasutatakse ROOSA/LILLA kõrval ka ühendeid PUNANE HELE, PUNANE SININE KOOS ja KIRSS VÄRV. 
Jälgides kõiki juhte, kus viipeid ROOSA/LILLA, LILLA 1 või LILLA 2 kasutatakse nii lihtviipena kui pikema kirjelduse osana nende värvitahvlite kirjeldamisel, mille dominantseks nimeks on ROOSA/LILLA või LILLA 1, on näha, et punase ning punase ja oranži vahetoonide (värvitahvlid R T4, RO T3 ja ROR T3) kirjeldamisel kasutatakse eelkõige viibet ROOSA/LILLA. Seejuures on viibe sagedam heledate variantide kirjeldamisel (RO T3, ROR T3 ja R T4) ja harvem tumedate variantide kirjeldamisel (ROR S3 ja RVR S1). Punase ja lilla vahetoonide puhul väheneb aga viipe ROOSA/LILLA kasutus oluliselt (RVR S1, RVR S3, RV ja VRV), samal ajal tähistatakse heledamaid variante ikka pigem viipega ROOSA/LILLA (RV T2). Lilla ja sinise vahetoonide puhul muutub aga dominantseks viibe LILLA 1, seda isegi heledamate variantide puhul (VBV T4), kuigi osa keelejuhte jääb ka siin kasutama viibet ROOSA/LILLA (joonis 10).

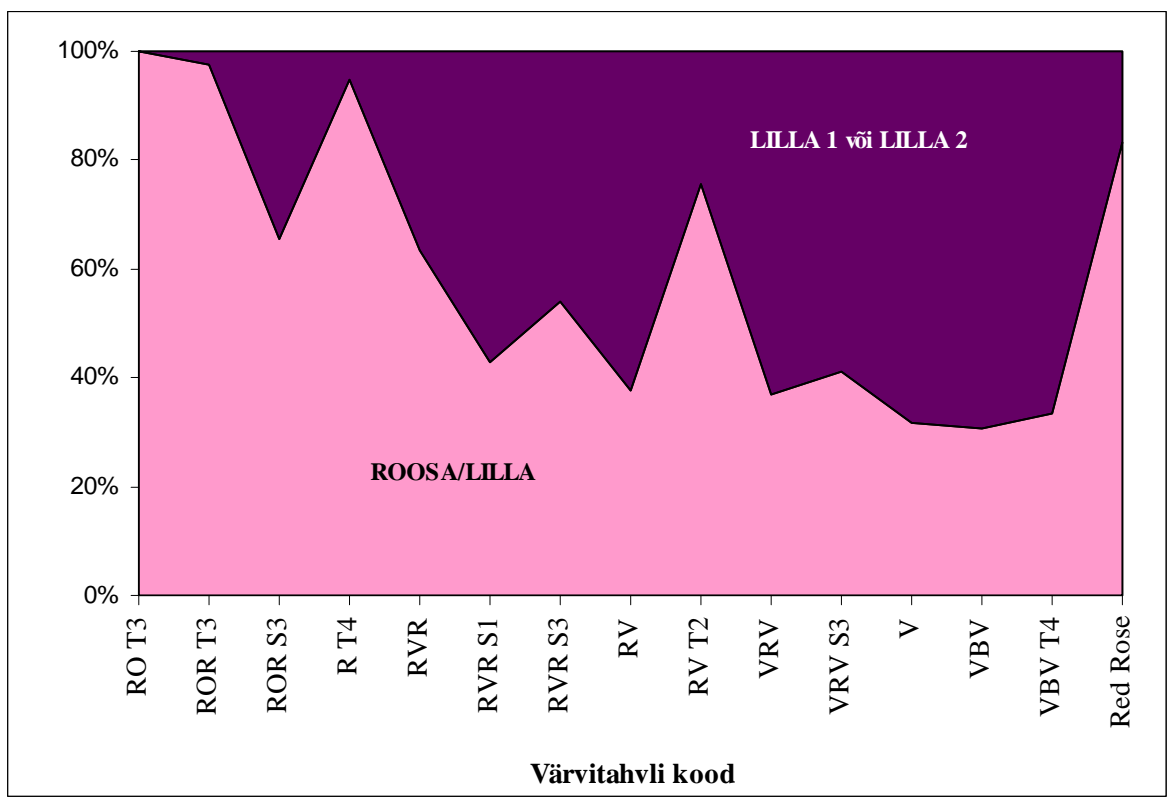

Joonis 10. Viibete ROOSA/LILLA, LILLA 1 ja LILLA 2 kasutus nimeandmiskatses.

Seega võib arvata, et viibe ROOSA/LILLA katab värviruumis tegelikult nii roosa kui ka lilla piirkonda sarnaselt värvinimega grue, mis katab sinist ja rohelist värviruumi piirkonda. LILLA 1 on seejuures ilmselt järgmine ROOSA/ LILLA värvinimest eristuv põhivärvinimi, mis põhinimena eesti viipekeelde tekib.

Initsialiseeritud viibete näideteks eesti viipekeele värvinimede seas on ORANŽ 1 (joonis 11a), LILLA 1 (joonis 11b) ja BEEŽ (joonis 11c). Seejuures on võimalik, et viipe BEEŽ, mis moodustatakse küll B käekujuga, tekkelugu on tegelikult seotud ühe viipe HELE variandiga, mis moodustatakse sama käekujuga samas kohas. 


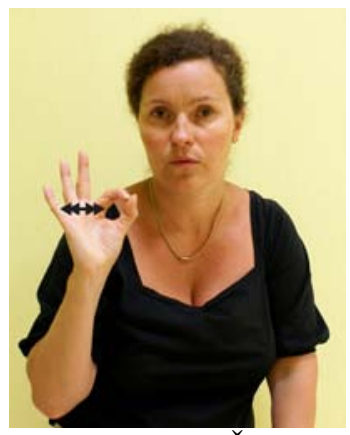

(a) ORANŽ 1

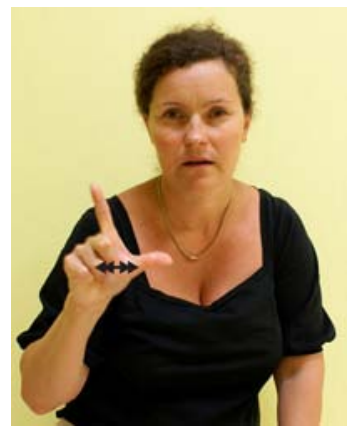

(b) LILLA 1

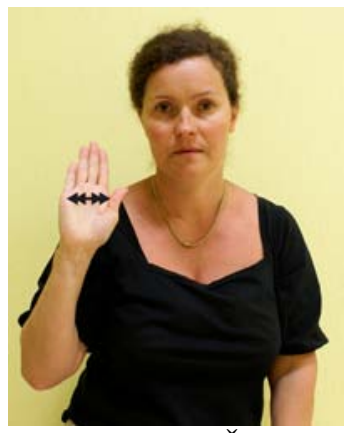

(c) BEEŽ

Joonis 11. Eesti viipekeele viiped ORANŽ 1, LILLA 1 ja BEEŽ.

Kuigi kõigi nende värvuste tähistamiseks on kasutusel ka arvukalt teisi viipeid (6 erinevat viibet nii lilla kui ka oranži tähistamiseks), on eesti keelest motiveeritud variandid käesoleva uurimuse tulemuste põhjal kõige levinumad. Nimeandmiskatses olid kõik kolm viibet kolmel korral ka värvitahvli kõige sagedasemaks nimetuseks, kuid nimetamiskatses jäi nende sagedus siiski oluliselt madalamaks.

Ülaltoodut kokku võttes võib öelda, et eesti viipekeeles on üheksa põhivärvinime: MUST, VALGE 1, PUNANE 1, KOLLANE, ROHELINE, SININE, HALL, PRUUN ja ROOSA/LILLA. Seega kinnitavad käesoleva uurimuse tulemused Berlini ja Kay teooria kehtivust eesti viipekeeles, mida võib pidada VII staadiumis või arengujärgus olevaks keeleks (joonis 12). ORANŽ 1 ja LILLA 1 on küll nimeandmiskatse tulemuste põhjal küllaltki levinud, kuid mõlema värvuse tähistamiseks kasutatakse ka mitut teist viibet. Kui Berlini ja Kay sõnastatud seaduspärasuste alusel esmalt keelde ilmuvate värvinimede hulgas on eesti viipekeeles rohkem omaviipeid (MUST, VALGE 1, VALGE 2, HALL), siis keele arengu hilisematel etappidel ilmuvate värvinimede hulgas tulevad esile pigem laenud teistest viipekeeltest (KOLLANE, SININE) ning initsialiseeritud viibete näol ka kohalikust suulisest keelest (ORANŽ 1, LILLA 1). Kuigi viibete KOLLANE ja SININE puhul on tegemist laenudega vene viipekeelest, kinnitab nende kuulumist põhinimede hulka esiletulek mõlemas katses. ORANŽ 1 ja LILLA 1 on aga tõenäoliselt järgmised värvinimed, mis eesti viipekeeles põhinime staatuse saavad.

Põhivärvinime definitsiooni kehtivus viipekeelte puhul eesti viipekeele taustal küsitavaks ei osutu. Initsialiseeritud viiped ei ole piisavalt esiletulevad ning viiped, mis on motiveeritud osutusest, on oma vormilt muutunud ja eristuvad selgelt osutuvast liigutusest. 

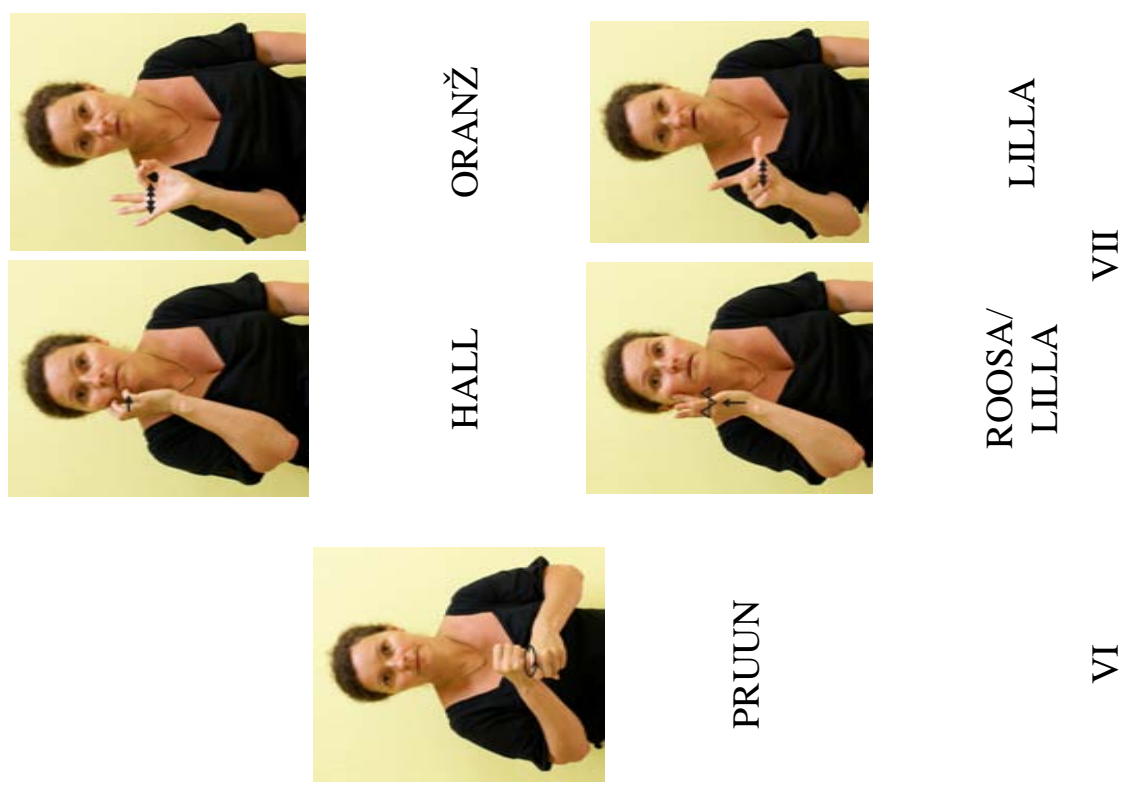

$z$
$\vdots$
$\vdots$
$\vdots$
$a$

5

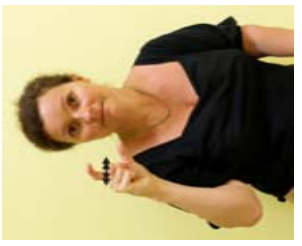

点

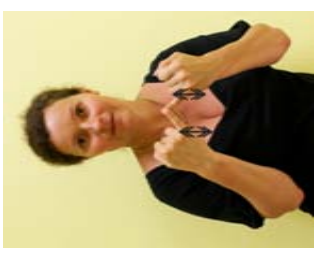

意

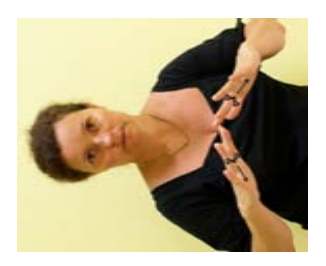

罗買当

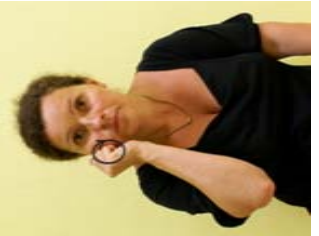

百

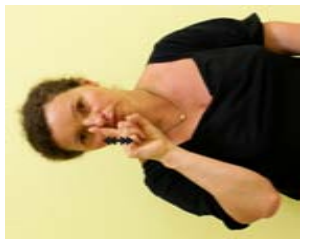

占

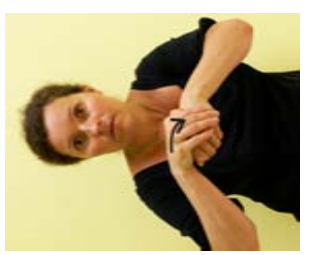

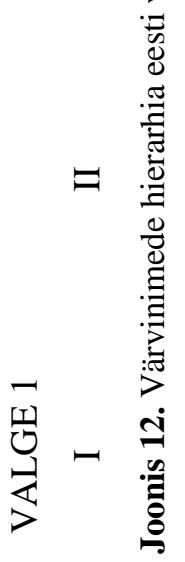




\section{REFERENCES}

Anderson, Diane 2006. Lexical Development of Deaf Children Acquiring Signed Languages. - Advances in Sign Language Development of Deaf Children. Oxford University Press, pp 135-160.

Battison, Robin; Jordan, I. King 1976. Cross-Cultural Communication with Foreign Signers. - Sign Language Studies. Vol 10.

Berlin, Brent; Kay, Paul 1969. Basic Color Terms, Their Universality and Evolution. University of California Press. Berkeley.

Crawford, T. D. 1982. Defining "Basic Color Term”. - Anthropological Linguistics 24, pp 338-343.

Davies, Ian R. L.; Macdermid, Catriona; Corbett, Greville G.; McGurk, Harry; Jerrett, David; Jerrett, Tiny, Sowden, Paul 1992. Color terms in Setswana: a linguistic and perceptual approach. - Linguistics 30, pp 1065-1103.

Davies, Ian R. L.; Corbett, Greville G. 1994. The basic color terms of Russian. - Linguistics 32, pp 65-89.

Davies, Ian R. L.; Davies, Christine; Corbett, Greville G. 1994. The basic colour terms of Ndebele. - African Languages and Cultures 7, pp 36-48.

Davies, Ian R. L.; Corbett, Greville G. 1995. A practical field method for identifying probable basic colour terms. - Languages of the World 9, pp 25-36.

Davies, Ian R. L.; Corbett, Greville G.; Margalef, José Bayo 1995. Colour terms in Catalan: An investigation of eighty informants, concentrating on the purple and blue regions. - Transactions of the Philological Society 93, pp 17-49.

Eriksson, Per 1998. The History of Deaf People. A Source Book. Tryckmakarna I Örebro AB.

EKL VL 2008. E-viiped kõigile. [E-signs for everybody, DVD produced by Estonian Association for Parents of Deaf Children].

Fletcher, Robert 1998. The City University Colour Vision Test. 3rd ed. London: Keeler.

Fox, Margalit 2007. Talking Hands. Simon \& Schuster.

Frishberg, Nancy 1975. Arbitrariness and Iconicity: Historical Change in American Sign Language. - Language, Vol. 51, No 3, pp 696-719.

Hollman, Liivi 2008. Why black is MUST and white is VALGE. On colour terms in Estonian Sign Language. - Keel ja Kirjandus No 11, pp 847-862.

Hollman, Liivi; Sutrop, Urmas 2009-submitted. Basic color terms in Estonian Sign Language.

Johnston, Trevor; Schembri, Trevor 2007. Australian Sign Language. An introduction to sign language linguistics. Cambridge University Press.

Kay, Paul 1975. Synchronic variability and diachronic change in basic color terms. - Language and Society 4, pp 257-270.

Kay, Paul; Berlin, Brent; Merrifield, William 1991. Biocultural Implications of Systems of Color Naming. - Journal of Linguistic Anthropology, pp 1225.

Kay, Paul; Maffi, Luisa. 1999. Color Appearance and the Emergence and Evolution of Basic Color Lexicons. - American Anthropologist, pp 743-760.

Kay, Paul; McDaniel Chad K. 1978. The linguistic significance of the meanings of basic color terms. - Language 54, pp 610-646. 
Kay, Paul; Regier, Terry. 2006. Language, thought and color: recent developments. - Trends in Cognitive Sciences 10, pp 51-54.

Kay, Paul; Regier, Terry 2007. Color naming universals: The case of Berinmo. Cognition 102, pp 289-298.

Kivisild, Kai; Toom, Regina 1990. Eesti kristlikud viiped. [Estonian Christian Signs]. Tartu, Stockholm.

Kotsar, Juta; Kotsar, Kaarel 1997. Eesti kurtide elu ajaraamat. Esimene osa. [Chronicles of the Estonian Deaf I]. Tallinn.

Kreutzwald, Friedrich Reinhold 1849. Sõrme-keele pookstavid. Ma-ilm ja mõnda, mis seal sees leida on. [Letters of the Finger-Language. In The World and Something of What It Contains]. Neljas and. [The fourth issue], pp. 123-125.

Kyle, Jim G; Woll, Bencie 1995. Sign Language. The study of deaf people and their language. Cambridge University Press.

Laiapea, Vahur 1992. Mis on viipekeel. [What is sign language?]. - Akadeemia 10, pp 2098-2136.

Laiapea, Vahur 2001. Kuulja märkmeid kurtidest, viipekeeltest ja nende iseolemisest. [Notes on the Deaf by a hearing person - sign language and Deaf identity]. Akadeemia 12, pp 2603-2623.

Laiapea, Vahur 2007. Keel on lahti. Tähendusi viipekeelest. [Estonian Sign Language: language, deaf children and the Deaf identity]. Eesti Keele Sihtasutus.

Laiapea, Vahur; Miljan, Merilin, Sutrop, Urmas; Toom, Regina 2003. Eesti viipekeel. [Estonian Sign Language]. Eesti Keele Sihtasutus. Tallinn.

Lucas, Ceil 2000. Language contact phenomena in deaf communities. - Estudios de Sociolingüístic 1 (1), pp. 145-152.

Miljan, Merilin 2000. The Noun Phrase in Estonian Sign Language from the Typological Perspective. BA Thesis. Estonian Institute of Humanities. Tallinn.

Miljan, Merilin 2001. Adjectival Modification in Estonian and Estonian Sign Language. - Estonian Typological Studies V. Publications of the Department of Estonian of the University of Tartu 18. Tartu, pp 169-188.

Miljan, Merilin 2003. Number in Estonian Sign Language. - Trames 2003, 7(57/52), 3, pp 293-223.

Nonaka, Angela, M 2004. The forgotten endangered languages: Lessons on the importance of remembering from Thailand's Ban Khor Sign Language. - Language in Society 33, pp 737-767.

Nonaka, Angela, M 2009. Estimating size, scope, and membership of the speech/sign communities of undocumented indigenous/village sign languages: The Ban Khor case study. - Language \& Communication 29, pp 210-229.

Nyst, Victoria 2007. A Descriptive Analysis of Adamorobe Sign Language (Ghana). LOT, Utrecht University.

Paabo, Regina; Födisch, Monika, Hollman, Liivi 2009. Rules for Estonian Sign Language transcription - Trames, 13, 4, pp 401-424.

Paales, Liina 2002. Isiku- ja kohanimed eesti kurtide märgipärimuses. [Name Signs for Persons and Places in Estonian Deaf Folklore] - Lemmeleht. Pro Folkloristika IX. Eesti Kirjandusmuusum. Tartu, pp 154-167.

Plato 1976. The Cratylus of Plato. - Cratylus, Phaedo, Parmenides, Timaeus and Critias of Plato. Wizards Bookshelf, Minneapolis, pp 7-84.

Püvi, Egle 2006. Eesti viipekeele keroloogiasüsteemi kirjeldus. [Description of Estonian Sign Language Chereology]. BA Thesis. University of Tartu. 
Reagan, Timothy, G 1990. The Development and Reform of Sign Languages. Language Reform. History and Future. Ed-s İstván Fodor \& Claude Hagège. Helmut Buske Verlag, Hamburg, pp 253-267.

Saarep, Olev 1978. Sõrmendid. [Fingerspelling alphabet]. ENSV Haridusministeerium, Tallinn.

Sallagoity, Pierre 1975. The Sign Language of Southern France. - Sign Language Studies Vol 7.

Sandler, Wendy; Lillo-Martin, Diane 2006. Sign Language and Linguistic Universals. Cambridge University Press.

Schermer, Trude 1987. Bernard Tervoort. - Sign and School. Ed. Kyle, J. Multilingual Matters Ltd. Clevedon, Phildelphia, pp 1-3.

Siple, Patricia 1978. Visual Constraints for Sign Language Communication. Sign Language Studies Vol 19, 1978.

Stokoe, William 1978. Sign Language Structure. Linstok Press.

Stokoe, Wiliam 1987. Lexical Indicators of Cultural Change. - Sign and School. Ed. J.Kyle. Multilingual Matters LTD, pp 7-11.

Stokoe, William 2005. Visible Verbs Become Spoken. - Sign Language Studies, Vol.5, No 2, pp 152-169.

Sutrop, Urmas 2000a. Estonian Sign Language. - Ethnologue: Volume 1. Languages of the World 14th ed. Barbara F. Grimes, ed. Dallas, Texas: Summer Institute of Linguistics, Inc., sub. Estonia, p 663.

Sutrop, Urmas 2000b. The Basic Color Terms of Estonian. - Trames, 4(54/49), 1, pp 143-168.

Sutrop, Urmas 2001. List Task and a Cognitive Salience Index. - Field Methods, Vol. 13, No. 3, pp 263-276.

Sutrop, Urmas 2002. The Vocabulary of Sense Perception in Estonian: Structure and History. Opuscula Fenno-Ugrica Gottingensia. Frankfurt am Main: Peter Lang.

Sutton-Spence, Rachel; Woll, Bencie 2003. The Linguistics of British Sign Language. An Introduction. Cambridge University Press.

Zeshan, Ulrike 2005. Sign Languages. - The World Atlas of Language Structures. Oxford University Press, pp 558-559.

Taniroo, Liisi 2007. Eesti viibete võrdlus vene viibetega Swdesh 200 nimekirja alusel. [Comparison of ESL signs to Russian Sign Language signs according to Swadesh word list 200]. BA Thesis. University of Tartu 2007.

Toom, Regina 1988. Kõnelevad Käed. Eesti viipekeele sõnaraamat. [Talking Hands. Estonian Sign Language Dictionary]. University of Tartu, Estonian Association of the Deaf.

Toom, Regina 1990. Abimaterjale eesti viipekeele omandamiseks. [Guidelines for learners of Estonian Sign Language]. University of Tartu, Estonian Association of the Deaf.

Toom, Regina 2002. Kurtide keeleline variatiivsus kommunikatsioonis. [Language Diversity in the Communication of Deaf People]. - Eripedagoogika. Logopeedia ja emakeel 2002 No 3, pp 25-32.

Toom, Reigina, 2003. Üks perekond - kaks keelt ja kultuuri. [One Family - Two Languages and Cultures]. - Haridus kõigile 2003. University of Tartu, pp 185-189.

Trükmann, Monika 2006. Ajasuhete väljendamine eesti viipekeeles. [Temporal Relations in Estonian Sign Language]. MA Thesis. University of Tartu.

Toom, Reigina; Trükmann, Monika; Hollman, Liivi 2006. Eesti viipekeele transkriptsioonist. [Estonian Sign Language Transcription]. Preliminary version Eesti Rakenduslingvistika Ühingu Aastaraamat 2, pp 285-301. 
Uusküla, Mari 2006. Distribution of colour terms in Ostwald's colour space in Estonian, Finnish, Hungarian, Russian and English - Trames, 10, 2, pp 152-168.

Uusküla, Mari 2007. The basic colour terms of Finnish - SKY Journal of Linguistics, 20, pp 367-397.

Uusküla, Mari 2008a. The basic colour terms of Czech - Trames, 12, 1, pp 3-28.

Uusküla, Mari 2008b. Basic colour terms in Finno-Ugric and Slavonic languages: Myths and facts. Tartu University Press.

Uusküla-Bogatkin, Mari; Sutrop, Urmas 2005. Tänapäeva ungari keele põhivärvinimed. [The Basic Colour Terms in Modern Hungarian] - Keel ja Kirjandus No 7, pp 558-570.

Uusküla, Mari; Sutrop, Urmas 2007. Preliminary study of basic colour terms in Modern Hungarian - Linguistica Uralica, 43, 2, pp 102-123

Valli, Clayton; Lucas, Ceil 2000. Linguistics of American Sign Language. Gallaudet University Press, pp 493.

Woll, Bencie 1987. Historical and Comparative Aspects of BSL. - Sign and School, Ed. Kyle, J. Multilingual Matters Ltd, Clevedon, Phildelphia, pp 12-34.

Woll, Bencie 2003. Modality, Universality and the Similarities among Sign Languages: An Historical Perspective - Cross-linguistic perspectives in sign language research. Selected papers from TISLR 2000. International Studies on Sign Language and the Communication of the Deaf. Eds. Baker, A, van den Bogaerde, B, Crasborn, O. Vol 41. pp 17-27.

Woodward, James 1989. Basic Color Term Lexicalization across Sign Languages. - Sign Language Studies, Vol 63, pp 145-152. 


\section{CONVENTIONS FOR SIGN NOTATION}

SIGN The English gloss of a sign is written in capital letters in its base form, e.g. CAR

SIGN_SIGN If the meaning of a sign needs to be glossed with more than one word, low lines are used, e.g. DRIVE_A_CAR

SIGN+SIGN Elements of a compound sign are separated by plus symbol, e.g. SREEN+KEYBOARD (=COMPUTER)

SIGN+ The modification of a sign are described by following letters using plus symbol:

$+\mathrm{f}-$ sign moves forward

$+\mathrm{c}-$ sign moves towards the signer

+ lf - sign moves to the left

$+\mathrm{rt}$ - sign moves to the right

SIGN/SIGN Two distinct English glosses of a sign are separated by a slash, e.g. PINK/PURPLE

SIGN 1 If more than one sign is described by the same English gloss, the sign varieties are notated by numbered glosses, e.g. WHITE 1, WHITE 2

w-o-r-d Fingerspelled words are written in lowercase letters, using hyphens, e.g. p-i-n-k

PRO- $\quad$ A personal pronoun, e.g. PRO-1, PRO-2, PRO-3

POSS- $\quad$ A possessive pronoun, e.g. POSS-1, POSS-2, POSS-3 
Estonian Sign Language handshapes are referred to in the text using following symbols from ESL transcription system:

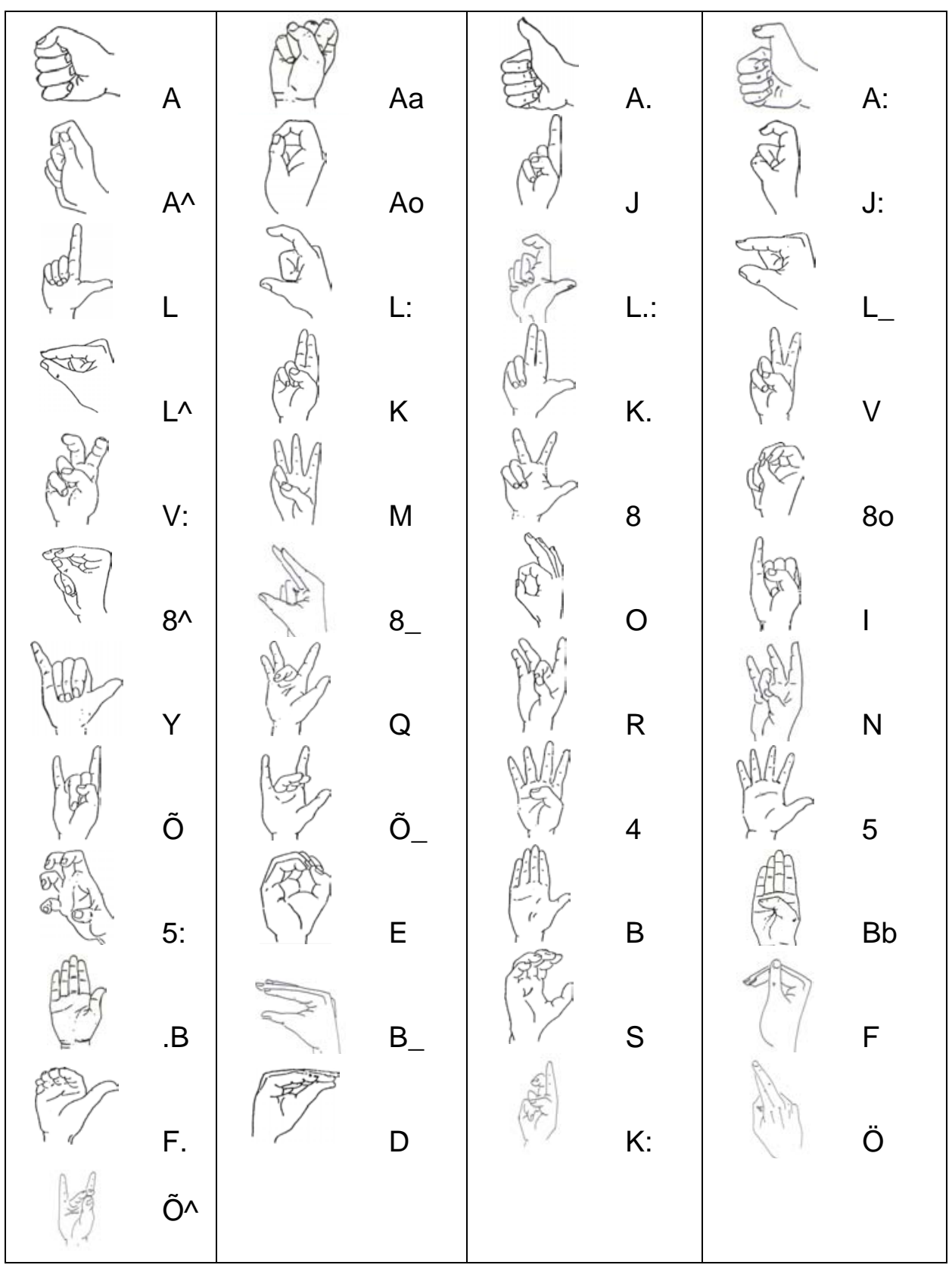


Sign formation is marked on the pictures using following line and arrow types:

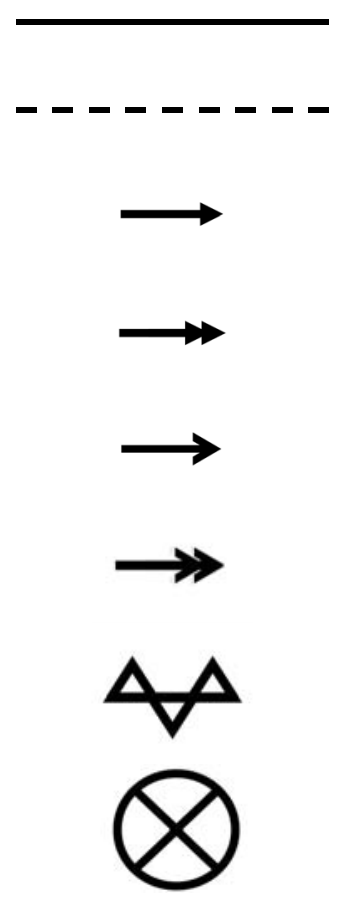

marks neutral movement towards the arrow

gradual, interrupted movement

movements to the left, right, up and down

repeated movements to the left, right, up and down

movements towards and away from the signer

repeated movements towards and away from the signer

wiggling of the fingers

no movement, stationary hand

\section{Abbreviations}

AdaSL - Adamorobe Sign Language

ASL - American Sign Language

Auslan - Australian Sign Language

BSL - British Sign Language

ESL - Estonian Sign Language

LSF - French Sign Language

SL - Sign Language 


\section{APPENDIX}

\section{Questionnaire for the subjects in the color terms survey in ESL}

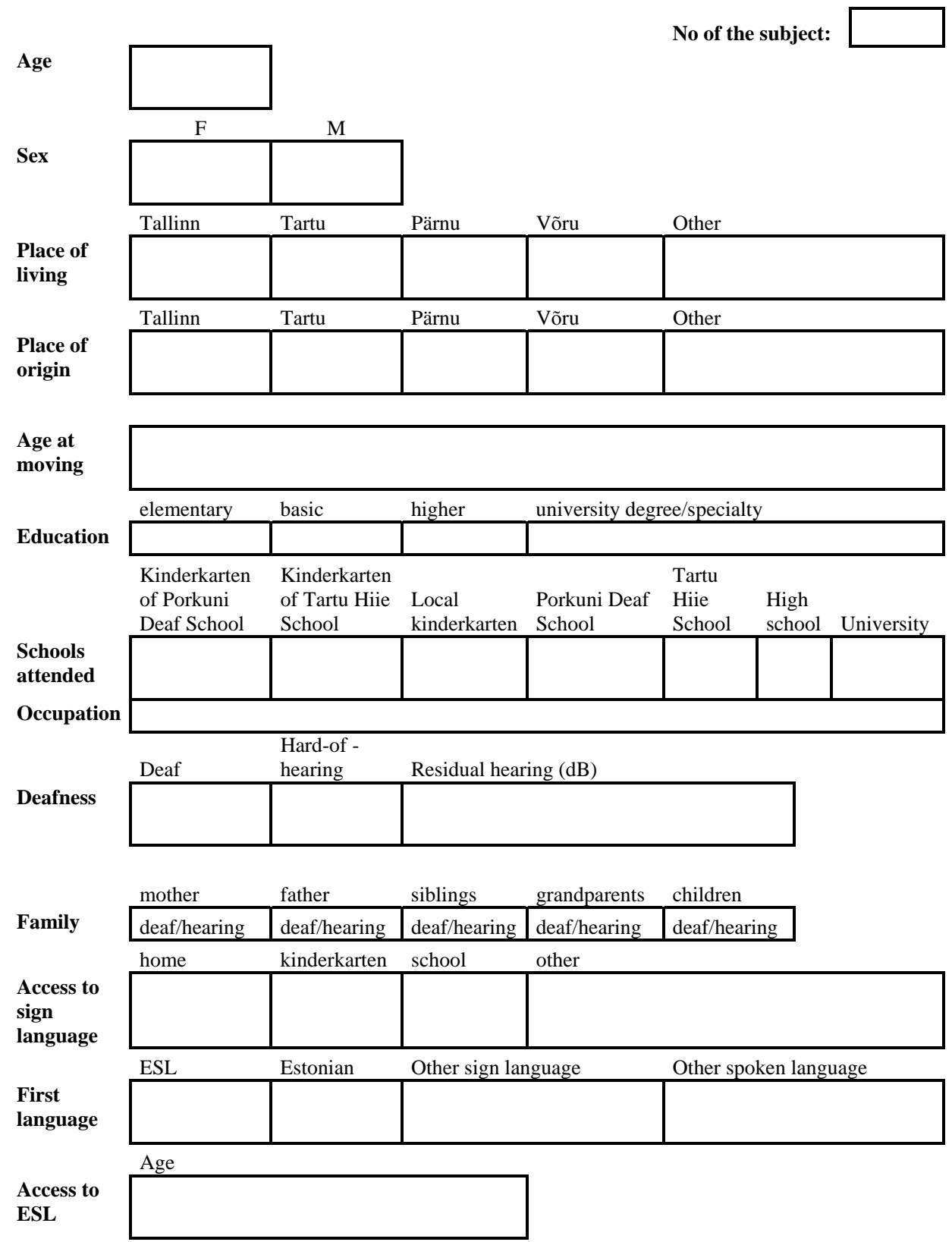




\section{CURRICULUM VITAE}

\section{Liivi Hollman}

Born September 11, 1971, Tallinn

Citizenship: Estonian

Single

Address: Pärnamäe tee 19a, 11914 Tallinn

Telephone: +372 5147822

E-post: liivi@evkty.ee

\section{Education}

1989-1994 University of Tartu, BA Special education

2000-2002 University of Tartu, MA Special education

2005-2010 University of Tartu, doctoral studies

\section{Additional courses}

1996-1998 Estonian Association of the Deaf, Estonian Sign Language interpreter training program

2005 Estonian Association of the Deaf, Estonian Association of Sign Language Interpreters, International Signing

2008 Estonian Association of Sign Language Interpreters, Sign language interpreting in court

\section{Professional experience}

1993-1996

1994-1997

1995-1998

1996-2008

1997-1998

1999-2003

2005-2009

2007-
Tallinn Pedagogical College, ESL interpreter

Tallinn Special Correspondence School, speech therapist and English teacher

The Estonian Chamber of Disabled People, ESL interpreter

Estonian Association of the Deaf, ESL interpreter

Communication Support Centre KomaKe, interpreter trainer and ESL teacher

Estonian Association of Sign Language Interpreters, interpreter trainer

Institute of the Estonian Language, researcher

University of Tartu, lectures on: Role of the interpreter, interpreting settings, Educational interpreting, Consecutive interpreting: theory and practice, Simultaneous interpreting: theory and practice 
2009- $\quad$ Viipekeeletõlkide OÜ, ESL interpreter

2010- Institute of the Estonian Language, lexicographer

\section{Research interests}

Research areas: sign language interpreters and interpreting, role of the interpreter, Estonian Sign Language, color terms in Estonian Sign Language

\section{Publications}

Paabo, R., Födisch, M., \& Hollman, L. (2009). Rules for Estonian Sign Language transcription. Trames 13(63/58), 4, 401-424.

Hollman, L. (2008). Why black is MUST and white is VALGE. On colour terms in Estonian Sign Language. Keel ja Kirjandus, 11, 847-862.

Toom, R., Trükmann M., \& Hollman, L (2006). Estonian Sign Language Transcription. Estonian Papers in Applied Linguistics 2, 286-301.

Hollman, L. (2005). Educational interpreters and educational interpreting. Special Education, March 2005, 49-54.

Toom, R., Hollman L. (2004). Estonian Sign Language dictionaries: development of Christian signs. Toimiv keel II, 309-319. 


\title{
ELULOOKIRJELDUS
}

\section{Liivi Hollman}

\author{
Sündinud 11. septembril 1971 Tallinnas \\ Kodakondsus: Eesti \\ Vallaline \\ Aadress: Pärnamäe tee 19a, 11914 Tallinn \\ Telefon: +3725147 822 \\ E-post: liivi@evkty.ee
}

\section{Haridus}

1989-1994 Tartu Ülikool, BA eripedagoogika

2000-2002 Tartu Ülikool, MA eripedagoogika

2005-2010 Tartu Ülikool, doktorant

\section{Täienduskoolitus}

1996-1998 Eesti Kurtide Liit, Eesti viipekeele tõlkide koolitus

2005

2008

Eesti Kurtide Liit, Eesti Viipekeele Tõlkide Ühing, Rahvusvaheline viiplemine

Eesti Viipekeele Tõlkide Ühing, Viipekeelne tõlge Eesti kohtusüsteemis

\section{Teenistuskäik}

1993-1996 Tallinna Pedagoogiline Seminar, eesti viipekeele tõlk

1994-1997 Tallinna Kaugõppe-Erikeskkool, kõneravi ja inglise keele õpetaja

1995-1998

Eesti Puuetega Inimeste Koda, eesti viipekeele tõlk

1996-2008

Eesti Kurtide Liit, eesti viipekeele tõlk

1997-1998

Kommunikatsiooniabi Keskus KomaKe, viipekeeletõlkide koolitaja ja eesti viipekeele õpetaja

1999-2003

2005-2009 Eesti Viipekeele Tõlkide Ühing, viipekeeletõlkide koolitaja

Eesti Keele Instituut, erakorraline teadur

Tartu Ülikool, õppeülesande täitja. Õpetatavad ained: tõlgi roll ja tõlkesituatsioonid, õpingutõlge, järeltõlke teooria ja praktika, sünkroontõlke teooria ja praktika

2009- Viipekeeletõlkide OÜ, eesti viipekeele tõlk

2010_ Eesti Keele Instituut, leksikograaf 


\section{Teadustegevus}

Uurimisvaldkonnad: viipekeeletõlgid ja tõlkimine, viipekeeletõlgi roll, eesti viipekeel, värvinimed eesti viipekeeles

\section{Publikatsioonid}

Paabo, R., Födisch, M. \& Hollman, L. (2009). Rules for Estonian Sign Language transcription. Trames 13(63/58), 4, 401-424.

Hollman, L. (2008). Miks MUST on must ja VALGE valge. Eesti viipekeele värvinimedest. Keel ja Kirjandus, 11, 847-862.

Toom, R., Trükmann M. \& Hollman, L (2006). Eesti viipekeele transkriptsioonist. Eesti Rakenduslingvistika Aastaraamat 2, 286-301.

Hollman, L (2005). Õpingutõlkest ja õpingutõlkidest. Eripedagoogika, märts 2005, 49-54.

Toom, R., Hollman, L. (2004). Eesti viipekeele sõnaraamatud: kristlike viibete areng. Toimiv keel II, 309-319. 


\section{DISSERTATIONES LINGUISTICAE UNIVERSITATIS TARTUENSIS}

1. Anna Verschik. Estonian yiddish and its contacts with coterritorial languages. Tartu, 2000, $196 \mathrm{p}$.

2. Silvi Tenjes. Nonverbal means as regulators in communication: sociocultural perspectives. Tartu, 2001, 214 p.

3. Ilona Tragel. Eesti keele tuumverbid. Tartu, 2003, 196 p.

4. Einar Meister. Promoting Estonian speech technology: from resources to prototypes. Tartu, 2003, $217 \mathrm{p}$.

5. Ene Vainik. Lexical knowledge of emotions: the structure, variability and semantics of the Estonian emotion vocabulary. Tartu, 2004, 166 p.

6. Heili Orav. Isiksuseomaduste sõnavara semantika eesti keeles. Tartu, 2006, 175 p.

7. Larissa Degel. Intellektuaalsfäär intellektuaalseid võimeid tähistavate sõnade kasutuse põhjal eesti ja vene keeles. Tartu, 2007, 225 p.

8. Meelis Mihkla. Kõne ajalise struktuuri modelleerimine eestikeelsele tekstkõne sünteesile. Modelling the temporal stucture of speech for the Estonian text-to-speech synthesis. Tartu, 2007, 176 p.

9. Mari Uusküla. Basic colour terms in Finno-Ugric and Slavonic languages: myths and facts. Tartu, 2008, 207 p.

10. Petar Kehayov. An Areal-Typological Perspective to Evidentiality: the Cases of the Balkan and Baltic Linguistic Areas. Tartu, 2008, 201 p.

11. Ann Veismann. Eesti keele kaas- ja määrsõnade semantika võimalusi. Tartu, 2009, 145 p.

12. Erki Luuk. The noun/verb and predicate/argument structures. Tartu, 2009, $99 \mathrm{p}$.

13. Andriela Rääbis. Eesti telefonivestluste sissejuhatus: struktuur ja suhtlusfunktsioonid. Tartu, 2009, 196 p. 